NBER WORKING PAPER SERIES

\title{
THE CHOICE CHANNEL OF FINANCIAL INNOVATION
}

\author{
Felipe S. Iachan \\ Plamen T. Nenov \\ Alp Simsek \\ Working Paper 21686 \\ http://www.nber.org/papers/w21686 \\ NATIONAL BUREAU OF ECONOMIC RESEARCH \\ 1050 Massachusetts Avenue \\ Cambridge, MA 02138 \\ October 2015, Revised January 2020
}

We would like to thank Marios Angeletos, Ricardo Caballero, Nicolae Garleanu, Simon Gilchrist, Bernard Herskovic, Ron Kaniel, Chen Lian, Andrei Shleifer, and participants at numerous conferences and seminars for helpful comments. Masao Fukui, Rafael C. Araujo, and Cecilie Øiulfstad provided outstanding research assistance. Simsek acknowledges support from the National Science Foundation (NSF) under Grant Number SES-1455319. Any opinions, findings, conclusions or recommendations expressed in this material are those of the authors and do not necessarily reflect the views of the NSF or the National Bureau of Economic Research. Iachan acknowledges that this study was financed in part by the Coordenação de Aperfeiçoamento de Pessoal de Nível Superior - Brasil (CAPES) - Finance Code 001.

NBER working papers are circulated for discussion and comment purposes. They have not been peer-reviewed or been subject to the review by the NBER Board of Directors that accompanies official NBER publications.

(C) 2015 by Felipe S. Iachan, Plamen T. Nenov, and Alp Simsek. All rights reserved. Short sections of text, not to exceed two paragraphs, may be quoted without explicit permission provided that full credit, including (C) notice, is given to the source. 
The Choice Channel of Financial Innovation

Felipe S. Iachan, Plamen T. Nenov, and Alp Simsek

NBER Working Paper No. 21686

October 2015, Revised January 2020

JEL No. E21,E43,E44,G11,G12

\section{ABSTRACT}

Financial innovation in recent decades has expanded portfolio choice. We investigate how greater choice affects investors' savings and asset returns. We establish a choice channel by which greater portfolio choice increases investors' savings—by enabling them to earn the aggregate risk premium or to take speculative positions. In equilibrium, portfolio customization (access to risky assets beyond the market portfolio) reduces the risk-free rate. Participation (access to the market portfolio) reduces the risk premium but typically increases the risk-free rate. Empirically, stock market participants in the U.S. save more than nonparticipants, and have increasingly dispersed portfolio returns, consistent with the choice channel.

Felipe S. Iachan

FGV EPGE

Praia de Botafogo, 190/1115

Rio de Janeiro, RJ, Brazil

fiachan@gmail.com

Plamen T. Nenov

Norwegian Business School (BI)

Nydalsveien 370484 Oslo, Norway

plamen.nenov@bi.no
Alp Simsek

Department of Economics, E52-552

MIT

50 Memorial Drive

Cambridge, MA 02142

and NBER

asimsek@mit.edu

A latest version of the paper is available at

https://www.dropbox.com/s/tvi2imjct966r7h/financialInnovationSaving.pdf?dl=0 

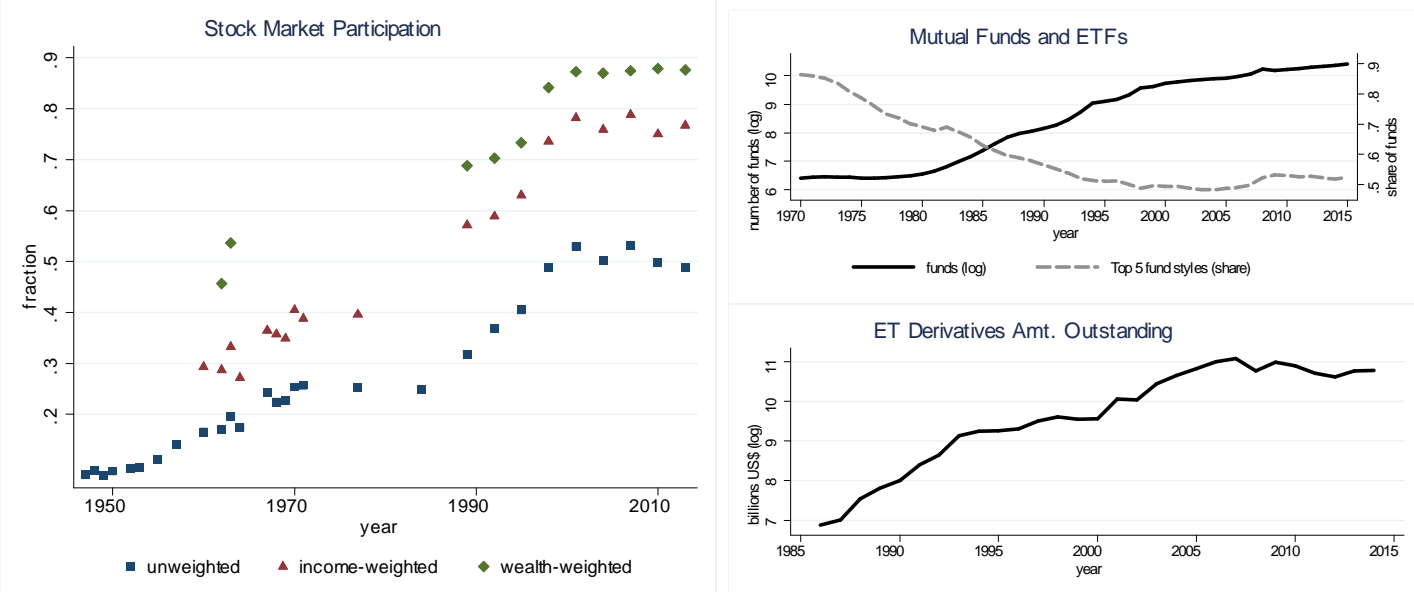

Figure 1: The left panel shows the fraction of households in the U.S. that invested in stocks over the period 1947-2013. The right top panel shows the number of mutual funds and exchange-traded funds in the U.S and the share of the top 5 fund styles. The right bottom panel plots the amount of outstanding exchange traded derivatives (in year 2000 U.S. dollars). Sources: Authors' calculations using data from the Michigan Survey of Consumer Finances (1947-1977), the PSID (1984), and the Survey of Consumer Finances (1989-2013)); CRSP Mutual Funds Database; Bank for International Settlements.

Financial innovation in recent decades has vastly increased households' portfolio choices. In the 1950s, a typical household in the U.S. had limited choice in constructing her savings portfolio. She could hold bank deposits, and perhaps save in her own house, but mutual funds and well-diversified equity positions were out of reach. These days, largely due to financial innovation, a comparable household has inexpensive access to a rich set of financial instruments. The left panel of Figure 1 shows that stock market participation in the U.S. has increased from about $10 \%$ of households in the early 1950 s to more than $50 \%$ (in wealthweighted terms, about 90\%) by the end of the 1990s. Portfolio customization has also increased: households can choose from a plethora of passive or active mutual funds, hedge funds, retirement funds, or ETFs. They can also construct their own portfolios by trading stocks, bonds, or derivatives at low transaction costs. The right panels of Figure 1 show that mutual funds with different investment styles and exchange-traded derivatives, both of which facilitate portfolio customization, have been growing rapidly since the early 1980s (until the recent financial crisis). 
A natural question is how innovations that expand portfolio choice affect investors' consumption-savings decisions and asset prices. A traditional macroeconomics literature that studies precautionary savings predicts that, with greater portfolio choice, investors should save less (see, for instance, Bewley, 1977, Huggett, 1993, Aiyagari, 1994). The idea is that uninsured background risks induce agents to save for precautionary reasons. Therefore, greater portfolio choice that improves the sharing (or hedging) of background risks should reduce desired savings. For instance, when investors participate in the stock market, they could hedge their labor income risks by reducing their positions in the companies or industries in which they are employed. This would typically reduce desired savings, and in equilibrium, also increase interest rates (see Elul, 1997 for a formalization and Carvajal et al., 2012 for a recent contribution).

While precautionary saving is certainly important, empirical evidence suggests that greater portfolio choice does not necessarily lead to improved sharing of background risks. Most investors tend to overinvest in domestic stocks (French and Poterba, 1991), as well as in own company or related stocks (e.g., Benartzi, 2001; Poterba, 2003; Døskeland and Hvide, 2011). If stock market participants do not hedge their background risks, they might also not lower their savings. Figure 2 illustrates using data from the Panel Study of Income Dynamics (PSID) that the U.S. households that participate in the stock market have on average a considerably higher saving rate than nonparticipants (and the difference remains significant after including various controls such as income and wealth). Moreover, while there is a wellknown negative trend in saving rates since the 1980s, the trend has been much weaker for participants. Put differently, stock market participants have increased their saving relative to nonparticipants since the 1980s.

Motivated by this evidence, we offer an alternative channel by which greater portfolio choice - in the form of market participation or customization - increases investors' savings. In our model, investors with standard Epstein-Zin preferences hold assets to transfer wealth to a future period. Investors optimally choose saving portfolios that consist of the risk-free asset and various risky assets. Each investor has access to the risk-free asset, but investors have limited and (possibly) heterogeneous access to risky assets. We capture financial innovation as an improvement in investors' access sets. We also allow the investors to have heterogeneous beliefs about risky asset returns, which provides one rationale for portfolio customization. In benchmark models with homogeneous beliefs, investors would only need one risky asset- 


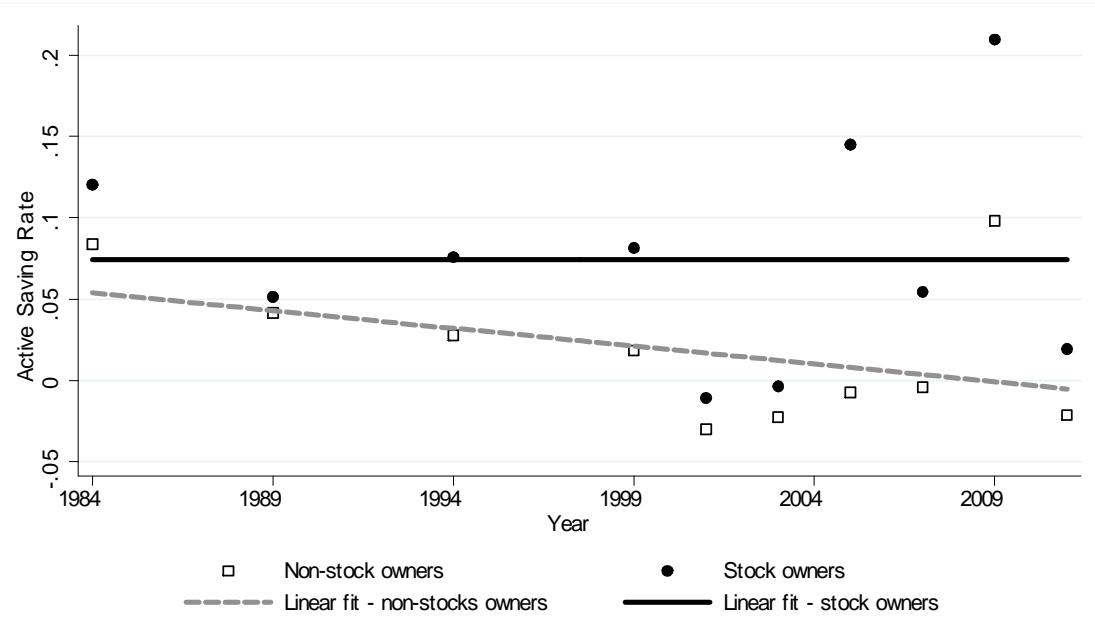

Figure 2: Saving and stock market participation. Source: Panel Study of Income Dynamics Wealth Supplement.

namely, the market portfolio - to construct their optimal portfolios. In contrast, investors in our model will demand customized portfolios because they will speculate based on their different beliefs.

Our main result delineates two assumptions under which greater portfolio choice increases savings. First, we take the elasticity of intertemporal substitution (EIS) to be greater than one, which we view as a modeling device to generate a savings function that is increasing in asset returns (see Section 2). Second, we assume that financial innovation does not provide additional benefits in terms of hedging the investor's background risks such as income fluctuations. We then show that greater choice induces the investor to save more. This result has a simple intuition. Greater portfolio choice increases the investor's perceived riskadjusted return, either by enabling her to earn the aggregate risk premium (in the case of market participation) or by allowing her to take speculative positions (in the case of portfolio customization). As long as the savings function is increasing in asset returns, the investor responds by increasing her savings. Put differently, with greater choice in financial markets, saving becomes more attractive, and the investor does more of it.

How does the choice channel affect asset prices and returns in equilibrium? We theoretically address this question using a canonical case of our model in which the available financial assets consist of a market portfolio of all cash flows and several other risky assets in zero net 
supply. We also assume a log-normal approximation for portfolio returns (as in Campbell and Viceira, 2002), which leads to a tractable mean-variance analysis. Greater choice, which increases investors' savings, exerts an upward pressure on asset prices. However, financial innovation might also generate relative price changes across asset classes. The net effect on each price depends on the type of innovation.

Our main asset pricing result concerns portfolio customization, which we capture with improved access to an arbitrary subset of the risky assets other than the market portfolio. Under a symmetry assumption on investors' beliefs, we show that greater customization reduces the risk-free rate while leaving risk premia unchanged. In particular, customization reduces the expected return on each (risk-free or risky) asset. For intuition, imagine financial assets as a forest that contains several types of trees (a metaphor for individual stocks, industries, or mutual funds with different managers or strategies). Customization enables investors to expand their positions in the trees about which they are optimistic (relative to the average investor), while reducing their positions in other trees. Moreover, for every relatively optimistic investor that buys a particular tree, there are relatively pessimistic investors that sell that tree. Consequently, investors collectively like the forest more, in view of the choice channel, but the relative appeal of individual trees remains unchanged. We show that this logic is general and implies that customization increases the valuation (and reduces the expected return) of each tree in tandem.

We also analyze the asset pricing implications of greater market participation, modeled as an improvement in investors' access to the market portfolio. Participation tends to increase asset prices in view of the choice channel, but it also increases the demand for risky assets relative to the safe asset. We find that these relative demand effects are strong, whereas the choice channel is relatively weak in this context. In particular, while greater participation always reduces the risk premium, it typically increases the risk-free rate -unlike greater customization.

As we explain in Section 3.4, our asset pricing results can shed some light on the dynamics of the interest rate in the U.S. both in the decades before and after the 1980s due to different types of choice-expanding innovations taking place during the two periods. There are of course many other contributing factors to these trends that are left out of our analysis. Therefore, in our empirical analysis we focus largely on the cross-sectional implications for investors' savings. 


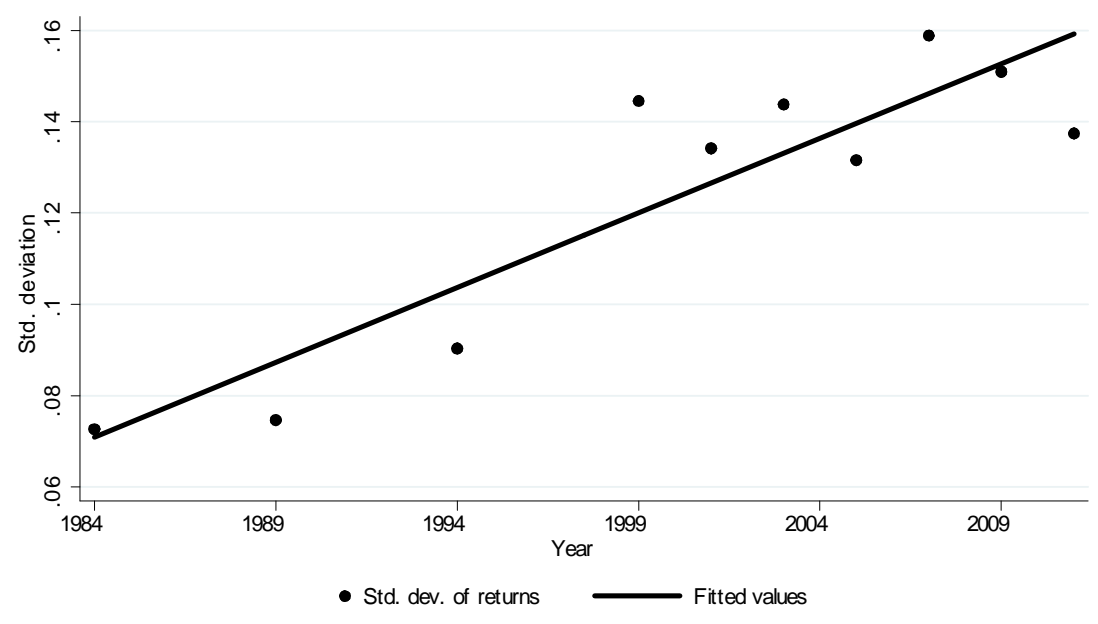

Figure 3: Trends in the cross-sectional standard deviation of (implicit) return on wealth among stock holders (excluding business owners). See Online Appendix D for an adjustment that deals with the data frequency.

We investigate two testable implications using household saving and balance sheet data from the PSID. First, the choice channel predicts that stock market participants save more than nonparticipants - and more so in recent years that feature greater customization opportunities. Empirically, we find that the positive association between stock market participation and saving illustrated in Figure 2 remains after controlling for demographic characteristics, education, income, wealth, and household fixed effects; as well as after instrumenting for participation using lagged participation. In addition, the widening difference in the saving of participants and non-participants is robust to a number of controls including education, income and wealth.

Second, the choice channel also predicts that greater customization opportunities in recent years increase the dispersion of portfolio returns for stock market participants. Figure 3 illustrates that the cross-sectional standard deviation of the portfolio returns of stock holders has indeed increased in recent years. We show that the trend is not driven by business owners, and it is robust to controlling for investors' risk taking (portfolio share of stocks), demographics, income, and total wealth. Consistent with an increase in customization and speculation, similar households seem to receive more dispersed portfolio returns in recent years. 
The rest of the paper is organized as follows. After discussing the related literature, we present in Section 1 an example that illustrates the choice channel and motivates the rest of our analysis. Section 2 introduces the basic environment and establishes the choice channel. Section 3 extends the basic framework into a general equilibrium model with endogenous prices, establishing our asset pricing results on market participation and portfolio customization. Section 4 presents our empirical results and Section 5 concludes. Appendix A contains selected extensions and proofs omitted from the main text. Online Appendices $\mathrm{B}$ and $\mathrm{C}$ contain the remaining extensions and proofs, and Online Appendix $\mathrm{D}$ contains the details of our empirical analysis.

Related literature. Our paper is related to a large body of "precautionary savings" literature, which can be divided into two strands based on the sources of risks. The first strand, which we discussed earlier, focuses on background risks such as income fluctuations. A second strand examines investment (rate-of-return) risks, and emphasizes that enabling firms (or entrepreneurs) to share these risks can increase aggregate investment. The logic is similar to our choice channel and relies on a relatively large elasticity of intertemporal substitution. However, our results are different because we analyze households' savings as opposed to firms' investment. Consequently, we show that financial innovation can reduce the interest rate, whereas this literature emphasizes that financial innovation can raise investment while still increasing the interest rate (see Angeletos and Calvet, 2006 and Angeletos, 2007). In addition, we show that portfolio customization increases savings due to speculation as opposed to risk sharing.

In parallel and independent work, Guzman and Stiglitz (2016) and Ehling et al. (2018) also analyze households' consumption and savings decisions in environments with belief disagreements. Guzman and Stiglitz (2016) emphasize that disagreements increase investors' perceived wealth, which they refer to as pseudo-wealth, and argue that pseudo-wealth can generate business cycle fluctuations. We emphasize the case in which the substitution effect dominates the wealth effect and we analyze the longer run implications for asset returns as opposed to business cycle fluctuations. Ehling et al. (2018) analyze more specifically how belief disagreements about the inflation rate affect the real interest rate, focusing on the case in which the wealth effect dominates (as in Guzman and Stiglitz, 2016). Relatedly, Schmidt and Toda (2018) analyze investors' consumption and savings decisions in response to bad 
news. As one example of bad news, they consider the shrinkage of investment opportunities, which leads to a result that is similar to our choice channel. We emphasize financial innovation as opposed to news as the driving force behind the change in investors' choice sets. We also obtain several general equilibrium results for asset returns.

Our paper is part of a literature that analyzes the asset pricing implications of financial innovation in an environment with belief disagreements. 1 Fostel and Geanakoplos (2016) focus on financial innovations that relax collateral constraints, which enable investors to selfselect into tranches they value relatively more and raise the price of the underlying collateral (as well as investment). While the logic of this result is similar to our choice channel, the testable implications are different. Our analysis does not rely on collateral constraints, allowing us to focus on plain-vanilla saving decisions, whereas the analysis in Fostel and Geanakoplos (2016) might be more relevant for households that borrow to purchase a house or a durable good. We also focus on the risk-free rate whereas most of this literature takes the risk-free rate as given and focuses on the relative price of a single risky asset.

Another strand of this literature emphasizes that belief disagreements and speculation can increase portfolio risks, and more so with financial innovation (see, for instance, Simsek, 2013b; Kondor and Koszegi, 2017). We show that speculation can also increase savings. Our analysis is positive and complements the papers that focus on normative issues surrounding speculation (e.g., Brunnermeier et al. (2014); Gilboa et al. (2014); Posner and Weyl (2013); Dávila (2017); Heyerdahl-Larsen and Walden (2017)). More broadly, our paper is part of a large literature that analyzes the effects of belief disagreements on financial markets. ${ }^{2}$

Our paper is also related to an empirical household finance literature that analyzes whether financial innovation can mitigate some households' reluctance to save. We discuss these papers and how they relate to the choice channel in Section 4.4. We contribute to this literature by providing new empirical evidence that suggests stock market participation

\footnotetext{
${ }^{1}$ See, for instance, Fostel and Geanakoplos (2012); Simsek (2013a); Geerolf (2017); Gong and Phelan (2016); Buss et al. (2017). More broadly, there is a vast literature on financial innovation and asset prices. In addition to the papers mentioned earlier, see, e.g., Allen and Gale (1994); Calvet et al. (2004); Brunnermeier and Sannikov (2014).

${ }^{2}$ An incomplete list includes Lintner, 1969, Miller, 1977; Harrison and Kreps, 1978; Varian, 1985; Harris and Raviv, 1993: Detemple and Murthy, 1994; Chen et al., 2002: Scheinkman and Xiong, 2003; Buraschi and Jiltsov, 2006; Jouini and Napp, 2007; Dumas et al., 2009, Xiong and Yan, 2009, Geanakoplos, 2010, Banerjee and Kremer, 2010, Hong and Sraer, 2016, Barberis et al., 2018, Cao, 2017; Dumas et al., 2017, Caballero and Simsek, 2017.
} 
is associated with higher savings.

Finally, we contribute to a literature on limited stock market participation..$^{3}$ We theoretically and empirically analyze the effect of participation on savings, while also investigating its asset pricing implications. Our result that greater participation reduces the risk premium is well known (see, for instance, Mankiw and Zeldes, 1991). The result that greater participation increases the risk-free rate is more novel. Basak and Cuoco (1998) obtain a similar result in a dynamic environment in which participants' consumption share evolves endogenously, and nonparticipants are restricted to have log utility.

\section{A Motivating Example}

We first present a simple example that illustrates the choice channel and provides the motivation for our more general model. Consider an economy with two dates, $t \in\{0,1\}$, and a single consumption good. At date 1, the economy can be in one of two states, denoted by $\mathbf{z} \in\{$ shine, rain $\}$. There is a financial asset in unit supply that represents claims to all output in period 1 . We refer to this asset as the market portfolio and denote it with subscript $m$. Its payoff at date 1 is normalized to one (which does not depend on the state for simplicity).

There are two types of investors which we refer to as "optimists" and "pessimists," with heterogeneous prior beliefs about the state $\mathbf{z}$, denoted by $q^{\text {opt }}(\mathbf{z})$ and $q^{\text {pes }}(\mathbf{z})$. Optimists assign a higher probability to the shine state, $q^{\text {opt }}$ (shine) $>q^{\text {pes }}$ (shine). Investors have time-separable risk-neutral preferences and have a discount factor of one between dates 0 and 1 ; they simply maximize the sum of their own expected consumption across the two dates.

They can take long or short positions in the available financial assets, as long as they obtain nonnegative consumption at each date and state. Investors have large endowments of the consumption good and equal endowments of the market portfolio at date 0 , and have no endowment of the consumption good at date 1 .

First, suppose the only available financial asset is the market portfolio. In this case, the

\footnotetext{
${ }^{3}$ An incomplete list includes Heaton and Lucas (1999); Attanasio et al. (2002); Vissing-Jørgensen and Attanasio (2003); Cao et al. (2005); Gomes and Michaelides (2008); Guvenen (2009); Favilukis (2013); Calvet et al. (2017).
} 
equilibrium price of the market portfolio equals its constant payoff, $P_{m}=1$, which reflects the investors' common valuation. At this price, investors are indifferent between consuming and saving.

Next, suppose that, thanks to financial innovation, there is also an Arrow-Debreu security for the shine state in zero net supply, denoted by $s$, that has payoff $\varphi_{s}($ shine $)=1$ and $\varphi_{s}($ rain $)=0$. Together with the market portfolio, this security completes the financial market. Specifically, investors can also construct a synthetic Arrow-Debreu security for the rain state by buying one unit of the market portfolio and selling one unit of $s$.

In equilibrium, optimists invest only in the Arrow-Debreu security for the shine state, as they assign a relatively high probability to this state, $q^{\text {opt }}$ (shine) $>q^{\text {pes }}$ (shine) (and they invest zero and consume nothing in the other state). Consequently, optimists are indifferent to hold this security, which implies, $P_{s}=q^{\text {opt }}$ (shine). Analogously, pessimists are indifferent to hold the synthetic Arrow-Debreu security for the rain state, which implies, $P_{m}-P_{s}=q^{\text {pes }}$ (rain). Combining these expressions, the price of the market portfolio is,

$$
P_{m}=q^{\text {opt }}(\text { shine })+q^{\text {pes }}(\text { rain })>1
$$

where the inequality follows since $q^{\text {opt }}($ shine $)>q^{\text {pes }}($ shine $)=1-q^{\text {pes }}$ (rain).

Comparing the two cases shows that financial innovation increases the price of the market portfolio. Intuitively, providing investors with greater portfolio choice makes saving more attractive, since investors self-select into holding assets or portfolios in which they perceive greater returns. If prices did not change, investors would increase their savings (because they have linear utility that ensures their savings increase in returns). We refer to this effect as the choice channel of financial innovation. In equilibrium, greater desired savings translate into greater asset prices (and lower asset returns according to the average belief). We next systematically analyze a more general model and establish the robustness of the choice channel as well as its asset-pricing implications for different types of innovation.

\section{The Choice Channel and Savings}

Consider an economy with two dates, $t \in\{0,1\}$, and a single consumption good (see Remark 1 later in the section on how to interpret our two period model in a dynamic context). The 
uncertainty is described by the realization of the random variable, $\mathbf{z} \in Z$. There are financial assets denoted by the subscript $j \in\{f\} \cup \mathbf{J}$, which make a nonnegative payoff at date 1 . We use $\varphi_{j}(\mathbf{z})$ to denote the asset payoff in state $\mathbf{z}$. The asset $f$ captures the risk-free asset that makes a constant payment in all states, $\varphi_{f}(\mathbf{z})=1>0$ for each $\mathbf{z}$. The set $\mathbf{J}$ captures risky assets. We assume (until Section 3) that the state space $Z$ is finite, and the vectors, $\left(\varphi_{j}(\mathbf{z})\right)_{\mathbf{z} \in Z}$ for $j \in\{f\} \cup \mathbf{J}$, are linearly independent so that each asset is non-redundant. Each asset is traded in a competitive market at some price, $P_{j}>0$. In this section, we take these prices as given and analyze how financial innovation that expands an investor's choices affects her savings. We endogenize the prices in Section 3 .

Specifically, consider an investor (denoted by superscript $i$ ) that starts with some endowment of the consumption good at date 0 , denoted by $Y_{0}>0$, as well as some positions on financial assets, $\left\{x_{-1, j}\right\}_{j}$. We denote her financial wealth by $W_{0}=\sum_{j} x_{-1, j} P_{j}$. The investor also receives some endowment of the consumption good in state $\mathbf{z}$ of date 1 , denoted by $L(\mathbf{z})$, which can be thought of as her labor (or other non-financial) income. The investor can invest in the risk-free asset $f$, as well as an exogenous and potentially limited subset of risky financial assets, $J^{i} \subset \mathbf{J}$, which we refer to as her access set. We will formally capture the choice-expanding financial innovations by exogenously enlarging the investor's access set. To simplify the notation, we assume throughout that investors are identical except, possibly, for their access sets and their beliefs about $\mathbf{z}$ (as we describe below).

The investor chooses her consumption and total asset holdings at date 0 , denoted by $C_{0}$ and $A_{0}$, as well as positions in financial assets in her access set, $\left\{x_{j}\right\}_{j \in\{f\} \cup J^{i}}$, to solve,

$$
\begin{array}{ll} 
& \max C_{0}, A_{0},\left\{x_{j}\right\}_{j \in\{f\} \cup J^{i}} U_{0}\left(C_{0},\left(C_{1}(\mathbf{z})\right)_{Z}\right) \\
\text { s.t. } & C_{0}+A_{0}=Y_{0}+W_{0} \text { where } A_{0}=\sum_{j \in\{f\} \cup J^{i}} P_{j} x_{j}, \\
\text { and } & C_{1}(\mathbf{z})=L(\mathbf{z})+\sum_{j \in\{f\} \cup J^{i}} x_{j} \varphi_{j}(\mathbf{z}) \text { for each } \mathbf{z} \in Z .
\end{array}
$$

Here, $C_{1}(\mathbf{z})$ denotes the total wealth in state $\mathbf{z}$ of date 1 , which the investor consumes because there is no subsequent period. The second line captures her budget constraint at date 0 in terms of consumption and asset holdings. Note that the investor can take unrestricted long or short positions (we allow for short-selling constraints in Online Appendix B.3). 
We assume the investor has recursive Epstein-Zin preferences, given by,

$$
\begin{aligned}
U_{0} & =\frac{C_{0}^{1-1 / \varepsilon}-1}{1-1 / \varepsilon}+\beta \frac{U_{1}^{1-1 / \varepsilon}-1}{1-1 / \varepsilon}, \\
\text { where } U_{1} & =\left(E^{i}\left[C_{1}(\mathbf{z})^{1-\gamma}\right]\right)^{1 /(1-\gamma)} .
\end{aligned}
$$

Here, $\varepsilon$ and $\gamma$ denote, respectively, the elasticity of intertemporal substitution (EIS) and the coefficient of risk aversion. The expectation operator, $E^{i}[\cdot]$, is specific to the investor since we allow for heterogeneous beliefs about $\mathbf{z}$. We also assume the beliefs are dogmatic in the sense that investors do not change their beliefs after they observe the prices. We will use belief disagreements of this type to capture investors' demand for customized assets.

It is well known that the presence of background risks, $L(\mathbf{z})$, when combined with Epstein-Zin preferences, creates a precautionary savings motive. A traditional macroeconomic literature has focused on this precautionary component of savings, and argued that financial innovation should reduce overall savings. We derive a version of this argument in Online Appendix B.1. Intuitively, if financial innovation provides investors with new opportunities to hedge their background risks, then this weakens their precautionary savings motive. If several other assumptions are added - so as to keep the nonprecautionary part of the savings constant - then financial innovation also reduces overall savings.

Set against this traditional benchmark, we investigate the effect of financial innovation on investors' nonprecautionary savings. To this end, we assume financial innovation does not provide the investor with additional opportunities to hedge background risks.

Assumption 1. There exists scalars, $\left\{l_{j}\right\}_{j \in\{f\} \cup J^{i}}$, such that $L(\mathbf{z})=\sum_{j \in\{f\} \cup J^{i}} l_{j} \varphi_{j}(\mathbf{z})$ for each $\mathbf{z} \in Z$.

The assumption holds when the investor's future endowment is constant. It is also satisfied if the investor's future endowment is perfectly correlated with a combination of the risky assets in her access set. Therefore, financial innovation that expands the set $J^{i}$ does not bring any additional risk-sharing benefits. While Assumption 1 provides analytical tractability, it is not strictly necessary. As we show in Appendix A.1 with a numerical exercise, our main result continues to apply when there are uninsurable background risks, as long as financial innovation does not substantially affect the investors' ability to hedge those risks.

We next present our main result that formalizes the choice channel. We capture choice- 
expanding innovations as an expansion of the investor's access set from some $J^{i, o l d}$ to a greater set $J^{i, \text { new }} \supset J^{i \text {,old }}$. We let $\left(C_{0}^{i, \text { old }}, A_{0}^{i, \text { old }},\left\{x_{j}^{i, \text { old }}\right\}_{j}\right)$ and $\left(C_{0}^{i, \text { new }}, A_{0}^{i \text {,new }},\left\{x_{j}^{i, \text { new }}\right\}_{j}\right)$ denote the solution to investor's problem (1) corresponding to, respectively, the old and the new access sets. Note that the investor's savings is equal to the change in investors' asset holdings within the period [cf. Eq. (11)],

$$
S_{0}^{i}=Y_{0}-C_{0}^{i}=A_{0}^{i}-W_{0}=\sum_{j \in\{f\} \cup J}\left(x_{j}^{i}-x_{-1, j}^{i}\right) P_{j} .
$$

Since asset prices (and thus, $W_{0}$ ) are held constant, the savings is determined by the desired asset holdings, $A_{0}^{i}$.

Proposition 1 (Choice Channel). Suppose Assumption 1 holds and $\varepsilon>1$ (so that the investor's asset holdings are increasing in the interest rate). Then, financial innovation increases the investor's asset holdings (and thus, savings), $A_{0}^{i, n e w} \geq A_{0}^{i, o l d}$, with strict inequality if $x_{j}^{i, \text { new }} \neq 0$ for some $j \in J^{i, \text { new }} \backslash J^{i, o l d}$.

The result establishes conditions under which greater portfolio choice induces the investor to save more. Moreover, the inequality is strict as long as the investor takes a nonzero position on some new asset - so that the assets are not completely redundant from her perspective.

We provide a sketch proof for this result (completed in Appendix A.2), which is also useful for understanding the intuition. Suppose that the investor has zero future endowment, $L(\mathbf{z})=0$. As we show in the appendix, this is without loss of generality, in view of Assumption 1, since an investor with non-zero future labor endowment can be hypothetically thought of as selling her endowment and repurchasing assets.

The investor's problem can then be split into two parts. Conditional on asset holdings, $A_{0}$, the investor solves the portfolio problem

$$
\begin{aligned}
& V_{1}\left(A_{0}\right)=\max _{\left\{x_{j}\right\}_{\{f\} \cup J^{i}}}\left(E^{i}\left[C_{1}(\mathbf{z})^{1-\gamma}\right]\right)^{1 /(1-\gamma)}, \\
& \text { s.t. } \sum_{j \in\{f\} \cup J^{i}} P_{j} x_{j}=A_{0} \text { and } C_{1}(\mathbf{z})=\sum_{j \in\{f\} \cup J^{i}} x_{j} \varphi_{j}(\mathbf{z}) .
\end{aligned}
$$

In turn, given the value function $V_{1}(\cdot)$, she chooses asset holdings to solve the intertemporal 
problem,

$$
\max _{A_{0}}\left(W_{0}-A_{0}\right)^{1-1 / \varepsilon}+\beta\left(V_{1}\left(A_{0}\right)\right)^{1-1 / \varepsilon} .
$$

The result then follows from three observations. First, the portfolio problem is linearly homogeneous, which implies that the value function is linear in asset holdings,

$$
V_{1}\left(A_{0}\right)=R_{c e}^{i} A_{0}
$$

We refer to $R_{c e}^{i}$ as the investor's certainty-equivalent return. Second, and most importantly, financial innovation increases the certainty-equivalent return, $R_{c e}^{i, n e w} \geq R_{c e}^{i, o l d}$, because it expands the choice set of feasible portfolios. Third, in the intertemporal problem, a greater risk-adjusted return implies an increase in asset holdings in view of the assumption $\varepsilon>1$.

Intuitively, with greater portfolio choice, the investor's certainty-equivalent portfolio return increases. This creates substitution and income effects. On the one hand, the investor finds saving more attractive, which induces her to save more. On the other hand, the investor also feels richer, which induces her to consume more and save less. The substitution effect dominates, and financial innovation increases savings, whenever the EIS is sufficiently high.

As this intuition suggests, the result can be further generalized. The particular comparative statics we focus on, the expansion of the access set from $J^{i \text { old }}$ to some $J^{i, n e w}$, does not play an important role beyond ensuring that the investor has greater choice. Any other financial innovation that expands the investor's choice would lead to the same effect. Financial innovations that increase the investor's marginal return without affecting her choice would also induce her to save more. For instance, financial innovation that decreases participation or trading costs in a way to increase the net marginal return also increases savings.

Perhaps less obviously, financial innovations that improve market liquidity and enable the investor to retrade more frequently would have the same effect. To illustrate this, consider a version of the model in which there is an intermediate date, $t=1 / 2$, that features additional states, $s \in S$. These states affect investors' beliefs about the likelihood of payoff-states, $\mathbf{z} \in Z$. The investor's beliefs obey the law of iterated expectations, so the baseline analysis is a special case in which the investors choose a buy-and-hold strategy and they keep the same portfolio regardless of the state realization at the intermediate date. Now suppose that, thanks to financial innovation, the investor can costlessly adjust her portfolio at the intermediate date. The investor solves a version of problem (8) in which she chooses a 
collection of portfolios for each state, $\left(\left\{x_{j}(s)\right\}_{\{f\} \cup J^{i}}\right)_{s \in S}$. It is then easy to see that the expanded choice increases the investor's perceived certainty-equivalent return on her financial portfolio, $R_{c e}$, which in turn induces her to increase her savings at date 0 .

The result requires a relatively high EIS, which ensures that greater portfolio return increases savings. Using different methodologies, empirical studies find a wide range of estimates for the EIS (see Hall, 1988; Blundell et al., 1994; Attanasio and Browning, 1995; Vissing-Jørgensen, 2002; Vissing-Jørgensen and Attanasio, 2003; Gruber, 2013). Most of the studies assume that investors with separable or Epstein-Zin preferences fully observe the changes in asset returns and make optimal decisions. Even though we also make the same assumptions, some of these features are not central for our analysis. What is important is that investors have an asset holding (or saving) function that is increasing in their perceived marginal return. We believe this assumption is plausible. Moreover, under some behavioral biases such as limited attention, investors can have an increasing asset holding function even if their estimated EIS is below one $4^{4}$ Thus, we view the condition, $\varepsilon>1$, as a simple way of generating an increasing asset holding function: ${ }^{5}$

The result also exploits the irrelevance of background risks (Assumption 1), which enables us to focus on nonprecautionary savings. A natural question is what happens when there are some uninsurable background risks, so that financial innovation can affect precautionary savings. We address this concern in Appendix A.1 using a numerical example that also features uninsurable labor income risk. An increase in the risk-adjusted portfolio return (via greater choice) increases savings also in this context even in the presence of uninsurable risk. For each level of the portfolio return gain, we also calculate the required decrease in

\footnotetext{
${ }^{4}$ To illustrate this, consider an investor with Epstein-Zin preferences with $\varepsilon>1$ who makes consumption and saving decisions over several periods. The investor has limited attention and observes the asset returns only with some probability. In any period, if she observes the asset returns, then she follows a fully optimal consumption plan. If she does not observe the returns, then she follows a default rule: say, she consumes and saves according to her earlier plan (many other default rules would also work). This investor's expected asset holdings and savings would also increase in response to an increase in returns (albeit not as much as in our model). Thus, our qualitative results would continue to apply in this setting. However, the investor's consumption growth would not increase by a large magnitude after a (surprise) increase in the interest rate. Thus, an empirical strategy that focuses on consumption growth over a relatively short horizon and a fully rational model will estimate $\hat{\varepsilon}<1$.

${ }^{5}$ Most of the recent asset pricing literature works with $\varepsilon>1$. This is because when $\varepsilon<1$ (and risk aversion satisfies, $\gamma>1$ ) the Epstein-Zin preferences lead to unintuitive and unrealistic predictions. For instance, under this configuration, an increase in the volatility of output growth would lead to an increase in asset valuations (see Bansal and Yaron, 2004).
} 
the uninsurable risk that would keep the investor's overall savings constant (see Figure 8 in the appendix). When the investor has relatively standard preferences $(\varepsilon=1.5$ and $\gamma=3)$, and her portfolio return gains are calibrated using the Sharpe ratios observed in practice, it takes a large decline in the uninsurable risk (more than 15 percent) to neutralize the choice channel.

Remark 1 (Interpreting the Two Period Model). We view our two period model as capturing a single portfolio choice and savings decision. Consequently, we also view the time length between the two periods as corresponding to a typical planning horizon for investors when they make their portfolio choice decisions (such as one year). In a dynamic setting, investors would make many such decisions, but each decision would be subject to similar forces as in our model. Hence, our model can be viewed as isolating mechanisms that are likely to apply also in dynamic models. That said, dynamics would generate additional effects that could interfere with these mechanisms. A specific concern is the market selection hypothesis, which posits that investors with less accurate beliefs will disappear in the long run (see Blume and Easley (2006) for a formalization). In recent work, Borovicka (2018) shows that this hypothesis does not necessarily apply when investors have Epstein-Zin preferences (as opposed to separable preferences). In fact, he finds that investors with different beliefs coexist for a broad range of plausible parameterizations for the elasticity of substitution and relative risk aversion (including the parameters that we use in our numerical analysis in Section 3.3). This suggests that our results are likely to be robust to the market selection hypothesis.

\section{The Choice Channel and Asset Returns}

This section investigates how the choice channel affects asset prices and returns in general equilibrium. To facilitate analytical tractability, we make several simplifying assumptions. We first describe these assumptions and define the equilibrium. We then characterize the equilibrium in two special cases that establish our general equilibrium results, respectively, for market participation and portfolio customization. We also provide a numerical analysis that illustrates the quantitative strength of these results. We conclude the section by discussing the extent to which our results are consistent with the trends in asset returns in developed countries in postwar years.

There are several types of investors denoted by $i \in I$, with masses $n^{i} \geq 0$ that satisfy 
$\sum_{i} n^{i}=1$. Investors are identical in all dimensions (including their endowments) except possibly their market access and beliefs. We make the following analogue of Assumption 1. Assumption $\mathbf{1}^{\mathrm{G}}$. $L(\mathbf{z})=0$ and $\varepsilon>1$.

As before, we normalize the future endowments to zero (see Section 2). We also assume the EIS is relatively high so that the choice channel is operational.

To endogenize asset prices, we impose additional structure on asset supplies and payoffs. Each asset $j \in \mathbf{J}$ is in fixed supply denoted by $\eta_{j} \geq 0$. The uncertainty is now described by a $K \times 1$ vector of continuous risk factors, $\mathbf{z}=\left(z_{1}, \ldots, z_{K}\right)^{\prime}$ (in particular, the state space is now given by, $\mathbf{Z}=\mathbb{R}^{K}$ ). The $\log$ payoff of a risky asset $j \in \mathbf{J}$ can be written as a linear combination of the risk factors,

$$
\log \varphi_{j}(\mathbf{z})=\mathbf{F}_{j}^{\prime} \mathbf{z}
$$

where $\mathbf{F}_{j}$ is a $K \times 1$ vector. We assume investors' beliefs for $\mathbf{z}$ are normally distributed.

Assumption 2. Investor $i$ 's prior belief for $\mathbf{z}$ has a Normal distribution, $N\left(\boldsymbol{\mu}_{\mathbf{z}}^{i}, \Lambda_{\mathbf{z}}\right)$, where $\boldsymbol{\mu}_{\mathbf{z}}^{i} \in \mathbb{R}^{K}$ is the mean vector and $\Lambda_{\mathbf{z}}$ is the $K \times K$ positive definite covariance matrix. In addition, the $K \times|\mathbf{J}|$ matrix of asset loadings, $\mathbf{F}=\left[\mathbf{F}_{j}\right]_{j \in \mathbf{J}}$, has full rank.

We also find it convenient to work with gross and log asset returns defined by, respectively, $R_{j}(\mathbf{z}) \equiv \varphi_{j}(\mathbf{z}) / A_{0}$ and $r_{j}(\mathbf{z}) \equiv \log R_{j}(\mathbf{z})$. Assumption 2 implies that the investor believes $\log$ asset returns are jointly normally distributed with mean and variance given by,

$$
E^{i}\left[r_{j}\right]=\left(\mathbf{F}_{j}\right)^{\prime} \boldsymbol{\mu}_{\mathbf{z}}^{i}-\log P_{j} \text { and } \operatorname{var}\left(\left\{r_{j}\right\}_{j \in \mathbf{J}}\right)=\Lambda \equiv \mathbf{F}^{\prime} \Lambda_{\mathbf{z}} \mathbf{F} \text {. }
$$

Note that investors can disagree on the mean of asset returns but they agree on the variance of $\log$ returns (for simplicity). As before, belief disagreements are dogmatic.

We define the investor's gross and log portfolio returns by, respectively, $R_{p}(\mathbf{z}) \equiv$ $C_{1}(\mathbf{z}) / A_{0}$ and $r_{p}(\mathbf{z}) \equiv \log R_{p}(\mathbf{z})$. We also write the gross return as a weighted-average of asset returns, $R_{p}(\mathbf{z})=\sum_{j \in\{f\} \cup J^{i}} \omega_{j} R_{j}(\mathbf{z})$ (with portfolio weights, $\omega_{j} \equiv x_{j} P_{j} / A_{0}$, that sum to one). Despite Assumption 2, the log portfolio return is not necessarily normally distributed. For analytical tractability, we assume the investor optimizes her portfolio after approximating it with a normal distribution as in Campbell and Viceira (2002). This reduces 
the portfolio problem (4) to mean-variance optimization,

$$
\begin{aligned}
r_{c e}^{i}-r_{f} & =\max _{\boldsymbol{\omega}_{J^{i}}} \boldsymbol{\omega}_{J^{i}}^{\prime} \boldsymbol{\pi}_{J^{i}}^{i}-\frac{\gamma}{2}\left(\boldsymbol{\omega}_{J^{i}}^{\prime} \Lambda_{J^{i}} \boldsymbol{\omega}_{J^{i}}\right), \\
\text { where } \pi_{j}^{i} & =E^{i}\left[r_{j}\right]+\frac{\Lambda_{j}}{2}-r_{f} \text { for each } j .
\end{aligned}
$$

Here, $r_{c e}^{i}=\log R_{c e}^{i}$ denotes the $\log$ of the investor's certainty-equivalent return from asset holdings [cf. Eq. (6)]. The variable $\pi_{j}^{i}$ denotes the investor's perceived risk premium on asset $j$ (defined as $\log E^{i}\left[R_{j}\right]-\log R_{f}$ ). The vectors $\boldsymbol{\pi}_{J^{i}}^{i}$ and $\boldsymbol{\omega}_{J^{i}}^{i}$ denote, respectively, the risk premia and the portfolio weights corresponding to the risky assets in the access set. The matrix $\Lambda_{J^{i}}$ represents the restriction of the covariance matrix to assets in $J^{i}$. The investor chooses her portfolio weights on risky assets (with the residual weight invested in the risk-free asset) to trade off expected return with risk.

The portfolio approximation in (8) becomes exact in the continuous time limit. Over longer horizons, it provides insights for optimal portfolio choice, and it is often used in applied work. ${ }^{6}$ In our numerical analysis, which relies on a calibration with one-year horizon, we also calculate the exact equilibrium and show that the approximation error is negligible (see Section 3.3). Hence, the main role of the portfolio approximation is to provide analytical tractability.

In particular, problem (8) has a closed form solution given by,

$$
\boldsymbol{\omega}_{J^{i}}^{i}=\frac{1}{\gamma} \Lambda_{J^{i}}^{-1} \boldsymbol{\pi}_{J^{i}}^{i} \text { and } r_{c e}^{i}=r_{f}+\frac{1}{2 \gamma}\left(\boldsymbol{\pi}_{J^{i}}^{i}\right)^{\prime} \Lambda_{J^{i}}^{-1} \boldsymbol{\pi}_{J^{i}}^{i}
$$

It is easy to check that expanding the access set, $J^{i}$, increases the investor's certaintyequivalent return, $r_{c e}^{i}$, as in the previous section.

As before, the investor chooses her consumption and savings to maximize the intertemporal utility function in (2) given the certainty-equivalent return from her portfolio problem. The solution can be written as

$$
A_{0}^{i}=a\left(r_{c e}^{i}\right)\left(Y_{0}+W_{0}\right) \text { where } a\left(r_{c e}\right)=\frac{\beta^{\varepsilon} \exp \left(r_{c e}(\varepsilon-1)\right)}{1+\beta^{\varepsilon} \exp \left(r_{c e}(\varepsilon-1)\right)} .
$$

\footnotetext{
${ }^{6}$ For instance, Campbell and Viceira (2002) use a similar framework to analyze portfolio allocation for long-term investors.
} 
Here, $a\left(r_{c e}\right)$ describes the investors' effective asset holding as a fraction of wealth. It is an increasing function, as in the previous section, in view of the assumption $\varepsilon>1$.

The asset market clearing conditions can then be written as,

$$
\eta_{j} P_{j}=\sum_{\left\{i \mid j \in\{f\} \cup J^{i}\right\}} n^{i} \omega_{j}^{i} a\left(r_{c e}^{i}\right)\left(Y_{0}+W_{0}\right) \text { for each } j \in\{f\} \cup \mathbf{J},
$$

where $W_{0}=\sum_{j} P_{j} \eta_{j}$ for each $i$. Here, we used $x_{-1, j}^{i}=\eta_{j}$, which follows since investors have symmetric endowments (by assumption).

Definition 1 (Equilibrium). Under Assumptions $1^{G}$ and 2 , an equilibrium, $\left\{\left(\omega_{J^{i}}^{i}, A_{0}^{i}\right)_{i}, P_{j}\right\}$, is a collection such that the investors' beliefs for asset returns and premiums are given by (7) and (9), their portfolio weights and certainty-equivalent returns are given by (10), their asset holdings are given by (11), and the asset markets clear [cf. Eq. (12)].

The following result establishes the existence of an equilibrium.

Proposition 2 (Existence). Under Assumptions $1^{G}$ and 2, there exists an equilibrium with $P_{j}>0$ for each $j \in\{f\} \cup \mathbf{J}$.

At this level of generality, we cannot characterize the equilibrium much further. We thus analyze a canonical case that can accommodate the key aspects of recent financial innovations.

Assumption 3. There exist $K$ risky assets in total, $\mathbf{J}=\{m, 1, \ldots, K-1\}$. The asset $m$ is in positive supply, $\eta_{m}>0$, while the remaining risky assets, as well as the risk-free asset are in zero net supply, $\eta_{j}=0$ for $j \neq m$.

The first part ensures that the risky assets are sufficient for spanning all combinations of the $K$ risk factors. The second part says that one of the risky assets correspond to the market portfolio, denoted by $m$, that represents all of the cash flows generated by the economy's productive assets. The remaining risky assets, $j \in\{1, . ., K-1\}$, enable investors to customize their risk exposures.

We also impose some structure on investors' access sets and beliefs. Specifically, investors' types have two dimensions, $\left\{i=\left(i_{A}, \mathbf{i}_{B}\right)\right\}_{i}$. The sub-type $i_{A} \in I_{A}$ captures the variation in investors' access to financial assets, while the sub-type $\mathbf{i}_{B} \in I_{B}$ (which itself is a vector) captures the variation in beliefs. In particular, investors with type $\mathbf{i}_{B} \in I_{B}$ have the mean 
belief about risk factors, $\boldsymbol{\mu}_{\mathbf{z}}^{\mathbf{i}_{B}}=\boldsymbol{\mu}_{\mathbf{z}}+\mathbf{i}_{B}$, where we define $\boldsymbol{\mu}_{\mathbf{z}}$ as a reference belief (which will also correspond to the average belief). We make the following assumptions on beliefs.

Assumption 4.(i) The mass of type $i=\left(i_{A}, \mathbf{i}_{B}\right)$ investors is $n^{i}=n^{i_{A}} \times n^{\mathbf{i}_{B}}$, where $n^{i_{A}}$ (resp. $\left.n^{\mathbf{i}_{B}}\right)$ denotes the mass with access type $i_{A}\left(\right.$ resp. $\left.\mathbf{i}_{B}\right)$, with $\sum_{i_{A}} n^{i_{A}}=1\left(\operatorname{resp} . \sum_{\mathbf{i}_{B}} n^{\mathbf{i}_{B}}=1\right)$.

(ii) For each belief type, $\mathbf{i}_{B} \in I_{B}$, the opposite belief type also exists, $-\mathbf{i}_{B} \in I_{B}$, and has equal mass, $n^{\mathbf{i}_{B}}=n^{-\mathbf{i}_{B}}$ for each $\mathbf{i}_{B} \in I_{B}$.

(iii) Investors do not disagree on the market portfolio: $\mathbf{F}_{\mathbf{m}}^{\prime} \mathbf{i}_{B}=0$, for each $\mathbf{i}_{B} \in I_{B}$.

The first part says that investors' beliefs are drawn independently of their choice set. The second part is a mild symmetry assumption on the cross-sectional belief distribution. The last part is arguably restrictive but its main role is to provide analytical tractability; our results hold numerically also in the absence of this assumption (see Section 3.2 and Appendix B.3. This part also ensures that investors agree on the risk-premium on the market portfolio, $\pi_{m}^{i} \equiv \pi_{m}$ for each $i$ [cf. Eq. (9)].

\subsection{Market Participation}

We next use this setup to analyze how different types of choice-expanding innovations affect asset returns. We start by analyzing market participation, which we capture with access to asset $m$. Formally, there are two access types, $i_{A} \in\{n, p\}$, where $J^{n}=\emptyset$ and $J^{p}=\{m\}$. Type $n$ investors (nonparticipants) have access only to the risk-free asset. Type $p$ investors (participants) also have access to asset $m$. The following result provides a closed-form characterization of equilibrium. To state the result, note that investors' certainty-equivalent returns do not depend on their beliefs, $r_{c e}^{i_{A}, \mathbf{i}_{B}}=r_{c e}^{i_{A}}$, because they disagree on nonmarket assets but the only available financial asset is the market portfolio (disagreements will play an important role when we analyze customization).

Lemma 1. Consider the above setup with limited participation in the market portfolio. In equilibrium, investors' allocations only depend on their access type $i_{A} \in\{p, n\}$ and:

(i) Participants' and nonparticipants' certainty-equivalent returns are,

$$
r_{c e}^{p}=r_{f}+\frac{\pi_{m}^{2}}{2 \gamma \Lambda_{m}} \text { and } r_{c e}^{n} \equiv r_{f}
$$

Participants have greater return and savings, $r_{c e}^{p}>r_{c e}^{n}$ and $a\left(r_{c e}^{p}\right)>a\left(r_{c e}^{n}\right)$. 
(ii) The market risk premium and the risk-free rate, $\pi_{m}$ and $r_{f}$, are the solution to,

$$
\begin{aligned}
\pi_{m} & =\gamma \Lambda_{m}\left(1+\frac{1-n^{p}}{n^{p}} \frac{a\left(r_{f}\right)}{a\left(r_{c e}^{p}\right)}\right), \\
\frac{\eta_{m} P_{m}}{Y_{0}+\eta_{m} P_{m}} & =\left(1-n^{p}\right) a\left(r_{f}\right)+n^{p} a\left(r_{c e}^{p}\right),
\end{aligned}
$$

where $P_{m}=\exp \left(\mathbf{F}_{\mathbf{m}}^{\prime} \boldsymbol{\mu}_{\mathbf{z}}+\frac{\Lambda_{m}}{2}-r_{f}-\pi_{m}\right)$.

The first part derives the implications for the choice channel in the context of market participation. Market access increases the certainty-equivalent return by enabling the investors to earn the aggregate risk premium. All else equal, this also implies market participants save more than nonparticipants.

The second part characterizes the asset returns. To understand Eq. (14), note that the market risk premium with full participation would be given by $\pi_{m}=\gamma \Lambda_{m}$. Limited participation increases the risk premium because aggregate risk is shared among fewer investors, who require greater premium. Eq. (15) is a market clearing condition for all assets, which equates the value of the market portfolio to the aggregate savings. The next result describes how financial innovation that increases participation, $n^{p} \in[0,1]$, affects asset returns.

Proposition 3 (Increased Participation). Consider the equilibrium characterized in Lemma 1. Financial innovation that increases the relative mass of participants, $n^{p}$, decreases the risk premium, $\pi_{m}$, as well as the expected return on the market portfolio, $r_{f}+\pi_{m}$.

The effect on the risk-free rate $r_{f}$ is theoretically ambiguous. In our numerical analysis, we also find that greater participation typically increases the risk-free rate, $r_{f}$ (see Section 3.3).

The result on the return on the market portfolio follows from the choice channel. Increased access to the market portfolio increases aggregate savings, as illustrated by Eqs. (13) and (15), which increases the valuation of all assets. The result on the risk premium follows from improved aggregate risk sharing, as illustrated by Eq. (14). This also implies that greater participation increases the value of risky assets relative to the safe asset, which is why the result on the risk-free rate is theoretically ambiguous. 


\subsection{Portfolio Customization}

We next present our main general equilibrium results on customization. Suppose all investors have access to the market portfolio (for simplicity) but they might have limited access to the remaining risky assets, $j \in\{1, . ., K-1\}$. The practical counterpart of these assets can be thought of as passive mutual funds or ETFs that specialize in certain styles or industries; active mutual funds that implement heterogeneous strategies on investors' behalf; direct trading of individual stocks and bonds; or derivatives such as futures or options. These financial instruments enable investors to construct customized portfolios, and increasingly so in recent years (see Figure 1).

To capture these assets, suppose the access types are now given by, $i_{A} \in\{0, \ldots, K-1\}$, such that $J^{i_{A}}=\{m\}$ for $i_{A}=0$, and $J^{i_{A}}=\left\{m, 1, . ., i_{A}\right\}$ for $i_{A} \geq 1$. Therefore, $i_{A}$ denotes the number of the non-market assets the investor has gained access to (in increasing order). The following result provides a closed-form characterization of equilibrium. To state the result, we define the risk-premium on a risky asset as the weighted-average of risk premia perceived by each investor, $\pi_{j}=\sum_{i} n^{i} \pi_{j}^{i}$ [cf. Eq.(9)].

Lemma 2. Consider the above setting with limited portfolio customization (and full market participation). In equilibrium:

(i) The certainty-equivalent return for each type $\left(i_{A}, \mathbf{i}_{B}\right)$ is,

$$
r_{c e}^{\left(i_{A}, \mathbf{i}_{B}\right)}=r_{f}+\frac{1}{2 \gamma} \frac{\pi_{m}^{2}}{\Lambda_{m}}+\frac{1}{2 \gamma}\left(\mathbf{F}_{J^{i} A}^{\prime} \mathbf{i}_{B}\right)^{\prime} \Lambda_{J^{i_{A}}}^{-1}\left(\mathbf{F}_{J^{i_{A}}}^{\prime} \mathbf{i}_{B}\right)
$$

Investors with greater access to customized assets have greater certainty-equivalent return and savings, that is, $r_{c e}^{\left(i_{A}, \mathbf{i}_{B}\right)}$ and $a\left(r_{c e}^{\left(i_{A}, \mathbf{i}_{B}\right)}\right)$ are increasing in $i_{A}$.

(ii) The risk premium on each risky asset satisfies,

$$
\pi_{j}=\frac{\Lambda_{j m}}{\Lambda_{m}} \pi_{m} \text {, where } \pi_{m}=\gamma \Lambda_{m}
$$

The risk-free rate is the solution to,

$$
\frac{\eta_{m} P_{m}}{Y_{0}+\eta_{m} P_{m}}=\sum_{i \in I} n^{i_{A}} n^{\mathbf{i}_{B}} a\left(r_{c e}^{\left(i_{A}, \mathbf{i}_{B}\right)}\right)
$$


where $P_{m}=\exp \left(\mathbf{F}_{\mathbf{m}}^{\prime} \boldsymbol{\mu}_{\mathbf{z}}+\frac{\Lambda_{m}}{2}-r_{f}-\pi_{m}\right)$.

The first part shows that, in view of the choice channel, access to customized assets increases the certainty-equivalent return by enabling the investors to construct speculative portfolios. All else equal, this also implies greater access to customized assets is associated with greater savings.

In the second part, Eq. (17) shows that the risk premium on an asset is determined by its "beta" with respect to the market portfolio. This is a standard asset pricing result that would also obtain in a version of our model with common beliefs and complete customization. Therefore, for the purposes of characterizing the risk premia, or relative asset prices, the unorthodox features of the model - belief heterogeneity and limited customization - can be ignored. Intuitively, due to the linear portfolio demand in (10), the risk premia are determined by the weighted-average belief (similar to Lintner (1969)).

On the other hand, belief heterogeneity and customization matter for absolute asset prices. The next result characterizes how financial innovation that expands customization opportunities affects asset returns. We formalize increased customization by a shift of mass from a type with less access to one with more access.

Proposition 4 (Increased Customization). Consider the equilibrium characterized in Lemma 2. Consider financial innovation that increases the scope of customization, $\tilde{n}^{i^{1}}=$ $n^{i_{A}^{1}}+\Delta n$ and $\tilde{n}_{A}^{i_{A}^{0}}=n^{i_{A}^{0}}-\Delta n$ where $i_{A}^{1}>i_{A}^{0}$ and $\Delta n>0$. This change reduces the risk free rate $r_{f}$, leaves unchanged the average risk premia, $\left\{\pi_{j}\right\}_{j \in \mathbf{J}}$, and decreases the average expected return on risky assets, $\left\{r_{f}+\pi_{j}\right\}_{j \in \mathbf{J}}$.

The result follows from the choice channel. Increased access to customized assets increases aggregate savings, as illustrated by Eqs. (16) and (18), which increases the valuation of all assets. Since the risk premia remain unchanged, higher prices translate into a decline in the risk-free rate, as in Example 1. The difference is that the current model features many assets, and the price of all assets increase (expected returns decrease) in tandem.

In Online Appendix B.3, we show that the effect of customization on the interest rate formalized in Proposition 4 is robust to various extensions. First, we relax the third part of Assumption 4 and allow for disagreement on the market portfolio. We use a numerical example to show that the result is largely unchanged. Disagreement on the market portfolio generates additional speculation that (typically) increases the certainty equivalent return and 
reduces the risk-free rate further. Moreover, increase in customization (typically) exacerbates speculation and reduces the risk-free rate also in this setting. We are unable to provide an analytical result mainly because speculation on the market portfolio breaks down the symmetry between optimists' and pessimists' returns in Eq. (16). 7

Second, we introduce short-selling constraints on a subset of non-market risky assets and generalize the result to this setting. Short-selling constraints generate additional effects on relative asset prices because risky assets that are subject to constraints are priced by the investors that value them the most, as first emphasized by Miller (1977). However, these effects are there both before and after the expansion of customization, so the qualitative effect of customization on the interest rate remains unchanged. On the other hand, short-selling constraints dampen speculation and therefore mitigate the quantitative effects of greater customization on the interest rate.

Third, we also show that the result is robust to allowing for aggregate investment in capital (that endogenizes the supply of the market portfolio). Intuitively, the reduction in the interest rate due to greater customization also generates an increase in investment. The induced investment response does not overturn the initial decline in the interest rate but it mitigates the impact, because some of the savings pressure is now absorbed by quantity of capital as opposed to its price. Therefore, in this setting, the magnitude of the interest rate decline also depends on the properties of the aggregate production function.

\subsection{Numerical Illustration}

We next quantify our results on participation and customization using a numerical example. Suppose $K=2$ so that there are two risk factors, denoted by $\left\{z_{m}, z_{s}\right\}$. The risk factor, $z_{m}$, captures systematic risks ("the market factor"): that is, the payoff of the market portfolio is given by $\log \varphi_{m}=z_{m}$. The remaining risk factor, $z_{s}$, captures non-systematic risks ("the speculative factor"). There is one non-market risky asset, which we denote by subscript $s$, with payoff $\log \varphi_{s}=z_{s}$ ("the speculative asset").

\footnotetext{
${ }^{7}$ Since the asset $m$ is in positive supply, all investors are its natural buyers. Even if optimists did not adjust their positions (relative to the average investor), their perceived return would be higher simply because they are already holding the market portfolio. Therefore, in equilibrium, optimists obtain a greater certainty-equivalent return - and hold more assets - relative to pessimists. This asymmetry makes an analytical characterization difficult.
} 
We assume each investor is optimistic or pessimistic about the speculative factor. Specifically, there are two belief types, $\mathbf{i}_{B} \in\left\{\Delta_{s},-\Delta_{s}\right\}$, that respectively think that the mean of $z_{s}$ is given by $\mu_{s}+\Delta_{s}$ and $\mu_{s}-\Delta_{s}$. All investors agree on the objective mean of the market factor. With these assumptions, investors' beliefs satisfy Assumption 4 so the results in this section apply.

In this example, there are three relevant access types, $i_{A} \in\{n, p, s\}$, where $J^{n}=\emptyset, J^{p}=$ $\{m\}$ and $J^{s}=\{m, s\}$. Types $n$ and $p$ correspond to nonparticipants and participants without access to the speculative asset. Type $s$ corresponds to participants that have access to the speculative assets in addition to the market portfolio. We consider an initial state in which no one has access to the speculative asset, $n^{s}=0$, and only a fraction of investors have access to the market portfolio, $n^{p}, n^{n} \in[0,1]$ with $n^{p}+n^{n}=1$. Starting from this initial state, we first illustrate Proposition 3 by analyzing an increase in $n^{p}$ (where $n^{n}=1-n^{p}$ ). We then consider a situation in which everyone has access to the market portfolio, $n^{n}=0$, but a fraction of investors also have access to the speculative asset, $n^{p}, n^{s} \in[0,1]$ with $n^{p}+n^{s}=1$. We illustrate Proposition 4 by analyzing an increase in $n^{s}$ (where $n^{p}=1-n^{s}$ ).

To calibrate the initial fraction of participants, $n^{p} \in[0,1]$, we rely on the left panel of Figure 1 (the wealth-weighted measure), which illustrates that in 1960 s around $50 \%$ of the U.S. wealth portfolios included any stocks. We choose as our initial state a more conservative number, $n^{p}=0.75$, because even nonparticipants are arguably exposed to some aggregate risk through their housing investments or labor income.

Throughout, we use the preference parameters, $\gamma=3$ and $\varepsilon=1.5$, and we calibrate the remaining parameters with a one-year time horizon (see Remark 1). The value $\varepsilon=1.5$ is taken from Vissing-Jørgensen and Attanasio (2003) as an estimate for the EIS of stockholders. The value $\gamma=3$ is in the middle of values for the risk aversion coefficient that are used when one focuses on the volatility of the stock market index (as opposed to aggregate consumption) to calibrate portfolio risks - essentially abstracting away from the equity premium puzzle (see, for instance Cochrane, 2005, section 21.1) 8 Similarly, we consider a value for the volatility of the market portfolio of $\sqrt{\Lambda_{m}} \approx 13 \%$. This leads to a yearly risk premium of $\pi_{m}=\gamma \Lambda_{m} \approx 5 \%$ and a yearly Sharpe ratio of $\pi_{m} / \sqrt{\Lambda_{m}}=0.4$. The implied Sharpe ratio is roughly consistent with the Sharpe ratio on the world equity index in dollars in recent decades

\footnotetext{
${ }^{8}$ The volatility of consumption growth in the U.S. is around $1 \%$, which leads to the equity premium puzzle (with relatively standard parameters such as $\gamma=3$ ).
} 
(see, for instance, Calvet et al., 2007). We also calibrate the growth rate of log output and the discount factor $\beta$ so that the yearly risk-free rate in the initial state $\left(n^{p}=0.75\right.$ and $\left.n^{s}=0\right)$ is equal to the historical average of the real risk-free rate, $r_{f}=1 \%$. We relegate the calibration of the disagreement parameter, $\Delta_{s}$, to the part where we discuss customization (because this parameter does not affect the equilibrium with limited participation - see Lemma 1).

Quantitative effects of greater participation The left panel of Figure 4 illustrates the quantitative effects of increasing market participation. The solid lines show that increased participation reduces the risk premium and the expected return on the market portfolio, consistent with Proposition 3, while also increasing the risk-free rate. The dashed lines illustrate the solution with $\varepsilon=1$, which provides a useful comparison case. In this case, the relative price effects are still active but the absolute price effects are absent since the choice channel is shut down. Comparing this case with our calibration, $\varepsilon=1.5$, shows that the choice channel from increased participation reduces asset returns by less than a half percentage point. This effect is too small to overturn the relative price effect, which is close to two percentage points. On net, greater participation increases the risk-free rate by about one and a half percentage points.

The choice channel is relatively weak in this context partly because of crowd-out effects that tend to lower the average investor's benefit from participation. Greater $n^{p}$ reduces the risk premium, which reduces the return for investors that already participate [cfs. Eq. (14) and [13)]. These investors react by reducing their asset holdings, which mitigates the effect of increased choice on asset prices. Specifically, the gains from participation, $r_{c e}^{p}-r_{c e}^{n}$, are decreasing in the extent of participation. This leads to a relatively small increase in aggregate savings, whose effect on the interest rate is easily dominated by the relative price effect.

Quantitative effects of greater customization Next suppose all investors have access to the market portfolio, $n^{n}=0$, and consider further financial innovation that increases the fraction of investors that also have access to the speculative asset, $n^{s} \in[0,1]$. Using Lemma 2. we have,

$$
r_{c e}^{\left(i_{A}, \Delta_{s}\right)}=r_{c e}^{\left(i_{A},-\Delta_{s}\right)}=\left\{\begin{array}{cl}
r_{f}+\frac{\pi_{m}^{2}}{2 \gamma \Lambda_{m}} & \text { if } i_{A}=p \\
r_{f}+\frac{\pi_{m}^{2}}{2 \gamma \Lambda_{m}}+\frac{\Delta_{s}^{2}}{2 \gamma \Lambda_{s}} & \text { if } i_{A}=s .
\end{array}\right.
$$



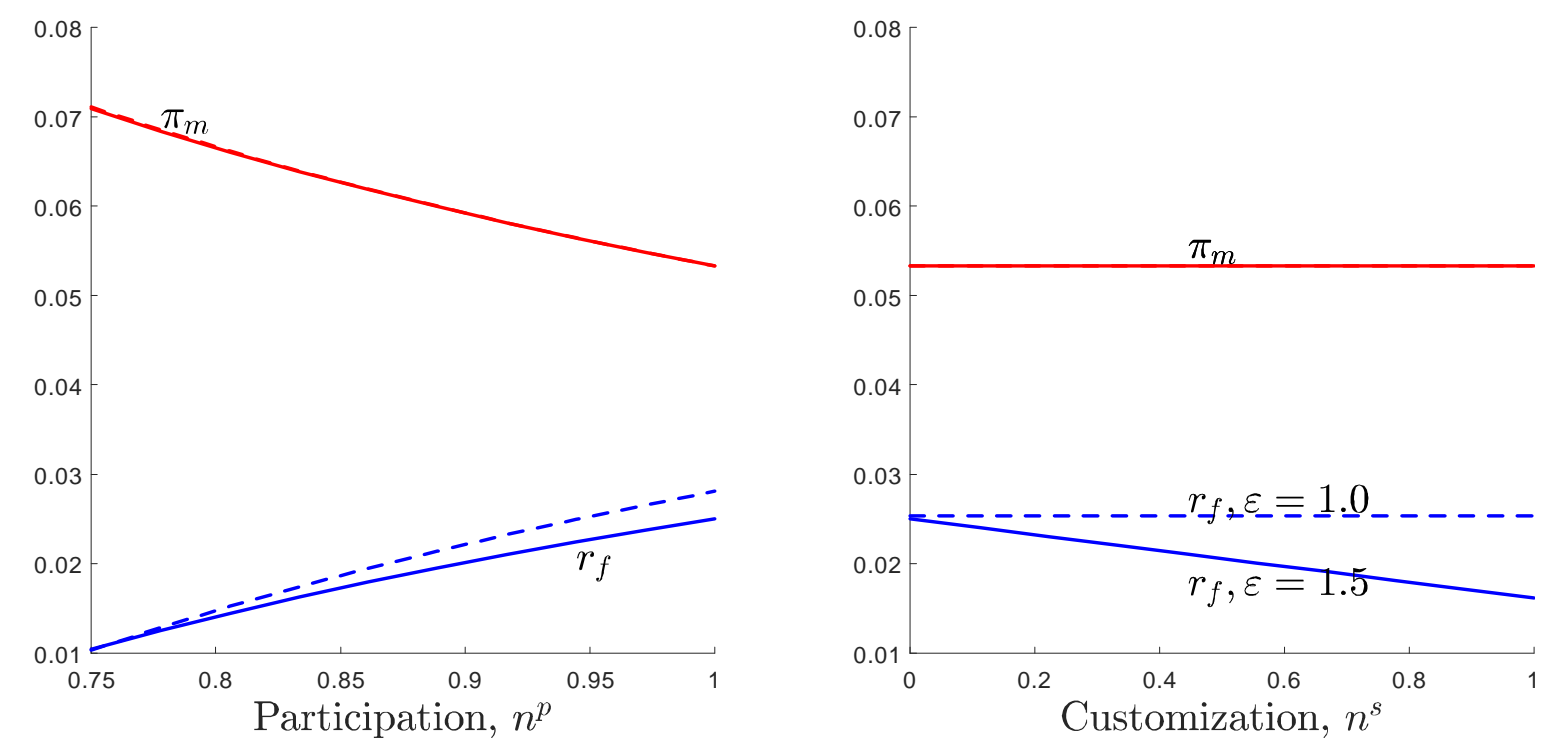

Figure 4: The left panel (resp. the right panel) illustrates the effect of increased participation (resp. customization) on asset returns for the benchmark calibration $\varepsilon=1.5$ (solid lines) and the comparison case $\varepsilon=1$ (dashed lines).

The first line is the certainty-equivalent return of investors that have access to the market portfolio but not the speculative asset. The second line is the certainty-equivalent return of investors that also have access to the speculative asset. Note that access to the speculative asset increases the certainty-equivalent return as in Section 3.2 .

As Eq. (19) illustrates, the key variable that modulates the strength of speculation is the term, $\left|\Delta_{s} / \sqrt{\Lambda_{s}}\right|$ : the investor's perceived Sharpe ratio on the speculative asset. We calibrate this term based on the empirical evidence provided by Calvet et al. (2007) using the portfolio returns of Swedish households. They perform a decomposition of the variance of portfolio returns and find that for households with the median total risk, more than half of the variance $(54.9 \%)$ is explained by idiosyncratic risks as opposed to systematic risks. We take the Sharpe ratio on the speculative asset to be equal to the Sharpe ratio on the market portfolio, $\left|\Delta_{s} / \sqrt{\Lambda_{s}}\right|=0.4$. This ensures that, when all risky assets are available, half of the portfolio variance for the investors in our model is driven by idiosyncratic risk.9

The right panel of Figure 4 illustrates the quantitative effects of increasing portfolio

\footnotetext{
${ }^{9}$ This can be viewed as a conservative calibration since the markets were arguably not fully developed over the time period (1999-2002) in which Calvet et al. (2007) conducted their study.
} 
customization. The $\mathrm{x}$-axis corresponds to the fraction of investors that have access to the speculative asset, $n^{s} \in[0,1]$. Note that customization reduces the risk-free rate and leaves the risk premium on the market portfolio constant, consistent with Proposition 4. Note also that the effects are quantitatively sizable. Going from zero customization to full customization reduces the risk-free rate by almost one percentage point 10

Participation and customization in the exact equilibrium We next use this numerical example to investigate the extent to which the portfolio approximation we adopt in (8) might be driving our results. In Section B.2, we define and compute the exact equilibrium (in which agents solve their portfolio problem exactly as opposed to relying on an approximation). Figure B.1 in Online Appendix B.2 replicates Figure 4 for the exact equilibrium. The difference between the approximate and the exact equilibria is very small (for each level of participation or customization). Therefore, the effect of greater participation or customization on asset returns remains qualitatively unchanged. This illustrates that, with relatively short planning horizons (our calibration relies on a one-year horizon), the approximation works well and its main role is to provide analytical tractability.

\subsection{The Choice Channel and the Postwar Trends in Asset Returns}

Our general equilibrium results are broadly consistent with the trends in asset returns in developed countries in postwar years. To see this, note from Figure 1 that participation has been the major force in earlier decades, whereas customization was dominant during later decades. Figure 5 illustrates that the interest rate in the U.S. has been increasing and the equity premium has been decreasing in the earlier period (pre 1990s), consistent with the left panel of Figure 4. The same figure also illustrates that the interest rate has been decreasing in the later period (post 1980s), consistent with the right panel of Figure $4^{11}$ There are of course many other contributing factors to these trends that are left out of our analysis. Our point is that choice-expanding innovations generate qualitative effects on asset returns that

\footnotetext{
${ }^{10}$ The numerical example in this section is only intended to give some sense of the magnitude of the effect of increased customization on the risk-free rate. The effect is larger for greater disagreements, higher values of the elasticity of intertemporal substitution, $\varepsilon$, and lower values of the risk aversion coefficient $\gamma$.

${ }^{11}$ The equity premium has been relatively flat after 1980s, consistent with Figure 4 , but it has been increasing in more recent years for reasons that are arguably outside our analysis (such as safe asset scarcity).
} 

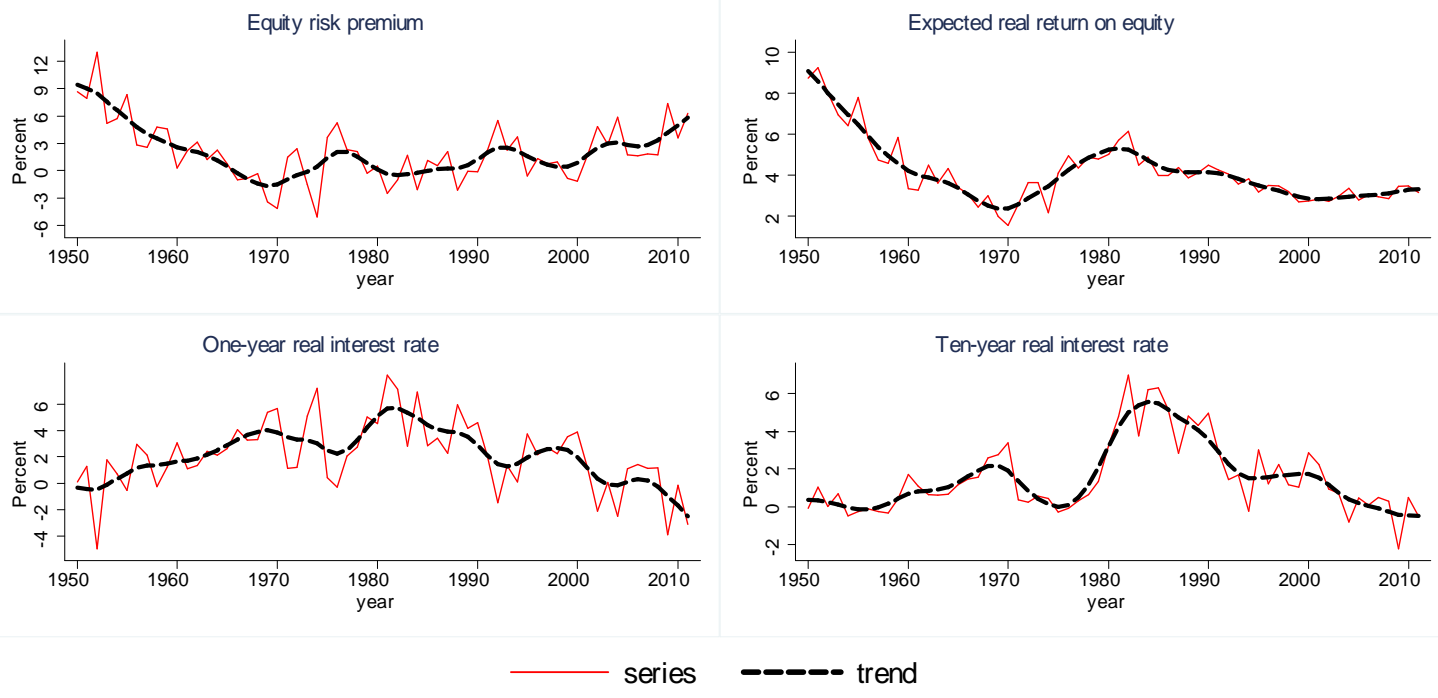

Figure 5: The plots are based on the authors' calculations using the methodology described in Blanchard (1993) and annual returns data for the U.S. from Robert Shiller (available at http://www.econ.yale.edu/ shiller/data.htm). The expected return on equity is calculated by using the dividend yield and the (model- based) expected dividend growth.

are in line with these trends. We next turn to a more systematic empirical analysis that uses household-level data to test the cross-sectional implications of the choice channel.

\section{Empirical Support for the Choice Channel}

This section presents a set of novel empirical facts that are consistent with the choice channel. We focus on two testable implications. First, as we formalize in Lemma 1, the choice channel predicts that (keeping all else equal) stock market participants save more than nonparticipants. Lemma 2 illustrates further that greater customization opportunities increase the saving rate of stock market participants relative to nonparticipants (since the latter group does not take advantage of customization opportunities). Therefore, we empirically investigate whether stock market participants in the U.S. save more than nonparticipants, and whether the differences increased in recent years that feature greater customization oppor- 
tunities ${ }^{12}$ Second, as we illustrate in Sections 3.2 and 3.3 , the choice channel also predicts that greater customization opportunities increase the dispersion of portfolio returns for stock market participants. Thus, we empirically analyze whether the U.S. stock market participants' portfolio returns have become more dispersed over time. At the end of the section, we also discuss evidence from the household finance literature that provides further support for the choice channel.

\subsection{The data and the variables of interest}

Our data comes from the wealth supplements of the Panel Survey of Income Dynamics (PSID) between 1984 and 2011. These wealth supplements were administered with every wave of the PSID from 1999 onward. Prior to these waves, they are also available for 1984, 1989, and 1994. The wealth supplements contain information on the balance sheets of surveyed households. They survey asset holdings in several broad asset categories including cash and transaction accounts, holdings of stocks of publicly traded companies, mutual funds, private business or farm, home equity, other real estate, annuities and IRAs, vehicles, and other savings. These asset holdings are defined net of any debt that they collateralize. In addition, there is information about purchases and sales of assets in categories that are subject to price changes (i.e. stock holdings, private business and other real estate) as well as net transfers 13

Given this information, we can construct information on households' savings. Recall from Section 2 that savings in our context is given by the sum of the changes in asset positions within the period evaluated at fixed asset prices [cf. Eq. (3)]. Therefore, we construct a measure of active savings, which takes into account investors' net reported asset purchases and sales between surveys, but excludes passive capital gains on different asset categories. ${ }^{14}$

\footnotetext{
${ }^{12}$ For the latter analysis, using nonparticipants as a control group is important because it helps to account for many omitted and time-varying factors that influence household savings (such as the interest rate).

${ }^{13}$ The PSID is particularly suitable for studying saving behavior over long horizons relative to the Survey of Consumer Finances (SCF), which is a cross-sectional survey that provides information on current household wealth only or the Consumer Expenditure Survey (CEX), which has been shown to have a time-varying bias in the measurement of consumption. See Bosworth et al. (2008) for additional details on the PSID wealth supplement data, and for a detailed discussion of the advantages and disadvantages of using the PSID wealth supplements to study saving behavior.

${ }^{14} \mathrm{An}$ alternative would be to measure savings from reported wealth changes over time. Active savings that excludes capital gains is not only more appropriate from a theoretical point of view (see Eq. (3)), but it
} 
As we are interested in savings relative to income, we construct an active saving rate in a given year as the (annualized) amount of active savings between that year and the subsequent survey year for the household divided by an average of the total income of the household head in that year and the subsequent survey year.

In addition, we construct an indicator variable for stock market participation in a given survey year based on the response to a survey question about stock and mutual fund ownership. We also construct a measure of the relative importance of stock holdings in the household's asset portfolio by constructing the share of stocks and mutual funds relative to all assets, excluding the primary residence of homeowners.

Finally, we define (implicit) return on wealth in the following way. First, we compute the annualized $(\log )$ reported growth rate of wealth between two consecutive dates of the wealth supplement. We then subtract our measure of (annualized) active savings divided by wealth ${ }^{15}$ Online Appendix $\mathrm{D}$ contains details on our sample restrictions and summary statistics for the main variables.

\subsection{Household savings by stock market participation}

We first investigate whether stock market participation is associated with greater savings. Figure 2 in the introduction illustrates that stock market participants on average have a greater saving rate than nonparticipants in every survey year. We verify the robustness of this result through regression analysis. Table 1 summarizes our results from regressing the

also arguably provides a cleaner estimate of households' savings intentions. Apart from measurement error, active savings equals the difference between the household's income and consumption within the period. In contrast, reported wealth changes also fluctuate due to the uncertainty in asset returns. Moreover, capital gains are based on subjective price estimates, which introduces additional noise. Perhaps for these reasons, several other papers in the literature also rely on active savings (see, e.g., Skinner (1996), Hurst et al. (1998), and Dynan et al. (2004), among others). Our precise measure of active savings follows the definition provided by the PSID between 1984 and 1989 (see Appendix D for details).

${ }^{15}$ In continuous time, we have that

$$
\dot{W}^{i}(t)=r^{i}(t) W^{i}(t)+S^{i}(t) \Longrightarrow r^{i}(t)=\frac{d\left(\log W^{i}(t)\right)}{d t}-\bar{s}^{i}(t),
$$

where $\bar{s}^{i}(t)=\frac{S(t)}{W(t)}$ is the ratio of active savings over wealth. As a consequence, $r_{t, t+\Delta}=\frac{\log W_{t+\Delta}-\log W_{t}}{\Delta}-$ $\bar{s}_{t, t+\Delta}^{i}$ measures the return on wealth between dates $t$ and $t+\Delta$. For the term $\bar{s}_{t, t+\Delta}^{i}$, to deal with measurement problems, we use active savings between the two dates divided by average wealth across these dates. 
active saving rate on stock market participation and additional controls. The first column shows that stock owners have a saving rate that is around 6 percentage points higher than non-stockowners.

One concern with this finding is that households with certain characteristics, such as higher wealth or income, might both save more and participate more in the stock market. The second column of Table 1 shows that the result is significant after controlling for household wealth, the household head's income, demographics (such as the log of age, gender, and educational categories), and state-year fixed effects. The third column shows the result is also significant within households: that is, the same household saves more in years in which it holds stocks compared to years in which it does not hold stocks. The coefficient declines slightly (as expected from unobserved factors that might generate positive correlation between saving and stock market participation) but it remains economically large.

Another concern is that these results might be driven by reverse causality. For example, a transitory saving pressure could be associated with the household choosing to participate in the stock market (and thus save partly in stocks). We try to address this concern by instrumenting for stock market participation using lagged stock market participation. If saving shocks do not persist beyond a few years, instrumenting current stock market participation will alleviate the reverse causality problems. The last column of Table 1 summarizes the results in this case. Even after instrumenting for stock market participation with lagged participation, stock market participants save more than non-participants. ${ }^{16}[17$

We next investigate whether the difference between stock market participants' and non-

\footnotetext{
${ }^{16}$ Instrumenting with the second lag of stock market participation leads to similar results. Notice that the coefficient estimate actually increases when instrumenting with lagged participation relative to the estimate in column (2). This is the opposite of the bias expected due to transitory saving pressures. One possible explanation is an attenuation bias due to stock market participation being only measured at the time of interview, while saving being measured over the two-year period between interviews. If households switch between participation and nonparticipation over the two years, this switch introduces a classical measurement error that creates an attenuation bias. Instrumenting with past participation alleviates the attenuation bias (as long as the measurement errors in the past survey and the current survey are uncorrelated).

${ }^{17}$ We have additionally instrumented for participation following Giannetti and Wang (2016), who show that the incidence of corporate fraud in a state has a negative effect of stock market participation by households who live in that state. The authors' interpretation is that households that are exposed to corporate fraud lose trust in the stock market.

We again obtain a positive coefficient, confirming the positive effect of stock market participation on saving uncovered from the OLS and fixed effect estimation. However, the coefficient is estimated less precisely in this case, indicating a weak instrument concern.
} 
Table 1: Saving and stock market participation.

\begin{tabular}{ccccc}
\hline \hline & $(1)$ & $(2)$ & $(3)$ & $(4)$ \\
\hline stock mkt. participation & $0.0583^{* *}$ & $0.0633^{* *}$ & $0.0471^{* *}$ & $0.1020^{* *}$ \\
& $(0.0061)$ & $(0.0061)$ & $(0.0129)$ & $(0.0211)$ \\
& & & & \\
\hline Additional controls & No & Yes & Yes & Yes \\
State-by-year FE & No & Yes & Yes & Yes \\
Household FE & No & No & Yes & No \\
Instrument for & No & No & No & lagged \\
participation & & & & participation \\
F statistic (first stage) & & & & 468.61 \\
$R^{2}$ & 0.006 & 0.062 & 0.321 & 0.068 \\
Observations & 17,118 & 16,582 & 14,656 & 11,221 \\
\hline \hline
\end{tabular}

Notes. Standard errors in parenthesis. The standard errors are clustered at the state level. The active saving rate is defined as the annualized amount of active savings between two survey years, divided by the average of the household head's income in the two survey years. Active savings are constructed by extending the definition of active savings in the PSID for the period 1984-1989 to later survey waves. Stock market participation is an indicator variable for whether the household holds shares of publicly traded companies or mutual funds (outside of IRAs post 1999). Additional controls include log of the household head's income and total household wealth, an educational category for the household head, gender of the household head, log of age for the household head. For specification (3) the additional control include log of the household head's income and total household wealth, and log age of the household head. All regressions are weighted using the PSID sampling weights. ** denotes significance at $1 \%$, and $*$ denotes significance at $5 \%$.

participants' savings has been widening over time (due to greater customization opportunities in recent years). Figure 2 in the introduction illustrates that while saving rates display a strong negative time trend, the saving of stock owners has been either flat or only slightly decreasing on average over our sample period. One concern is that these trends might be driven by other contemporaneous changes in household characteristics. For instance, if households with higher income or wealth both save more and participate more in the stock market, then rising income or wealth inequality over this period might have also widened the savings gap between participants and nonparticipants. Our regression analysis, relegated to Online Appendix D, addresses these and other concerns. We find that saving rates trend downwards, but participants save more and the gap widens over time. Moreover, the widening gap between participants and nonparticipants is robust to controlling for household wealth 


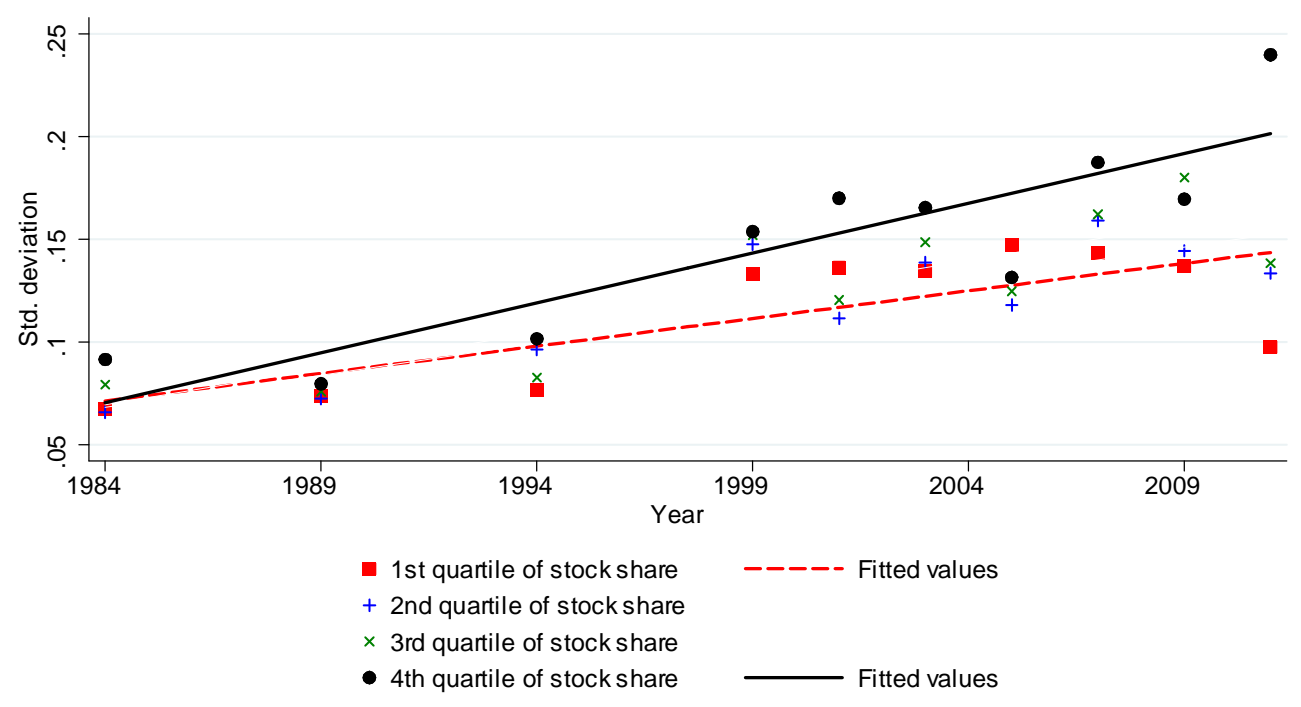

Figure 6: Trends in the cross-sectional standard deviation of (implicit) return on wealth among stock holders (excluding business owners) by quartile of share of wealth invested in stocks.

and income as well as other household demographics and state fixed effects.

\subsection{Dispersion of portfolio returns}

We next analyze whether the dispersion of the portfolio returns of stock market participants has been increasing over time (due to greater customization opportunities that exacerbate speculation). To alleviate concerns that the trends in return dispersion might be driven by private equity holders, for this part of the empirical analysis we remove all households that have held a farm or business in any survey year. Figure 3 in the introduction plots the cross-sectional standard deviation of returns over time, and illustrates that there is a positive trend. Figure 6 shows that the observation is robust to controlling for investor risk taking. There, we divide households into bins with a fixed wealth share in stocks, and observe that the return dispersion has been increasing within each bin. Moreover, the increase in return dispersion is most pronounced for investors that have the highest share of stocks, consistent with speculation being a driving force behind this trend.

One concern is that the trend in return dispersion might be driven by other contempo- 
raneous trends unrelated to portfolio choice. For example, if individuals with higher income or wealth earn higher returns, then the trend in return dispersion could be due to recent increases in income and wealth inequality. Similarly, if portfolio returns vary with different demographic characteristics (like age or education), then population aging or a higher share of individuals with advanced degrees would also imply an increase in return dispersion. To address these concerns, we first regress log returns on a number of controls (separately for each year), including the demographics for the household head (such as log age, education categories, and sex), log of the household head's income, log of total household wealth, the wealth share in stocks, and state fixed effects. We then construct the cross-sectional standard deviation of the residuals from this regression (for each year) as a measure of conditional return dispersion. Figure 7 plots the resulting trends in conditional return dispersion. As with the raw return dispersion, there is a clear positive trend 18

One potential issue that could be causing a spurious positive trend in return dispersion is the change in the frequency of data availability. For the early years of our data, annualized wealth growth is obtained by averaging across five years, while from 1999 onward, it is obtained by averaging across two years. Figure D.1 in Online Appendix D addresses this concern and confirms the current findings.

In sum, our analysis suggests that the increase in portfolio return dispersion illustrated in Figure 3 is a robust fact. It is also broadly consistent with the patterns documented in Fagereng et al. (2016) for individual return heterogeneity based on data form Norway. Beyond providing support for the choice channel, this fact is interesting in its own right. A growing literature in macroeconomics has argued that heterogeneity in returns to financial investments can help to explain the patterns of large and rapidly increasing wealth inequality (see Benhabib et al., 2017; Bisin and Benhabib, 2017; Gabaix et al., 2016). Therefore, the increase in the dispersion of portfolio returns might have important implications for the dynamics of wealth inequality going forward.

Overall, the empirical results in this section are consistent with the choice channel.

\footnotetext{
${ }^{18}$ Another possible driver of this trend is an increase in idiosyncratic volatility of individual stocks (as documented in Campbell et al. (2001)) which may mechanically increase return dispersion when individuals hold heterogeneous portfolios (without necessarily any change in portfolios). We believe this is unlikely to explain our results because most of the increase in idiosyncratic volatility occurred during the 1960s and 1970s (see Figure 4 in Campbell et al. (2001)). Moreover, idiosyncratic return volatility actually decreased in the early 2000s $($ Brandt et al. $(2009))$.
} 


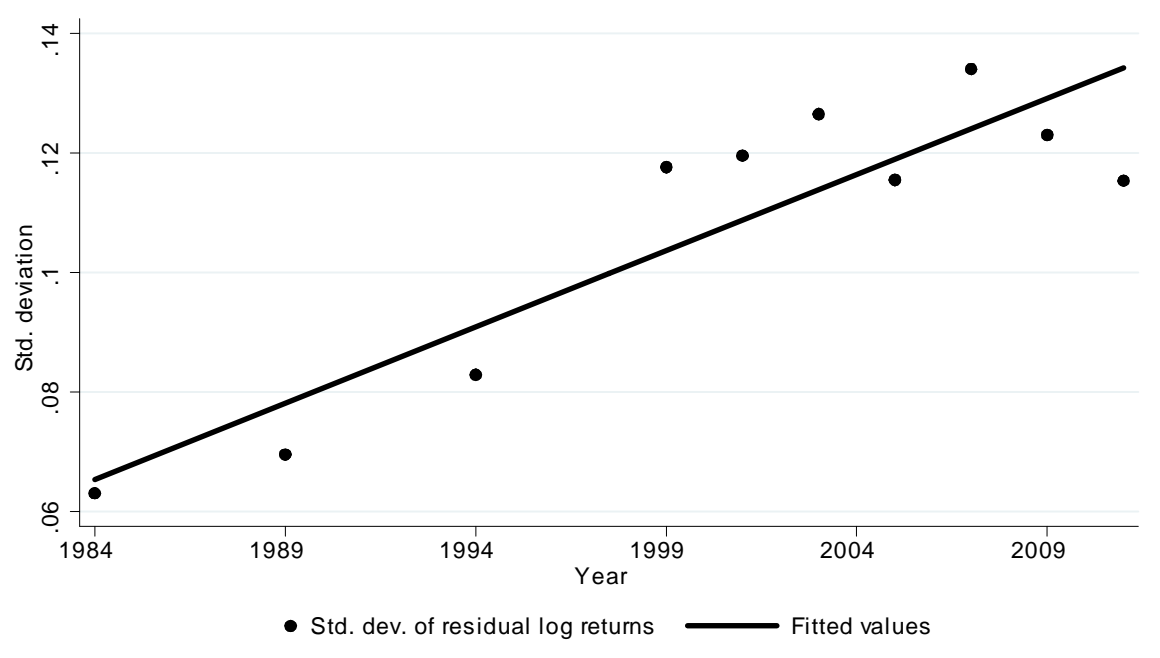

Figure 7: Trends in the cross-sectional standard deviation of residual (implicit) return on wealth among stock holders (excluding business owners). The residual return is obtained after regressing log return on demographics, income, wealth, wealth share in stocks, and state fixed effects.

Through the lens of the choice channel, market participants have a higher saving rate than non-participants, and increasingly so in recent years, because expansions in portfolio choice gradually enhance their perceived return from saving. Moreover, market participants have highly dispersed portfolio returns, and increasingly so in recent years, because they use incremental innovations to hold more customized portfolios driven by speculation.

\subsection{Other evidence for the choice channel}

In addition to the evidence we present, there are number of papers that document facts that are consistent with the choice channel. A strand of the empirical household finance literature analyzes prize-linked savings (PLS) accounts - innovative products that introduce a lottery-like component into returns from saving (see Kearney et al. (2010)). These products increase savings in experiments (e.g., Filiz-Ozbay et al., 2015; Atalay et al., 2014) as well as in real world settings (e.g., Cole et al., 2016). This fact can be reconciled with our choice channel, under the assumption that households perceive a higher return from the PLS account compared to a safe account with the same expected payoff (e.g., due to distorted 
beliefs that overweight small probabilities). Our analysis also suggests that PLS accounts that provide households with some choice can further boost savings.

Another related piece of evidence comes from Ameriks et al. (2003), who show that households who spend more time on financial planning have considerably higher saving rate and accumulate more financial wealth. This fact can be reconciled with our choice channel under the assumption that portfolio customization (as well as market participation) takes time and effort. Planners who spend time to customize their portfolios have greater (perceived) return and save more (although there might also be other explanations as discussed in Ameriks et al. (2003)).

A small household finance literature investigates the effect of greater portfolio choice on retirement savings, and finds mixed results. Consistent with our choice channel, Papke (2004) finds that households that are offered some investment choice are 36 percent more likely to participate in an employer-sponsored savings account (and they also contribute a greater fraction of their income). On the other hand, Sethi-Iyengar et al. (2004) find that the number of funds offered in a retirement savings account is negatively correlated with the participation rate. Their preferred explanation is "the choice overload": the idea that too much choice can overwhelm households and reduce their willingness to commit to a particular option. While choice overload is a reasonable concern, we believe it can be overcome by providing households with guidance or default plans (see Thaler and Sunstein, $2003)$.

\section{Conclusion}

Rapid financial innovation in recent years has vastly expanded portfolio choices for investors. We investigate the implications of greater portfolio choice for investors' savings in an environment that features belief disagreements and speculation. Our main result establishes a choice channel by which an investor that gains access to greater portfolio choices increases her savings. The intuition is that greater choice provides the investor with greater riskadjusted return, by enabling her to earn the aggregate risk premium or to take speculative positions. We also present new empirical evidence consistent with the choice channel. Our analysis of the PSID suggests that stock market participation is associated with higher savings by U.S. households, and more so in recent years that feature greater opportunities for 
customization and speculation. We also find that U.S. households' portfolio returns have become more dispersed in recent years, which is consistent with increased speculation due to greater customization opportunities.

We also theoretically analyze the implications of the choice channel for asset returns. In equilibrium, greater savings exert a generally downward pressure on asset returns, but the precise effects depend on the type of financial innovation. We show that greater portfolio customization typically reduces the expected return on all assets, including the risk-free rate, without affecting the risk premia. We also find that greater participation reduces the risk premium, but typically increases the risk-free interest rate. These results are broadly consistent with trends in the risk free rate and the equity risk premium in postwar years, although those trends also have many other contributing factors.

Our analysis has been purely positive, in part because the normative implications are complex and context-dependent. The household finance literature typically emphasizes that a fraction of households might be saving too little due to behavioral biases such as hyperbolic discounting, and explores ways to increase these household savings (as Carroll et al. (2009) and Choi et al. (2002), for example). Our analysis suggests that providing households with greater portfolio choice could improve welfare by countering other frictions that lower savings. On the other hand, households with heterogeneous beliefs typically use greater choice to load onto nonsystematic risks. The resulting rise in consumption risks reduces welfare according to a belief-neutral criterion (see, for instance, Brunnermeier et al., 2014). Hence, the net effect of financial innovation on household welfare is likely to be ambiguous.

The welfare analysis is further complicated by the fact that household savings might be associated with externalities. For instance, the recent macroeconomics literature on liquidity traps and secular stagnation suggests that households might be saving too much in aggregate, since their savings lower the natural interest rate and increases the likelihood of demand recessions. From this macro perspective, portfolio customization that lowers the interest rate might be further welfare reducing. More generally, our analysis highlights that financial innovation affects investors' consumption and savings decisions, with implications for aggregate demand. Economic agents that introduce or adopt these financial innovations do not internalize their effects on aggregate demand, which might create inefficiencies (see Korinek and Simsek, 2016). We leave the analysis of the interaction between financial innovation and aggregate demand externalities for future work. 


\section{A Appendix A: Selected Extensions and Proofs}

This appendix contains selected extensions and proofs for the analysis in the main text. Online Appendices $\mathrm{B}$ and $\mathrm{C}$ contain, respectively, the omitted extensions and the omitted proofs.

\section{A.1 Robustness of the choice channel to background risks}

In the main text, we abstracted away from uninsurable background risks to simplify the exposition. In this section, we consider a numerical example with uninsurable background risks. In this example, financial innovation can affect savings through the choice channel as well as the precautionary channel, which enables us to make three points. First, we show that the choice channel continues to hold even in the presence of uninsurable background risk, if financial innovation does not improve the opportunities to hedge those risks. This illustrates that Assumption 1, under which we derived the choice channel in Section 2, is made for analytical convenience and is not necessary for the choice channel. Second, we consider the case in which financial innovation also provides some risk-sharing benefits. We argue that the choice channel still dominates the precautionary channel for plausible calibrations based on the portfolio Sharpe ratios observed in practice as well as the empirical evidence on uninsurable risks and hedging opportunities in recent decades. Third, we also illustrate that the relative strength of the choice and the precautionary channels varies with risk aversion. The choice channel is especially powerful (and easily dominates the precautionary channel) for investors that are more risk tolerant, whereas the precautionary channel is relatively strong for investors that are more risk averse.

We consider a 2-by-2 set-up along the lines of Section 1, in a partial equilibrium context. Suppose that there are four possible states of the world at $t=1$ that jointly describe the labor income realizations of an individual investor (High and Low) and the payoff realizations for a risky asset (Up and Down). Therefore a state of the world is now given by, $z \in\{(i, j)\}_{i \in\{H, L\}, j \in\{U, D\}}$.

We assume that the investor's $t=1$ labor income realizations are independent of the payoff realizations of the risky asset. Also, we normalize the investor's (expected) labor income at $t=0$ and $t=1$ to unity. Let $\Delta_{L}$ denote the dispersion between the High and the Low labor income realizations. Therefore, the parameter $\Delta_{L}$ describes the amount of (residual) background risk that the investor is exposed to. As in Section 2 we allow the investor to hold different beliefs about the distribution of payoff realizations for the risky asset. Below we consider different perceived distributions for the payoff realizations for the risky asset that lead to different perceived risk premia and Sharpe ratios.

We consider two alternative asset structures for the investor's access set and the amount of 

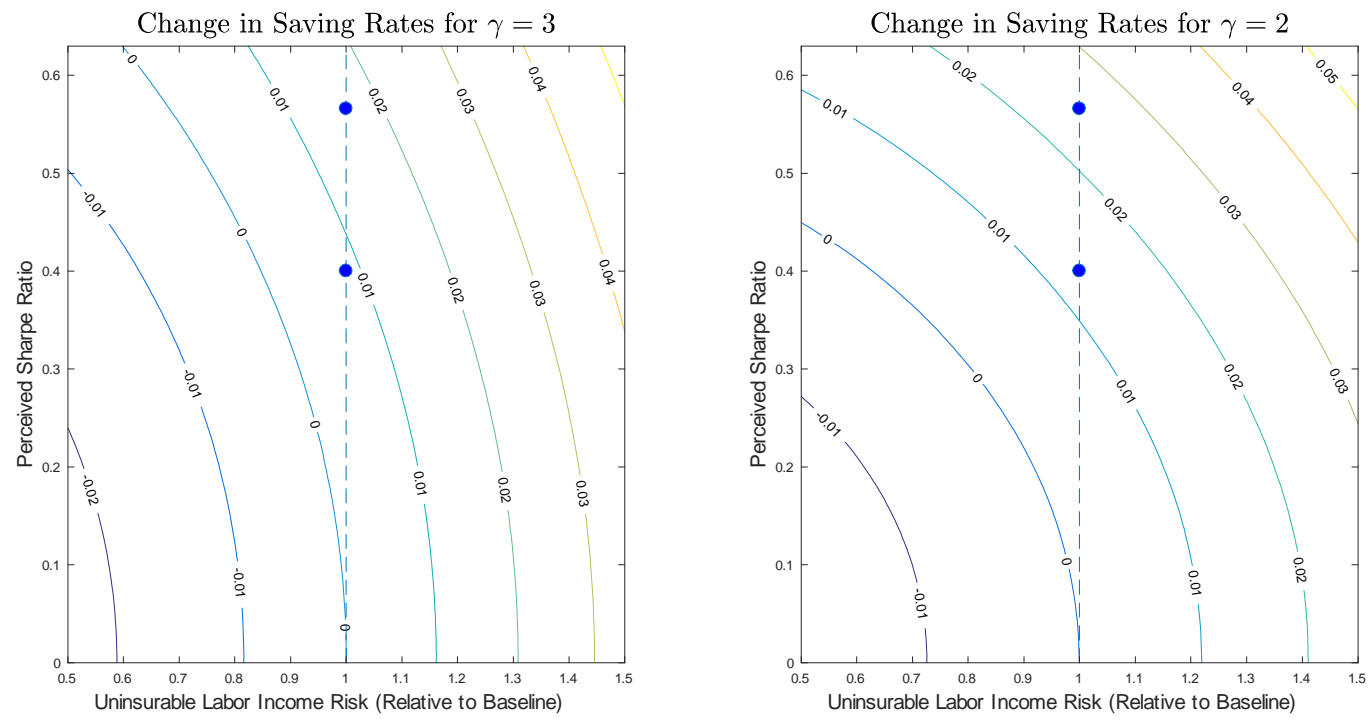

Figure 8: Changes in saving rates (in percentage points) after financial innovation that allows an investor to invest in a risky asset with a given (perceived) Sharpe ratio (vertical axis), and after changes in (residual) background risk (horizontal axis).

(residual) background risk. In the first case (baseline, before financial innovation), the investor has access only to a riskless asset and has a certain amount of uninsurable background risk. In the second case (after financial innovation), the investor has access to the risky asset and the amount of uninsurable background risk changes. This change originates from a combination of new hedging possibilities, which allow costless reductions in exposure (for simplicity, as standard in the literature, idiosyncratic risk does not carry a premium), or because risk in the labor income process itself changes. Notice that both forces can go in the same direction, when income processes become safer, or go in opposite directions, when hedging is available for some components of background risks, but income processes themselves become riskier.

We examine the change in saving between the second and first case in a number of alternative scenarios based on the relative change in background risk and the premium (Sharpe ratio) that the investor perceives. Apart from these free parameters we use the values of $R_{f}=\beta^{-1}=1.01$, and $\varepsilon=1.5$ as in the numerical examples in Section 3.3 . Finally, we set the background risk in the baseline case to $\Delta_{L}=0.15$, which is in line with the standard deviation of idiosyncratic risk estimated by Storesletten et al. (2004) 19

The left panel in Figure 8 plots the resulting changes in saving for the benchmark case of

\footnotetext{
${ }^{19}$ In addition, we set the initial financial wealth of the investor to half of his labor income. The results are qualitatively similar for other choices of the investor's initial financial wealth.
} 
$\gamma=3$ and alternative scenarios for the perceived Sharpe ratio and labor income risk. As the figure shows, holding the amount of uninsurable labor income risk fixed (the vertical dashed line) is associated with an increase in saving when the investor gains access to more assets, irrespective of the investor's perceived Sharpe ratio. Therefore, the choice channel operates even in the presence of uninsured idiosyncratic income risk. Two specific values for the perceived Sharpe ratio are of particular interest (illustrated with two blue dots on the figure) as they represent specific realistic examples. The first is the Sharpe ratio on the market portfolio (at 0.4), and it shows that increase in saving for an investor that moves from non-participation to participation in the stock market and only holds the broad market portfolio. This induces an increase in saving of around 90 basis points of current income given our numerical example. The second example is the (perceived) portfolio Sharpe ratio (at 0.57 ) for an investor that can both invest in the market portfolio and also speculate on his beliefs as parametrized in Section $3.3{ }^{20}$ In that case the investor increases his saving by around 1.7 percentage points of current income.

Second, the figure shows that saving tends to decrease only for large decreases in uninsurable labor income risk (a decline of more than 15 percent) and whenever the investor is not too optimistic. However, such a decline in uninsurable labor income risk would be counterfactually high given the developments in risk-sharing possibilities and in uninsurable labor income risk in recent decades discussed in the main text of the paper.

Third, we compare how the saving response varies with an investor's risk tolerance. Specifically, the right panel in Figure 8 shows the saving responses of an investor with a risk-aversion coefficient of $\gamma=2$, so that the investor is more risk-tolerant relative to the investor in the benchmark exercise. As the figure shows, the magnitude of the saving response is higher for the more risk-tolerant investor, since the choice channel is stronger in that case. Second, the reduction in uninsurable background risk that is required for saving to remain constant is also larger for that investor. This is due both to a relatively strong choice channel but also to a weaker precautionary channel in the case of a more risk-tolerant investor. For example, for a risk-tolerant investor that gains access to the market portfolio (an investment with a perceived Sharpe ratio of 0.4), the required decrease in background risk is of more than 40 percent.

Last, increases in initial financial wealth and reductions in the dispersion of background risk have consequences that are qualitatively equivalent to decreases in risk aversion. Increases in the

\footnotetext{
${ }^{20}$ In the numerical example in that Section the investor can hold the market portfolio and an additional speculative asset that loads on idiosyncratic risk. The perceived Sharpe ratio on the speculative asset equals the market Sharpe ratio of 0.4. Since the two assets have independent returns and the investor loads equally on the two, the resulting portfolio Sharpe ratio equals $\sqrt{(0.4)^{2}+(0.4)^{2}} \approx 0.57$.
} 
estimates for the intertemporal elasticity of substitution, as expected, amplify the response of saving rates to the perceived Sharpe ratio, bending the isoquants of saving to the left and decreasing the distance between their levels.

\section{A.2 Selected Proofs}

In this section, we first present the proof of our main result, Proposition 1. We then present the proofs of Lemmas 1 and 2, which help to establish our main results in Section 3 . The remaining proofs are relegated to Online Appendix C.

Proof of Proposition 1. Suppose that the investor has a positive future endowment, $L(\mathbf{z})$, and consider a hypothetical investor with zero future endowment, $\tilde{L}(\mathbf{z})=0$, but instead with financial wealth,

$$
\tilde{W}_{0}=\sum_{j \in\{f\} \cup J^{i}}\left(x_{-1, j}+l_{j}\right) P_{j} .
$$

In view of Assumption 1 , given the optimal choice by the hypothetical investor, $\tilde{C}_{0}, \tilde{A}_{0}, \tilde{x}_{j}$, the optimal choice by the original investor can be deduced from,

$$
C_{0}=\tilde{C}_{0}, A_{0}=\tilde{A}_{0}-\sum_{j \in\{f\} \cup J^{i}} l_{j} P_{j} \text { and } x_{j}=\tilde{x}_{j}-l_{j} \text { for each } j .
$$

As discussed in the body of the paper, the (hypothetical) investor's problem can be split into two parts. Conditional on asset holdings, $\tilde{A}_{0}$, the investor maximizes her certainty-equivalent payoff at date 1 . That is, she solves the portfolio problem (4). In turn, given the value function $V_{1}(\cdot)$, she chooses her asset holdings, $A_{0}$, by maximizing the intertemporal utility function in (2). It is straightforward to verify that the portfolio problem in (4) is linearly homogeneous, so $V_{1}(\cdot)$ is a linear function. In particular, $V_{1}(1)=R_{c e}^{i}$, which gives the investor's certainty-equivalent return. The remainder of the proposition follows from the discussion in the main text.

Proof of Lemma 1. To simplify notation, we leave implicit the dependence of $\omega_{1}\left(\pi_{m}\right), r_{c e}^{1}\left(r_{f}, \pi_{m}\right)$ and $P_{m}\left(r_{f}+\pi_{m}\right)$ on $\left(r_{f}, \pi_{m}\right)$. Using Eq. (10), type $p$ investors' portfolio share and return are given by,

$$
\omega_{m}^{p}=\frac{\pi_{m}}{\gamma \Lambda_{m}} \text { and } r_{c e}^{p}=r_{f}+\frac{1}{2 \gamma \Lambda_{m}} \pi_{m}^{2}
$$

establishing Eq. (13). Therefore, $r_{c e}^{p}>r_{f}=r_{c e}^{n}$ and since $a($.$) is an increasing function, it follows$ 
that $a\left(r_{c e}^{p}\right)>a\left(r_{c e}^{n}\right)$. This shows part (i).

To show part (ii), notice that the market clearing condition for the safe asset can be written as,

$$
0=n^{p}\left(1-\omega_{m}^{p}\right) a\left(r_{c e}^{p}\right)+\left(1-n^{p}\right) a\left(r_{f}\right)
$$

Rearranging this expression implies Eq. 14. Finally, Eq. 15 follows by adding all of the market clearing conditions 12 .

It remains to show that the system in $(14)-15$ has a unique solution. We establish this and complete the proof in Online Appendix C.

Proof of Lemma 2. We define the average portfolio share of an asset $j$ among all investors that have market access $i_{A} \in I_{A}$ as,

$$
\omega_{j}^{i_{A}}=\frac{\sum_{I_{B}} n^{\mathbf{i}_{B}} \omega_{j}^{\left(i_{A}, \mathbf{i}_{B}\right)} a\left(r_{c e}^{\left(i_{A}, \mathbf{i}_{B}\right)}\right)}{\sum_{I_{B}} n^{\mathbf{i}_{B}} a\left(r_{c e}^{\left(i_{A}, \mathbf{i}_{B}\right)}\right)} .
$$

We will establish the existence of an equilibrium in which prices are uniquely characterized by part (ii), investors' certainty-equivalent returns are given by Eq. (16), and their average portfolio shares are given by,

$$
\boldsymbol{\omega}_{J^{i} A}^{i_{A}}=\frac{1}{\gamma} \Lambda_{J^{i} A}^{-1} \boldsymbol{\pi}_{J^{i} A}=\left[\omega_{m}, 0, . .0\right]^{\prime} \text { for each } i_{A} \text {, where } \omega_{m}=\frac{\pi_{m}}{\gamma \Lambda_{m}} .
$$

Here, $\left[\omega_{m}, 0, . .0\right]$ is a $\left|J^{i}\right|$-dimensional vector whose first entry is $\omega_{m}$ and the remaining entries are zero. Hence, in addition to the properties in the lemma, we claim that investors' average portfolio shares are independent of the heterogeneity in beliefs or market access.

We first establish Eq. A.2, given the prices characterized by part (ii) and the certaintyequivalent returns in (16). To prove this, consider an investor's perceived risk premium for a risky asset $j$, which can be written as,

$$
\pi_{j}^{\left(i_{A}, \mathbf{i}_{B}\right)}=\left(\mathbf{F}_{j}\right)^{\prime} \boldsymbol{\mu}_{\mathbf{z}}^{i}+\frac{\Lambda_{j}}{2}-\log P_{j}-r_{f}=\pi_{j}+\mathbf{F}_{j}^{\prime} \mathbf{i}_{B}
$$

Using Eq. 10), her demand for the risky assets $J^{i_{A}}$ (as a proportion of her wealth) is given by the vector,

$$
\boldsymbol{\omega}_{J^{i} A}^{\left(i_{A}, \mathbf{i}_{B}\right)} a\left(r_{c e}^{\left(i_{A}, \mathbf{i}_{B}\right)}\right)=\frac{1}{\gamma} \Lambda_{J^{i} A}^{-1}\left(\boldsymbol{\pi}_{J^{i} A}+\mathbf{F}_{J^{i} A}^{\prime} \mathbf{i}_{B}\right) a\left(r_{c e}^{\left(i_{A}, \mathbf{i}_{B}\right)}\right) .
$$

In view of Eq. (16), investors of types $\left(i_{A}, \mathbf{i}_{B}\right)$ and $\left(i_{A},-\mathbf{i}_{B}\right)$ obtain exactly the same certainty- 
equivalent return. Combining these observations, the average demand across belief types $\mathbf{i}_{B}$ and $-\mathbf{i}_{B}$ is given by,

$$
\frac{\boldsymbol{\omega}_{J^{i} A}^{\left(i_{A}, \mathbf{i}_{B}\right)} a\left(r_{c e}^{\left(i_{A}, \mathbf{i}_{B}\right)}\right)+\boldsymbol{\omega}_{J^{A} A}^{\left(i_{A},-\mathbf{i}_{B}\right)} a\left(r_{c e}^{\left(i_{A},-\mathbf{i}_{B}\right)}\right)}{2}=\frac{1}{\gamma} \Lambda_{J^{i_{A}}}^{-1} \boldsymbol{\pi}_{J^{i} A} a\left(r_{c e}^{\left(i_{A}, \mathbf{i}_{B}\right)}\right) .
$$

Averaging across all belief types, and using the second part of Assumption 4, we further obtain,

$$
\sum_{\mathbf{i}_{B}} n^{\mathbf{i}_{B}} \boldsymbol{\omega}_{J^{i} A}^{\left(i_{A}, \mathbf{i}_{B}\right)} a\left(r_{c e}^{\left(i_{A}, \mathbf{i}_{B}\right)}\right)=\left(\frac{1}{\gamma} \Lambda_{J^{i} A}^{-1} \boldsymbol{\pi}_{J^{i} A}\right)\left(\sum_{\mathbf{i}_{B}} n^{\mathbf{i}_{B}} a\left(r_{c e}^{\left(i_{A}, \mathbf{i}_{B}\right)}\right)\right) .
$$

Using the definition of the average portfolio share in A.1, we obtain $\omega_{J^{i} A}^{i_{A}}=\frac{1}{\gamma} \Lambda_{J^{i} A}^{-1} \pi_{J^{i} A}$. Next note that,

$$
\left(\Lambda_{J^{i} A}\left[\omega_{m}, 0, . .0\right]^{\prime}\right)_{j}=\Lambda_{m j} \omega_{m}=\frac{1}{\gamma} \frac{\Lambda_{m j} \pi_{m}}{\Lambda_{m}}=\frac{1}{\gamma} \pi_{j}
$$

where the last equation uses the risk premia from part (ii). Applying $\Lambda_{J^{i} A}^{-1}$ to both sides of the expression implies, $\omega_{J^{i} A}^{i_{A}}=\frac{1}{\gamma} \Lambda_{J^{i} A}^{-1} \pi_{J^{i} A}=\left[\omega_{m}, 0, . .0\right]^{\prime}$, proving Eq. A.2.

We next check that the investors' certainty-equivalent returns are given by Eq. (16). Using Eqs. 10 and A.3, we have,

$$
\begin{aligned}
r_{c e}^{\left(i_{A}, \mathbf{i}_{B}\right)} & =r_{f}+\frac{1}{2 \gamma}\left(\boldsymbol{\pi}_{J^{i} A}+\mathbf{F}_{J^{i} A}^{\prime} \mathbf{i}_{B}\right)^{\prime} \Lambda_{J^{i_{A}}}^{-1}\left(\boldsymbol{\pi}_{J^{i_{A}}}+\mathbf{F}_{J^{i}}^{\prime} \mathbf{i}_{B}\right) \\
& =r_{f}+\frac{1}{2 \gamma}\left(\boldsymbol{\pi}_{J^{i} A}^{\prime} \Lambda_{J^{i_{A}}}^{-1} \boldsymbol{\pi}_{J^{i} A}+2\left(\mathbf{F}_{J^{i} A}^{\prime} \mathbf{i}_{B}\right)\left(\Lambda_{J^{i_{A}}}^{-1} \boldsymbol{\pi}_{J^{i} A}\right)+\left(\mathbf{F}_{J^{i} A}^{\prime} \mathbf{i}_{B}\right)^{\prime} \Lambda_{J^{i_{A}}}^{-1}\left(\mathbf{F}_{J^{i} A}^{\prime} \mathbf{i}_{B}\right)\right) \\
& =r_{f}+\frac{1}{2}\left(\boldsymbol{\pi}_{J^{i} A}^{\prime}\left[\omega_{m}, 0, . .0\right]^{\prime}\right)+\frac{1}{2 \gamma}\left(\mathbf{F}_{J^{i_{A}}}^{\prime} \mathbf{i}_{B}\right)^{\prime} \Lambda_{J^{i_{A}}}^{-1}\left(\mathbf{F}_{J^{i_{A}}}^{\prime} \mathbf{i}_{B}\right)+\left(\mathbf{F}_{J^{i} A}^{\prime} \mathbf{i}_{B}\right)\left[\omega_{m}, 0, . .0\right]^{\prime} \\
& =r_{f}+\frac{1}{2 \gamma} \frac{\pi_{m}^{2}}{\Lambda_{m}}+\frac{1}{2 \gamma}\left(\mathbf{F}_{J^{i} A}^{\prime} \mathbf{i}_{B}\right)^{\prime} \Lambda_{J^{i} A}^{-1}\left(\mathbf{F}_{J^{i_{A}}}^{\prime} \mathbf{i}_{B}\right),
\end{aligned}
$$

verifying Eq. (16). Here, the third line uses Eq. (A.2), and the last line uses the third part of Assumption 4, which says $\left(\mathbf{F}_{m}\right)^{\prime} \mathbf{i}_{B}=0$ (no disagreement on the market portfolio). To show that $r_{c e}^{\left(i_{A}, \mathbf{i}_{B}\right)}$ is increasing in $i_{A}$, let $i_{A}^{1}>i_{A}^{0}$ and notice that a direct extension of the revealed preference argument underlying the Choice Channel (Proposition 1) to the case of a continuous state space implies that $R_{c e}^{i_{A}^{1}} \geq R_{c e}^{i_{A}^{0}}$, and hence, $r_{c e}^{\left(i_{A}^{1}, \mathbf{i}_{B}\right)} \geq r_{c e}^{\left(i_{A}^{0}, \mathbf{i}_{B}\right)}$. Alternatively, a direct inspection of Eq. 16 and the observation that $\left(\mathbf{F}_{J^{i} A}^{\prime}\left(\mathbf{i}_{B}\right)\right)^{\prime} \Lambda_{J^{i} A}^{-1}\left(\mathbf{F}_{J^{i} A}^{\prime}\left(\mathbf{i}_{B}\right)\right)$, the square of the speculative Sharpe ratio (Simsek, 2013b), is higher for the $i_{A}^{1}$ investor also gives the same result. Finally, since $a($.$) is$ 
an increasing function, it follows that $a\left(r_{c e}^{\left(i_{A}^{1}, \mathbf{i}_{B}\right)}\right) \geq a\left(r_{c e}^{\left(i_{A}^{0}, \mathbf{i}_{B}\right)}\right)$. This establishes part (i).

Next note that part (ii) uniquely characterizes the equilibrium prices of all assets. We finally check that these prices satisfy the $|\mathbf{J}|+1$ market clearing conditions 12 . The conditions for $j \neq m$

hold because $\omega_{j}^{i_{A}}=0$ for each $i_{A}$ and $j \neq m$. To check the remaining conditions, substitute $\omega_{m}=1$ in view of the risk premia given in part (ii). After this substitution, the market clearing condition for asset $f$ holds since each investor has a zero weight on the risk-free asset, $\omega_{f}=1-\omega_{m}=0$. The market clearing condition for asset $m$ also holds, since the condition becomes identical to Eq. (18). This establishes the existence of an equilibrium that satisfies the conditions in part (ii) along with Eq. A.2, completing the proof.

\section{References}

Aiyagari, S. R., 1994. Uninsured idiosyncratic risk and aggregate saving. The Quarterly Journal of Economics, 659-684.

Allen, F., Gale, D., 1994. Financial innovation and risk sharing. MIT press.

Ameriks, J., Caplin, A., Leahy, J., 2003. Wealth accumulation and the propensity to plan. The Quarterly Journal of Economics 118 (3), 1007-1047.

Angeletos, G.-M., 2007. Uninsured idiosyncratic investment risk and aggregate saving. Review of Economic Dynamics 10 (1), 1-30.

Angeletos, G.-M., Calvet, L.-E., 2006. Idiosyncratic production risk, growth and the business cycle. Journal of Monetary Economics 53 (6), 1095-1115.

Atalay, K., Bakhtiar, F., Cheung, S., Slonim, R., 2014. Savings and prize-linked savings accounts. Journal of Economic Behavior \& Organization 107, 86-106.

Attanasio, O. P., Banks, J., Tanner, S., 2002. Asset holding and consumption volatility. Journal of political economy $110(4), 771-792$.

Attanasio, O. P., Browning, M., 1995. Consumption over the life cycle and over the business cycle. The American Economic Review, 1118-1137.

Banerjee, S., Kremer, I., 2010. Disagreement and learning: Dynamic patterns of trade. The Journal of Finance 65 (4), 1269-1302. 
Bansal, R., Yaron, A., 2004. Risks for the long run: A potential resolution of asset pricing puzzles. The Journal of Finance 59 (4), 1481-1509.

Barberis, N., Greenwood, R., Jin, L., Shleifer, A., 2018. Extrapolation and bubbles. Journal of Financial Economics.

Basak, S., Cuoco, D., 1998. An equilibrium model with restricted stock market participation. Review of Financial Studies 11 (2), 309-341.

Benartzi, S., 2001. Excessive extrapolation and the allocation of 401 (k) accounts to company stock. Journal of Finance, 1747-1764.

Benhabib, J., Bisin, A., Luo, M., 2017. Wealth distribution and social mobility: A quantitative analysis of u.s. data. Tech. rep., National Bureau of Economic Research.

Bewley, T., 1977. The permanent income hypothesis: A theoretical formulation. Journal of Economic Theory 16 (2), 252-292.

Bisin, A., Benhabib, J., 2017. Skewed wealth distributions: Theory and empirics. Journal of Economic Literature.

Blanchard, O. J., 1993. Movements in the equity premium. Brookings Papers on Economic Activity, $75-138$.

Blume, L., Easley, D., 2006. If you're so smart, why aren't you rich? belief selection in complete and incomplete markets. Econometrica 74 (4), 929-966.

Blundell, R., Browning, M., Meghir, C., 1994. Consumer demand and the life-cycle allocation of household expenditures. The Review of Economic Studies 61 (1), 57-80.

Borovicka, J., 2018. Survival and long-run dynamics with heterogeneous beliefs under recursive preferences. Journal of Political Economy Forthcoming.

Bosworth, B., Anders, S., et al., 2008. Saving and wealth accumulation in the psid, 1984-2005.

Brandt, M. W., Brav, A., Graham, J. R., Kumar, A., 2009. The idiosyncratic volatility puzzle: Time trend or speculative episodes? The Review of Financial Studies 23 (2), 863-899.

Brunnermeier, M. K., Sannikov, Y., 2014. A macroeconomic model with a financial sector. The American Economic Review 104 (2), 379-421. 
Brunnermeier, M. K., Simsek, A., Xiong, W., 2014. A welfare criterion for models with distorted beliefs. The Quarterly Journal of Economics 129 (4), 1753-1797.

Buraschi, A., Jiltsov, A., 2006. Model uncertainty and option markets with heterogeneous beliefs. The Journal of Finance 61 (6), 2841-2897.

Buss, A., Uppal, R., Vilkov, G., 2017. Financial innovation and asset prices. Tech. rep., working paper.

Caballero, R. J., Simsek, A., 2017. A risk-centric model of demand recessions and macroprudential policy. Tech. rep., National Bureau of Economic Research.

Calvet, L., Celerier, C., Vallee, B., Sodini, P., 2017. Can financial innovation solve household reluctance to take risk?

Calvet, L., Gonzalez-Eiras, M., Sodini, P., 2004. Financial innovation, market participation, and asset prices. Journal of Financial and Quantitative Analysis 39 (03), 431-459.

Calvet, L. E., Campbell, J. Y., Sodini, P., 2007. Down or out: Assessing the welfare costs of household investment mistakes. Journal of Political Economy 115 (5), 707-747.

Campbell, J. Y., Lettau, M., Malkiel, B. G., Xu, Y., 2001. Have individual stocks become more volatile? an empirical exploration of idiosyncratic risk. The Journal of Finance 56 (1), 1-43.

Campbell, J. Y., Viceira, L. M., 2002. Strategic asset allocation: portfolio choice for long-term investors. Oxford University Press.

Cao, D., 2017. Speculation and financial wealth distribution under belief heterogeneity. The Economic Journal.

Cao, H. H., Wang, T., Zhang, H. H., 2005. Model uncertainty, limited market participation, and asset prices. Review of Financial Studies 18 (4), 1219-1251.

Carroll, G. D., Choi, J. J., Laibson, D., Madrian, B. C., Metrick, A., 2009. Optimal defaults and active decisions. The Quarterly Journal of Economics 124 (4), 1639-1674.

Carvajal, A., Rostek, M., Weretka, M., 2012. Competition in financial innovation. Econometrica 80 (5), 1895-1936. 
Chen, J., Hong, H., Stein, J. C., 2002. Breadth of ownership and stock returns. Journal of Financial Economics 66 (2), 171-205.

Choi, J. J., Laibson, D., Madrian, B. C., Metrick, A., 2002. Defined contribution pensions: Plan rules, participant choices, and the path of least resistance. Tax policy and the economy 16, $67-113$.

Cochrane, J. H., 2005. Asset Pricing. Princeton University Press.

Cole, S., Iverson, B., Tufano, P., 2016. Can gambling increase savings? empirical evidence on prize-linked savings accounts.

Dávila, E., 2017. Optimal financial transaction taxes. Working Paper.

Detemple, J., Murthy, S., 1994. Intertemporal asset pricing with heterogeneous beliefs. Journal of Economic Theory 62 (2), 294-320.

Døskeland, T. M., Hvide, H. K., 2011. Do individual investors have asymmetric information based on work experience? The Journal of Finance 66 (3), 1011-1041.

Dumas, B., Kurshev, A., Uppal, R., 2009. Equilibrium portfolio strategies in the presence of sentiment risk and excess volatility. The Journal of Finance 64 (2), 579-629.

Dumas, B., Lewis, K. K., Osambela, E., 2017. Differences of opinion and international equity markets. The Review of Financial Studies 30 (3), 750-800.

Dynan, K. E., Skinner, J., Zeldes, S. P., 2004. Do the rich save more? Journal of Political Economy $112(2), 397-444$.

Ehling, P., Gallmeyer, M., Heyerdahl-Larsen, C., Illeditsch, P., 2018. Disagreement about inflation and the yield curve. Journal of Financial Economics 127 (3), 459-484.

Elul, R., 1997. Financial innovation, precautionary saving and the risk-free rate. Journal of Mathematical Economics 27 (1), 113-131.

Fagereng, A., Guiso, L., Malacrino, D., Pistaferri, L., 2016. Heterogeneity and persistence in returns to wealth. Working Paper.

Favilukis, J., 2013. Inequality, stock market participation, and the equity premium. Journal of Financial Economics 107 (3), 740-759. 
Filiz-Ozbay, E., Guryan, J., Hyndman, K., Kearney, M., Ozbay, E. Y., 2015. Do lottery payments induce savings behavior? evidence from the lab. Journal of Public Economics 126, 1-24.

Fostel, A., Geanakoplos, J., 2012. Tranching, cds, and asset prices: How financial innovation can cause bubbles and crashes. American Economic Journal: Macroeconomics 4 (1), 190-225.

Fostel, A., Geanakoplos, J., 2016. Financial innovation, collateral, and investment. American Economic Journal: Macroeconomics 8 (1), 242-284.

French, K. R., Poterba, J. M., 1991. Investor diversification and international equity markets. The American Economic Review 81 (2), 222.

Gabaix, X., Lasry, J.-M., Lions, P.-L., Moll, B., 2016. The dynamics of inequality. Econometrica 84 (6), 2071-2111.

Geanakoplos, J., 2010. The leverage cycle. In: NBER Macroeconomics Annual 2009, Volume 24. University of Chicago Press, pp. 1-65.

Geerolf, F., 2017. Leverage and disagreement. Tech. rep., Working Paper.

Giannetti, M., Wang, T. Y., 2016. Corporate scandals and household stock market participation. The Journal of Finance 71 (6), 2591-2636.

Gilboa, I., Samuelson, L., Schmeidler, D., 2014. No-betting-pareto dominance. Econometrica 82 (4), 1405-1442.

Gomes, F., Michaelides, A., 2008. Asset pricing with limited risk sharing and heterogeneous agents. Review of Financial Studies 21 (1), 415-448.

Gong, F., Phelan, G., 2016. Debt collateralization, capital structure, and maximal leverage.

Gruber, J., 2013. A tax-based estimate of the elasticity of intertemporal substitution. Quarterly Journal of Finance 3 (1), 1 - 20.

Guvenen, F., 2009. A parsimonious macroeconomic model for asset pricing. Econometrica 77 (6), $1711-1750$.

Guzman, M., Stiglitz, J. E., 2016. Pseudo-wealth and consumption fluctuations. Tech. rep., National Bureau of Economic Research. 
Hall, R. E., 1988. Intertemporal substitution in consumption. The Journal of Political Economy $96(2), 339-357$.

Harris, M., Raviv, A., 1993. Differences of opinion make a horse race. Review of Financial studies $6(3), 473-506$.

Harrison, J. M., Kreps, D. M., 1978. Speculative investor behavior in a stock market with heterogeneous expectations. The Quarterly Journal of Economics, 323-336.

Heaton, J., Lucas, D., 1999. Stock prices and fundamentals. In: NBER Macroeconomics Annual 1999, Volume 14. MIT, pp. 213-264.

Heyerdahl-Larsen, C., Walden, J., 2017. Welfare in economies with production and heterogeneous beliefs.

Hong, H., Sraer, D. A., 2016. Speculative betas. The Journal of Finance 71 (5), 2095-2144.

Huggett, M., 1993. The risk-free rate in heterogeneous-agent incomplete-insurance economies. Journal of economic Dynamics and Control 17 (5), 953-969.

Hurst, E., Luoh, M. C., Stafford, F. P., Gale, W. G., 1998. The wealth dynamics of american families, 1984-94. Brookings papers on Economic Activity 1998 (1), 267-337.

Jouini, E., Napp, C., 2007. Consensus consumer and intertemporal asset pricing with heterogeneous beliefs. The Review of Economic Studies 74 (4), 1149-1174.

Kearney, M. S., Tufano, P., Guryan, J., Hurst, E., 2010. Making savers winners: An overview of prize-linked savings products. Tech. rep., National Bureau of Economic Research.

Kondor, P., Koszegi, B., 2017. Financial choice and financial information.

Korinek, A., Simsek, A., 2016. Liquidity trap and excessive leverage. American Economic Review $106(3), 699-738$.

Lintner, J., 1969. The aggregation of investor's diverse judgments and preferences in purely competitive security markets. Journal of financial and quantitative analysis 4 (04), 347-400.

Mankiw, N. G., Zeldes, S. P., 1991. The consumption of stockholders and nonstockholders. Journal of Financial Economics 29 (1), 97-112. 
Miller, E. M., 1977. Risk, uncertainty, and divergence of opinion. The Journal of Finance 32 (4), $1151-1168$.

Papke, L. E., 2004. Individual financial decisions in retirement saving plans: the role of participantdirection. Journal of Public Economics 88 (1), 39-61.

Posner, E. A., Weyl, E. G., 2013. Benefit-cost analysis for financial regulation. The American Economic Review 103 (3), 393-397.

Poterba, J. M., 2003. Employer stock and 401 (k) plans. American Economic Review, 398-404.

Scheinkman, J. A., Xiong, W., 2003. Overconfidence and speculative bubbles. Journal of Political Economy 111 (6), 1183-1220.

Schmidt, L. D., Toda, A. A., 2018. Bad news and robust comparative statics for the elasticity of intertemporal substitution. Working Paper.

Sethi-Iyengar, S., Huberman, G., Jiang, W., 2004. How much choice is too much? contributions to 401 (k) retirement plans. Pension design and structure: New lessons from behavioral finance 83, $84-87$.

Simsek, A., 2013a. Belief disagreements and collateral constraints. Econometrica 81 (1), 1-53.

Simsek, A., 2013b. Speculation and risk sharing with new financial assets*. Quarterly Journal of Economics 128 (3).

Skinner, J. S., 1996. Is housing wealth a sideshow? In: Advances in the Economics of Aging. University of Chicago Press, pp. 241-272.

Storesletten, K., Telmer, C. I., Yaron, A., 2004. Cyclical dynamics in idiosyncratic labor market risk. Journal of Political Economy 112 (3), 695-717.

Thaler, R. H., Sunstein, C. R., 2003. Libertarian paternalism. The American Economic Review 93 (2), 175-179.

Varian, H. R., 1985. Divergence of opinion in complete markets: A note. The Journal of Finance 40 (1), 309-317.

Vissing-Jørgensen, A., 2002. Limited asset market participation and the elasticity of intertemporal substitution. Journal of political Economy 110 (4), 825-853. 
Vissing-Jørgensen, A., Attanasio, O. P., 2003. Stock-market participation, intertemporal substitution, and risk-aversion. American Economic Review, 383-391.

Xiong, W., Yan, H., 2009. Heterogeneous expectations and bond markets. The Review of Financial Studies 23 (4), 1433-1466. 


\section{Online Appendices: Not for Publication}

\section{B Online Appendix B: Omitted Extensions}

In this appendix, we present various extensions of the analysis in the main text. The proofs are relegated to Online Appendix $\mathrm{C}$.

\section{B.1 Background risks and the precautionary channel}

In the main text, we focused on the cases in which investors effectively do not face any background risks so that they do not have precautionary savings concerns. We next illustrate the effect of financial innovation in an environment with precautionary savings. We isolate an alternative precautionary channel of financial innovation and contrast it with our choice channel. We also obtain a testable implication of the precautionary channel with respect to market participation, which we empirically analyze in Section 4 .

Isolating the precautionary channel requires putting additional structure on the model. To this end, we replace Assumption 1 with the following set of assumptions.

\section{Assumption $\mathbf{1}^{\mathrm{P}}$.}

(i) Investors share the same beliefs, $E^{i}[\cdot]=E[\cdot]$ for some common $E[\cdot]$.

(ii) There exists a stochastic discount factor, $(M(\mathbf{z}))_{\mathbf{z} \in Z}$, that prices each asset, that is,

$$
P_{j}=E\left[M(\mathbf{z}) \varphi_{j}(\mathbf{z})\right] \text { for each } j \in \mathbf{J},
$$

(iii) Investors' background risks are orthogonal to the stochastic discount factor,

$$
\operatorname{cov}[L(\mathbf{z}) M(\mathbf{z})]=0 \text { for each } i .
$$

Here, the first assumption rules out speculation (and the income and the substitution effects that it generates). While speculation plays a central role for the choice channel, it is typically assumed away in traditional analyses that rely on rational (and thus, common) expectations. The second assumption is a no arbitrage condition. The third assumption holds if the background risks are idiosyncratic (and thus, uncorrelated with aggregate risk) - the typical case analyzed in the literature. Finally, we also set the elasticity of substitution to one, to ensure that the choice channel is completely shut down. 
Proposition 5 (Precautionary Channel). Suppose Assumption $1^{P}$ holds and $\varepsilon=1$. Suppose also that investors initially only have access to the risk-free asset, that is, $J^{o l d}=\{f\}$, and that financial innovation completes the market, that is, $|\mathbf{J}|=|Z|$. Then, financial innovation reduces the investor's asset holdings (and thus, savings), $A_{0}^{i, n e w} \leq A_{0}^{i, o l d}$.

The result establishes conditions under which financial innovation induces the investor to save less - consistent with much of the precautionary savings literature (see the references in the introduction). Intuitively, when markets are incomplete, the investor saves for precautionary reasons. This is because she faces some background risks, and the constant elasticity preferences satisfy the prudence condition. Financial innovation enables the investor to hedge her risks. By doing so, it alleviates the precautionary demand for saving, thereby reducing savings. Depending on the stochastic discount factor, financial innovation can also increase the investors' risk-adjusted return (even if there are no belief disagreements) by enabling her to participate in aggregate risk sharing. The assumption, $\varepsilon=1$, ensures that the substitution and the income effects exactly cancel, so that the precautionary channel is the only influence on saving ${ }^{21}$ The result also focuses on a specific type of innovation that takes the investor from the risk-free asset to a fully complete market. This is a technical requirement that enables us to obtain a theoretical result. The economic insights should apply more broadly as long as financial innovation provides new opportunities to hedge background risks.

\section{B.2 Exact solutions to the portfolio problem and equilibrium}

Section 3 assumes that the agents' asset demand is given by an approximate solution to their portfolio problem. In this section, we solve for an alternative equilibrium, under the assumption that agents solve an exact version of that problem. In this exact version, portfolio weights and asset demand functions do not admit closed-form solutions, so we resort to a numeric approach.

We first define an exact equilibrium as follows.

Definition 2 (Exact Equilibrium). Under Assumptions $1^{G}$ and 2, an exact equilibrium, $\left\{\left(\omega_{J^{i}}^{i}, A_{0}^{i}\right)_{i}, P_{j}\right\}$, is a collection such that the investors' beliefs for asset returns are given by (7), their portfolio weights are obtained from the solution to 4 4) using the definition $\omega_{j}^{i}=\frac{P_{j} x_{j}^{i}}{\sum_{\hat{\jmath} \in J^{i}} P_{j} x_{j}^{i}}$, their asset holdings $\left(A_{0}^{i}\right)$ are given by the solution to problem (5) taking as given the certainty equivalent implicit in $V_{1}\left(A_{0}\right)=R_{c e}^{i} A_{0}$, and the asset markets clear [cf. Eq. (12)].

\footnotetext{
${ }^{21}$ If there is no aggregate risk, as in Aiyagari (1994), then the first part of Assumption $1^{\mathrm{P}}$ is sufficient to shut down the choice channel. In this special case, the result can be generalized beyond $\varepsilon^{i}=1$.
} 

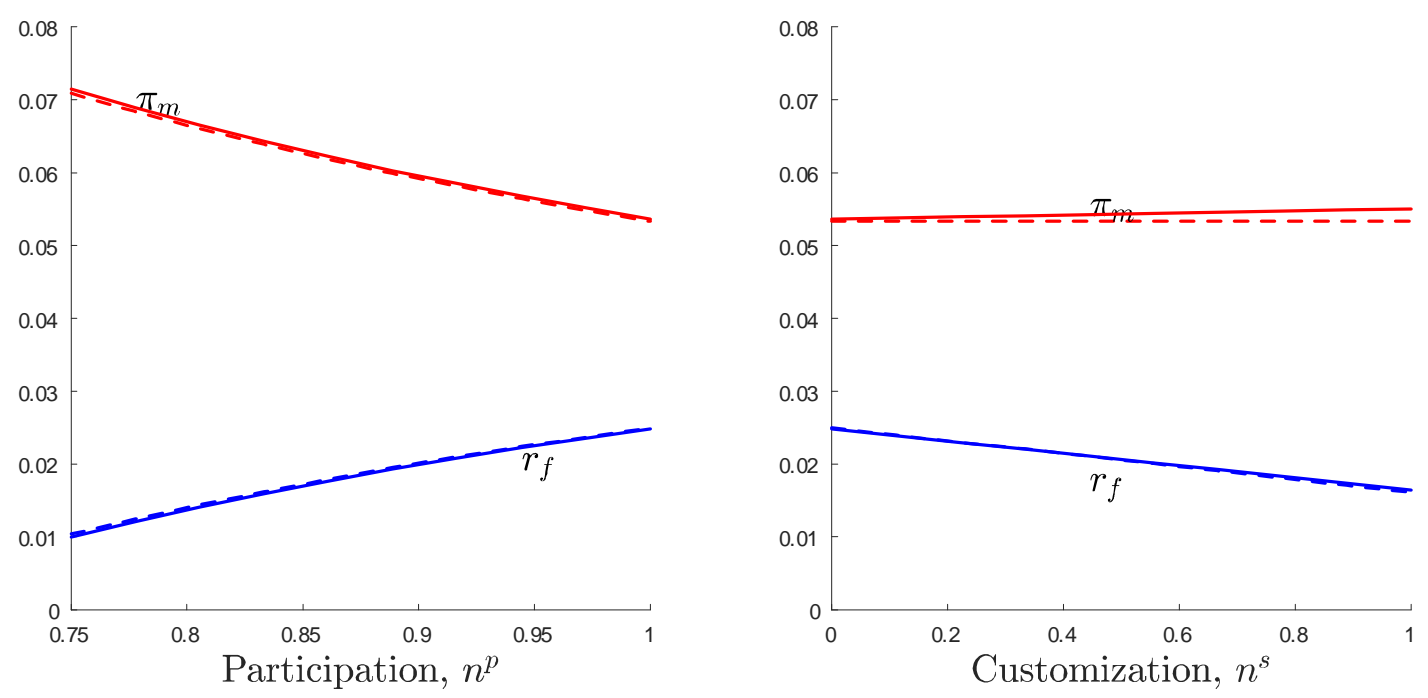

Figure B.1: Comparison of equilibrium interest rates and risk premia under the exact solution to the portfolio problem (solid lines) and the second-order approximation (dashed lines).

The environment we study is otherwise identical to Section 3.3 . Figure B.1 compares the exact and approximate equilibrium solutions for varying degrees of participation $\left(n^{p}\right)$ and customization $\left(n^{s}\right)$. The exact equilibrium risk premium and risk-free rate are displayed in solid lines, while the approximate solutions from Section 3.3 are displayed in dashed lines. The approximation error is small. The responses of the riskless rate and the risk premium to the comparative statics remain largely unchanged: participation leads to a decreasing risk premium and increasing interest rate, while customization leads to a decreasing interest rate. In the exact solution, increased customization leads to a minor increase in risk premia, originating from third and higher order terms in preferences.

\section{B.3 Robustness of the effect of customization on the interest rate}

Proposition 4 in Section 3.2 characterizes the effect of increasing portfolio customization on asset returns in a relatively stylized setting with strong assumptions. In this section, we show that the effect on the interest rate is robust to relaxing many of these assumptions. We first illustrate (numerically) that allowing for disagreement on the market portfolio does not overturn the effect on the interest rate. We then show that the result is also robust to allowing for short-selling constraints. Finally, we introduce investment into the model and show that the effect on the interest rate holds 


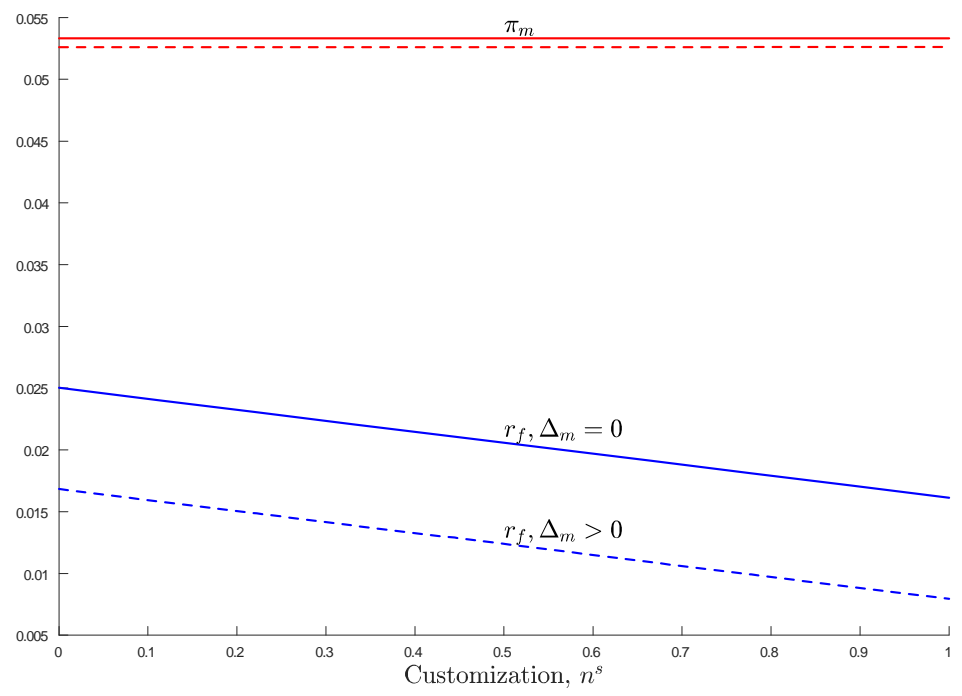

Figure B.2: Effect of customization when there is disagreement on the market portfolio.

also in this setting.

\section{B.3.1 Customization with disagreement on the market portfolio}

Recall that we rule out disagreement on the market portfolio (see the third part of Assumption 4). Absent this assumption, the effect of customization is largely unchanged in our numerical simulations, even though we are unable to prove an analytical result. To see this, consider the numerical example we analyze in Section 3.3 with the only difference being that investors also disagree about the market portfolio. Specifically, an investor who is optimistic (resp. pessimistic) about the speculative asset is also optimistic (resp. pessimistic) about the market portfolio, $\mu_{m}^{\Delta_{s}}=$

$\mu_{m}+\Delta_{m}$ (resp. $\mu_{m}^{-\Delta_{s}}=\mu_{m}-\Delta_{m}$ ) for some $\Delta_{m}>0$. We calibrate the level of disagreement on the market portfolio by assuming, $\left|\Delta_{m} / \sqrt{\Lambda_{m}}\right|=\left|\Delta_{s} / \sqrt{\Lambda_{s}}\right|$, so that the extent of disagreement on the market portfolio (normalized by risk) is the same as the extent of disagreement on the speculative asset. As in Sections 3.2 and 3.3 , we assume everyone has access to the market portfolio, $n^{n}=0$, and numerically investigate the effect of increasing the fraction of investors that have access to the speculative asset in addition to the market portfolio, $n^{s} \in[0,1]$.

Figure B.2 illustrates the results of increased customization in this case. Compared to the earlier case with $\Delta_{m}=0$, the risk-free rate is uniformly lower. The risk premium is also slightly lower, but the difference is not discernible. More importantly, increased customization reduces the risk-free rate and does not have a discernible effect on the risk premium, as in Proposition 4, even 
though the third part of Assumption 4 is violated.

When investors disagree on the market portfolio, they take speculative positions on the market portfolio as well as the speculative asset. This generates an additional increase in their certaintyequivalent returns and reduces the risk-free rate further. However, speculation on the market portfolio also breaks the symmetry between optimists' and pessimists' returns in Eq. (19). Since the asset $m$ is in positive supply, all investors are its natural buyers. Even if optimists did not adjust their positions (relative to the average investor), their perceived return would be higher simply because they are already holding the market portfolio. Therefore, in equilibrium, optimists have a greater (perceived) certainty-equivalent return - and hold more assets - relative to pessimists. This asymmetry implies that belief disagreements can potentially also affect relative asset prices and risk premia, which makes a theoretical characterization difficult. However, for empirically relevant parameters, these asymmetric effects are very small, as illustrated by Figure B.2, and the effect of greater customization remains qualitatively unchanged.

\section{B.3.2 Customization with short-selling constraints}

In our model, we assume the investors can short sell the risky assets without constraints. When short-selling constraints bind on some assets, there are additional complications but the effect of customization on the interest rate remains qualitatively unchanged ${ }^{22}$ To see this, suppose the investors cannot short sell a fraction of the nonmarket assets , $\tilde{\mathbf{J}} \subset\{1, . ., K-1\}$. Formally, the portfolio problem (8) features an additional constraint,

$$
\omega_{j}^{i} \geq 0 \text { for each } j \in \tilde{\mathbf{J}} \text {. }
$$

We continue to make all of the other assumptions in Lemma 2 (including no disagreement on the market portfolio). We also assume $n^{i_{A}}>0$ for each $i_{A} \in I_{A}$, that is, there is a positive mass of investors of each access type (even before customization improves the market access).

The following lemma characterizes the equilibrium with short-selling constraints. To state the result, we define the notation $\Lambda_{J^{i} A}=\left[\begin{array}{cc}\Lambda_{\tilde{J}^{i} A} & \tilde{\Lambda}_{\tilde{J}^{i} A} \\ \left(\tilde{\Lambda}_{\tilde{J}^{i} A}\right)^{\prime} & \Lambda_{J^{i} A \backslash \tilde{\mathbf{J}}}\end{array}\right]$ for any investor with market access

\footnotetext{
${ }^{22}$ We should note that our modeling strategy makes short selling seem more relevant than it would be in practice. For tractability, we assume there is a single asset $m$ in positive net supply, and nonmarket assets $j \neq m$ are in zero net supply. Thus, an investor who would like to reduce her exposure to a nonmarket asset is required to short sell. In practice, most nonmarket assets (such as stocks or bonds) would be in positive net supply. An investor who is pessimistic about these assets could simply not include them in her portfolio. The short-selling constraints would start to bind only if the investor is substantially pessimistic.
} 
$i_{A}$, where $\tilde{J}^{i_{A}}=J^{i_{A}} \cap \tilde{\mathbf{J}}$. We also let $\tilde{\Lambda}_{j, \tilde{J}^{i_{A}}}$ denote the $j$-th row of $\tilde{\Lambda}_{\tilde{J}^{i} A}$.

Lemma 3. Consider the setting in Lemma 2 with the short-selling constraints in (B.1). Then, in equilibrium, the risk premia satisfy

$$
\pi_{j}=\left\{\begin{array}{cc}
\frac{\Lambda_{j m}}{\Lambda_{m}} \pi_{m} & \text { for } j \notin \mathbf{J} \backslash \tilde{\mathbf{J}} \\
\frac{\Lambda_{j m}}{\Lambda_{m}} \pi_{m}-\max _{\left(\mathbf{i}_{A}, \mathbf{i}_{\mathbf{B}}\right)} \Delta_{j}^{\left(\mathbf{i}_{A}, \mathbf{i}_{\mathbf{B}}\right)} & \text { for } j \in \tilde{\mathbf{J}}
\end{array},\right.
$$

where $\pi_{m}=\gamma \Lambda_{m}$ and $\Delta_{j}^{\left(\mathbf{i}_{A}, \mathbf{i}_{\mathbf{B}}\right)} \equiv \mathbf{F}_{j}^{\prime} \mathbf{i}_{\mathbf{B}}-\tilde{\Lambda}_{j, \tilde{J}^{i} A} \Lambda_{J^{i} A \backslash \tilde{\mathbf{J}}}^{-1}\left(\mathbf{F}_{J^{i} A \backslash \tilde{\mathbf{J}}}\right)^{\prime} \mathbf{i}_{\mathbf{B}}$. The risk-free rate is the unique solution to Eq. (18), where $r_{c e}^{\left(\bar{i}_{A}, \mathbf{i}_{B}\right)}$ satisfies

$$
r_{c e}^{\left(\bar{i}_{A}, \mathbf{i}_{B}\right)}=r_{f}+\frac{\pi_{m}^{2}}{2 \gamma \Lambda_{m}}+\frac{1}{2 \gamma}\left(\mathbf{F}_{J^{i} A \backslash \tilde{\mathbf{J}}}^{\prime}\left(\mathbf{i}_{B}\right)\right)^{\prime} \Lambda_{J^{i} A \backslash \tilde{\mathbf{J}}}^{-1}\left(\mathbf{F}_{J^{i} A \backslash \tilde{\mathbf{J}}}^{\prime}\left(\mathbf{i}_{B}\right)\right) .
$$

Here, $\Delta_{j}^{\left(\mathbf{i}_{A}, \mathbf{i}_{\mathrm{B}}\right)}$ captures an investor's excess valuation of the asset relative to the average investor. The first part says that the asset is now priced by the investor that has the highest valuation. Hence, short-selling constraints change the characterization of relative asset prices. However, they leave the characterization of the risk-free rate largely unchanged. In particular, the second part says that the risk-free rate is determined by Eq. (18) as before. The difference is that the investors' certainty-equivalent returns are determined as if the assets on which the short-selling constraints bind are not available for trade (see $(B .3)$ ). This is intuitively because short-selling constraints dampen speculation.

Lemma 3 leads to the following generalization of Proposition 4.

Proposition 6 (Customization with Short Selling Constraints). Consider the setting in Lemma 2 with the short-selling constraints in (B.1). Consider financial innovation that increases the scope of customization for some market participants, $\tilde{n}^{i_{A}^{1}}=n^{i_{A}^{1}}+\Delta n$ and $\tilde{n}^{i_{A}^{0}}=n^{i_{A}^{0}}-\Delta n$ where $i_{A}^{1}>i_{A}^{0}$ and $\Delta n>0$. This change reduces the risk free rate $r_{f}$, and leaves unchanged the average risk premia, $\left\{\pi_{j}\right\}_{j \in \mathbf{J}}$.

The result follows by observing that increasing the scope of customization does not affect the characterization of the risk premia in $(B .2)$. This is because the maximum excess valuation, $\max _{\left(\mathbf{i}_{A}, \mathbf{i}_{\mathbf{B}}\right)} \Delta_{j}^{\left(\mathbf{i}_{A}, \mathbf{i}_{\mathbf{B}}\right)}$, remains unchanged before and after the innovation. In contrast, greater customization does affect the characterization of the risk-free rate by enabling more speculation, which reduces the risk-free interest rate as in Proposition 4. 


\section{B.3.3 Customization with investment}

In the main text, we examined the asset pricing implications of financial innovations in an environment with a fixed supply of the market portfolio, $m$, given by $\eta_{m}>0$. We next show that the effect of customization on the interest rate continues to hold if there is investment and $\eta_{m}$ is determined endogenously.

Suppose that the output of the economy at date $t=1$ is produced via a constant returns to scale neoclassical production function $Y_{1}=\Phi(\mathbf{z}) G(K, L)$. Here, we assume that $\Phi$ is a Hicks-neutral productivity shock that satisfies,

$$
\log \Phi(\mathbf{z})=\mathbf{F}_{m}^{\prime} \mathbf{z}
$$

Investors in this economy are also workers and supply one unit of labor inelastically. Therefore, we modify Assumption $\mathbf{1}^{\mathbf{G}}$ slightly to allow for a positive $t=1$ endowment by investors. We also maintain the structure of investors' market access and beliefs from Section 3.2 ,

The economy starts with zero units of capital at time 0 . Capital is produced at time 0 by a competitive sector of investment goods firms that can convert one unit of consumption good at time 0 into one unit of capital at time 1 . Since this is only a two-period model, we assume that the capital depreciates fully after use at time 1 . Capital and labor are rented at time 1 by a competitive sector of production firms that have access to the production technology of the economy. Given linearity in the investment good technology and production technology for the final good, both types of firms earn zero profits in equilibrium.

We use a similar equilibrium concept for this economy as our "approximate equilibrium" notion in Definition 1 but add additional market clearing conditions that capture the endogeneity of investment. In equilibrium, the price of a unit of capital at $t=0$ equals its cost of production (namely unity). In addition, the supply of the market portfolio, $\eta_{m}$, equals the supply of capital $K$. Thus, the price of the market portfolio also equals the price of capital, $P_{m}=1$. Finally, there is market clearing in the labor market.

We let $R_{m}\left(\eta_{m}\right)=\Phi G_{K}\left(\eta_{m}, 1\right)$ denote the gross return on the market portfolio in equilibrium given supply $\eta_{m}$. We let $r_{m}\left(\eta_{m}\right)$ denote the log return. Then, the expected log return is given by,

$$
E\left[r_{m}\left(\eta_{m}\right)\right]=E[\log \Phi]+\log G_{K}\left(\eta_{m}, 1\right)
$$

Note also that $(\log )$ expected return on the market portfolio is equal to the sum of the risk-free rate and the risk premium,

$$
E\left[r_{m}\left(\eta_{m}\right)\right]+\frac{\Lambda_{m}}{2}=r_{f}+\pi_{m}
$$


Here, $\Lambda_{m}=\operatorname{var}(\Phi)$ denotes the variance of the market portfolio as in the main text. Combining the last two equations yields the key equation of the characterization,

$$
\log G_{K}\left(\eta_{m}, 1\right)+\left(\frac{\Lambda_{m}}{2}+E[\log \Phi]\right)=r_{f}+\pi_{m}
$$

The terms in parentheses are exogenous variables. Hence, the equation says that the supply of capital, $\eta_{m}$, is decreasing in the return on the market portfolio, $r_{f}+\pi_{m}$. As we will see, the risk premium on the market portfolio, $\pi_{m}$, will also be determined by exogenous variables. Hence, the equation implies that a lower interest rate, $r_{f}$, increases the equilibrium supply of capital, $\eta_{m}$.

To characterize the rest of the equilibrium, we denote the equilibrium wage rate at time 1 by $w\left(\eta_{m}\right)=\Phi G_{L}\left(\eta_{m}, 1\right)$. Notice that, given the assumption of a Hicks-neutral productivity shock, $\Phi$, the return on the market portfolio and the wage rate are perfectly positively correlated. Since all investors are assumed to have access to the market portfolio, it follows that agents in this economy do not face uninsurable background risks. In particular, the investor's labor endowment is equivalent to holding $\frac{G_{L}\left(\eta_{m}, 1\right)}{G_{K}\left(\eta_{m}, 1\right)}$ units of the market portfolio. Therefore, investor $i$ 's effective wealth at time 0 is given by,

$$
\tilde{W}_{0}^{i}=Y_{0}+\frac{G_{L}\left(\eta_{m}, 1\right)}{G_{K}\left(\eta_{m}, 1\right)} P_{m}=Y_{0}+\frac{G_{L}\left(\eta_{m}, 1\right)}{G_{K}\left(\eta_{m}, 1\right)} .
$$

The investor's effective asset holding is given by $\tilde{A}_{0}^{i}=a^{i}\left(r_{c e}^{i}\right) \tilde{W}_{0}^{i}$, where $r_{c e}^{i}$ is the investor's (log) certainty-equivalent return as before. It follows that the investor's savings are given by,

$$
A_{0}^{i}=a^{i}\left(r_{c e}^{i}\right) \tilde{W}_{0}^{i}-\frac{G_{L}\left(\eta_{m}, 1\right)}{G_{K}\left(\eta_{m}, 1\right)} .
$$

The asset market clearing conditions can then be written as,

$$
\eta_{j} P_{j}=\sum_{\left\{i \mid j \in\{f\} \cup J^{i}\right\}} n^{i} \omega_{j}^{i}\left[a^{i}\left(r_{c e}^{i}\right) \tilde{W}_{0}^{i}-\frac{G_{L}\left(\eta_{m}, 1\right)}{G_{K}\left(\eta_{m}, 1\right)}\right] .
$$

The following result characterizes the equilibrium.

Lemma 4. Consider the setting with limited portfolio customization (and full market participation) and endogenous investment. In equilibrium, the aggregate risk premium on each risky asset satisfies $\pi_{j}=\frac{\Lambda_{j m}}{\Lambda_{m}} \pi_{m}$, where $\pi_{m}=\gamma \Lambda_{m}$. The supply of the market portfolio, $\eta_{m}$, and the risk-free rate, $r_{f}$, 
are jointly determined by Eq. B.4 and

$$
\frac{\eta_{m}+\frac{G_{L}\left(\eta_{m}, 1\right)}{G_{K}\left(\eta_{m}, 1\right)}}{Y_{0}+\frac{G_{L}\left(\eta_{m}, 1\right)}{G_{K}\left(\eta_{m}, 1\right)}}=\sum_{i \in I} n^{i_{A}} n^{\mathbf{i}_{\mathbf{B}}} a\left(r_{c e}^{\left(i_{A}, \mathbf{i}_{\mathbf{B}}\right)}\right)
$$

where the certainty-equivalent return for an investor with type $\left(i_{A}, \mathbf{i}_{\mathbf{B}}\right)$ is given by Eq. (16) as in the main text.

Compared to Lemma 2, the only difference is that the supply of the market portfolio, $\eta_{m}$, is endogenous and inversely related to the interest rate according to B.4. This leads to the following result, which generalizes Proposition 4 to this setting.

Proposition 7. Consider the equilibrium characterized in Lemma 4. Consider financial innovation that increases the scope of customization for some investors, $\tilde{n}_{A}^{i_{A}^{1}}=n^{i_{A}^{1}}+\Delta n$ and $\tilde{n}^{i_{A}^{0}}=n^{i_{A}^{0}}-\Delta n$, where $i_{A}^{1}>i_{A}^{0}$ and $\Delta n>0$. This change reduces the risk free rate $r_{f}$ and the expected return on risky assets $E\left[r_{j}\right], j \in \mathbf{J}$ and leaves unchanged the average risk premia. It also increases aggregate investment and the supply of the market portfolio, $\eta_{m}$.

As with the case of a fixed supply of the market portfolio, increased customization decreases the returns on all assets in the economy. In this case, the lower required returns (or the lower hurdle rates) also translate into greater investment and increased supply, $\eta_{m}$. It is illustrative to consider how the two responses compare. The proof in Online Appendix Cimplies that,

$$
\frac{\partial r_{f}}{\partial \Delta n} / \frac{\partial \eta_{m}}{\partial \Delta n}=\frac{G_{K K}}{G_{K}}
$$

Therefore, the relative response depends on properties of the aggregate production function. Specifically, if capital and labor are perfect substitutes in production, then $\frac{G_{K K}}{G_{K}}=0$, and only the quantity margin responds. If they are perfect complements, then $\frac{G_{K K}}{G_{K}} \rightarrow \infty$, and there is only a price respond. In between, the relative response should depend on the elasticity of substitution between capital and labor.

\section{Online Appendix C: Omitted Proofs}

In this appendix, we first present the proofs for the results in the main text, which are not included in Appendix A.2. We then present the proofs for the results in Online Appendix B. 


\section{C.1 Proofs of results in the main text}

Proof of Proposition 1. Included in Appendix A.2.

Proof of Proposition 2. The equilibrium is described by the following system of equations.

$$
\eta_{j} P_{j}=\sum_{\{i \quad \mid} n^{i} \omega_{j}^{i} a^{i}\left(r_{c e}^{i}\right)\left(Y_{0}^{i}+W_{0}^{i}\right) \text { for each } j \in\{f\} \cup \mathbf{J},
$$

where returns and risk premia are related to prices according to,

$$
\begin{aligned}
& E^{i}\left[r_{j}\right]=\left(\mathbf{F}_{j}\right)^{\prime} \boldsymbol{\mu}_{\mathbf{z}}^{i}-\log P_{j} \\
& \pi_{j}^{i}=E^{i}\left[r_{j}\right]+\frac{\Lambda_{j}}{2}-r_{f}
\end{aligned}
$$

and investors' asset demands and savings are determined by,

$$
\begin{aligned}
& \boldsymbol{\omega}_{J^{i}}^{i}=\frac{1}{\gamma^{i}} \Lambda_{J^{i}}^{-1} \boldsymbol{\pi}_{J^{i}}^{i} \\
& r_{c e}^{i}=r_{f}+\frac{1}{2 \gamma^{i}}\left(\boldsymbol{\pi}_{J^{i}}^{i}\right)^{\prime} \Lambda_{J^{i}}^{-1} \boldsymbol{\pi}_{J^{i}}^{i} \\
& a^{i}\left(r_{c e}^{i}\right)=\frac{\left(\beta^{i}\right)^{\varepsilon^{i}} \exp \left(r_{c e}^{i}\left(\varepsilon^{i}-1\right)\right)}{1+\left(\beta^{i}\right)^{\varepsilon^{i}} \exp \left(r_{c e}^{i}\left(\varepsilon^{i}-1\right)\right)} .
\end{aligned}
$$

Note that a lower price $P_{j}$ increases the return and the risk premium on asset $j$, which tends to increase the demand for that asset. We are looking for a vector, $P=\left\{P_{j}\right\}_{j \in\{f\} \cup J}$, that ensures all asset markets are simultaneously in equilibrium.

We work with a truncated economy, where prices satisfy $P_{j} \leq \alpha$ for each asset $j \in\{f\} \cup J$. We are only interested in sufficiently large $\alpha$ so that the truncation becomes inconsequential. First, let us define extended portfolio weights over assets that agent $i$ cannot trade, so that

$$
\hat{\omega}_{j}^{i}(P) \equiv\left\{\begin{array}{c}
\omega_{j}^{i}(P), \text { whenever } j \in\{f\} \cup J^{i} \\
0, \text { otherwise. }
\end{array}\right.
$$

For $P \gg 0$ we have individual excess demand for asset $j \in\{f\} \cup J$ defined as

$$
z_{j}^{i}(P) \equiv \frac{\hat{\omega_{j}^{i}}(P)}{P_{j}} A_{0}^{i}(P)-x_{-1, j}^{i}
$$

and we analogously define the excess demand for consumption at date $t=0$ as $z_{0}^{i}(P) \equiv c_{0}^{i}(P)-$ $Y_{0}^{i}$. Aggregate excess demands are then simply defined as $z_{j}(P) \equiv \sum_{i} n^{i} z_{j}^{i}(P)$ and $z_{0}(P) \equiv$ $\sum_{i} n^{i} z_{0}^{i}(P)$. Walras' Law, i.e., $z_{0}(P)+\sum_{j \in J} P_{j} z_{j}(P)=0$ can be trivially verified from individual 
optimality.

First, we impose a lower bound on prices $\hat{\epsilon}>0$, which we successively relax later. Define $S_{\hat{\epsilon}} \equiv\left\{P \in \mathbb{R}_{++}^{|J|} \mid P_{j} \geq \hat{\epsilon}\right.$ and $\left.P_{j} \leq \alpha, \forall j \in\{f\} \cup J\right\}$ which is compact and convex. We are only interested in $\alpha>\hat{\epsilon}$ as to ensure the non-emptiness of $S_{\hat{\epsilon}}$.

We next define a continuous price updating function. Let each entry, which describes the update to the price of asset $j \in J$, be defined by

$$
P_{j}^{u p d}(P, \hat{\epsilon}) \equiv\left\{\begin{array}{c}
\hat{\epsilon}, \text { if } z_{j}(P)<\hat{\epsilon}-P_{j} \\
P_{j}+z_{j}(P), \text { if } \hat{\epsilon}-P_{j} \leq z_{j}(P) \leq \alpha \\
\alpha, \text { if } z_{j}(P)>\alpha
\end{array}\right.
$$

Then, let the function $P^{u p d}(P, \hat{\epsilon}): S_{\hat{\epsilon}} \rightarrow S_{\hat{\epsilon}}$ be defined as $P^{u p d}(P, \hat{\epsilon})=\left\{P_{j}^{u p d}(P, \hat{\epsilon})\right\}_{j \in\{f\} \cup J}$. As excess demand functions are continuous, so is the function $P^{u p d}(\cdot, \hat{\epsilon})$, which maps the non-empty, convex, and compact set $S_{\hat{\epsilon}}$ into itself. From Brouwer's Fixed Point Theorem, there exists $P^{\hat{\epsilon}} \in S_{\hat{\epsilon}}$ such that $P_{j}^{u p d}\left(P^{\hat{\epsilon}}, \hat{\epsilon}\right)=P^{\hat{\epsilon}}$.

We now take a sequence $\left\{\hat{\epsilon}_{k}\right\}_{k \in \mathbb{N}}$ such that $\hat{\epsilon}_{k} \rightarrow 0$. Let $\left\{P^{\hat{\epsilon}_{k}}\right\}_{k \in \mathbb{N}}$ be the associated sequence of fixed points. As each price lies in $[0, \alpha]$ that sequence is bounded and admits a converging subsequence. To save on notation, assume we have selected such subsequence from the start. Define its limit by $P^{*}=\left(P_{1}^{*}, P_{2}^{*}, \ldots, P_{|J|}^{*}\right)$. Naturally $P^{*} \in \overline{\cup_{k} S_{\hat{\epsilon}_{k}}}=\left\{P \in \mathbb{R}_{+}^{|J|} \mid P_{j} \leq \alpha, \forall\{f\} \cup J\right\}$. We now show that $P^{*} \in \mathbb{R}_{++}^{|J|}$.

Consider the case with $P_{j}^{*}=0$ for risky assets, which w.l.o.g. we call assets $1, . ., m$, while the riskless rate remains bounded away from zero. In this case, the risk premia for assets $1, . ., m$ approach $+\infty$, and the risk premia for the remaining assets remain finite. Consider all investors that have access to at least one of the assets $1, . ., m$ and call that set $I_{r \rightarrow \infty}$. It is easy to check that each of these investors have $r_{c e} \rightarrow \infty$, and thus, they save all their wealth.

Now consider the net demand for assets that comes from these investors only, $z_{j}^{I_{r \rightarrow \infty}} \equiv$ $\sum_{i \in I_{r \rightarrow \infty}} n^{i} z_{j}^{i}(P)$. We claim that regardless of how the prices for $1, . ., m$ approach 0 (or conversely, regardless of the risk premia approach infinity), there exists at least one asset within $1, . ., m$ such that the total demand from these investors for that asset becomes unboundedly positive. Since the demand from the other investors is finite, this will provide a contradiction.

Let us rewrite risk premia along the sequence. Take a given agent $i \in I_{r \rightarrow \infty}$, then the (individually perceived) risk-premium $\pi_{j}^{i, k}\left(P^{\hat{\epsilon}_{k}}\right)$ on any asset $j \in J$ can be appropriately rewritten as 
$\pi_{j}^{i, k}=\left\|\pi^{i, k}\right\| \hat{\pi}_{j}^{i, k}$ where $\left\|\pi^{i, k}\right\|:=\sum_{j}\left|\pi_{j}^{i, k}\right|$ denotes a norm and

$$
\hat{\pi}_{j}^{i, k} \equiv \frac{\pi_{j}^{i, k}}{\left\|\pi^{i, k}\right\|}
$$

denotes the $j$-th entry of a normalized risk-premium vector ${ }^{23}$ The vector $\hat{\pi}^{i, k}=\left\{\hat{\pi}_{j}^{i, k}\right\}_{j \in J}$ belongs to the surface of the unit ball centered at zero.

As that surface is a compact set, $\left\{\hat{\pi}^{i, k}\right\}_{k \in \mathbb{N}}$ admits a converging subsequence, which we can index by $k_{i} \in \mathbb{N}$. That forms another price sequence $\left\{P^{\hat{\epsilon}_{k_{i}}}\right\}_{k_{i} \in \mathbb{N}}$, from which we can extract a subsequence to ensure that the analogously defined vector ${\hat{\pi}^{i}}^{\prime}, k_{i}$ converges for any second agent $i^{\prime} \in I_{r \rightarrow \infty}$. Given that $I_{r \rightarrow \infty}$ is finite, this step can be iteratively repeated until a subsequence, indexed by $\tilde{k} \in \mathbb{N}$, is extracted and ensures that each $\hat{\pi}^{i, \tilde{k}}$ converges. Additionally, for each $i \in I_{r \rightarrow \infty}, \lim _{\tilde{k} \rightarrow \infty} \hat{\pi}^{i, \tilde{k}}=\hat{\pi}$, i.e., the limit of the normalized risk-premia are the same and independent of $i \in I_{r \rightarrow \infty}$, since disagreements are bounded, while at least one return goes to infinity.

Take a given agent $i \in I_{r \rightarrow \infty}$. Define $\hat{\pi}_{J_{i}}^{i, \tilde{k}}$ and $\hat{\pi}_{J_{i}}$ to be respectively the restriction of the normalized risk premia vectors $\hat{\pi}^{i, \tilde{k}}$ and $\hat{\pi}$ to the assets that agent $i$ can trade. Notice that along that subsequence portfolio weights of the form $\omega_{J^{i}}^{i}\left(P^{\hat{\epsilon}_{\tilde{k}}}\right)=\frac{1}{\gamma^{i}} \Lambda_{J^{i}}^{-1} \hat{\pi}_{J_{i}}^{i, \tilde{k}}\left\|\pi^{i, \tilde{k}}\right\|$ are optimal from equation (10). Therefore, we take the following limit of an inner product

$$
\lim _{\tilde{k} \rightarrow \infty}\left\langle\hat{\pi}_{J_{i}}^{i, \tilde{k}}, \frac{\omega_{J^{i}}^{i}\left(P^{\hat{\epsilon}_{\tilde{k}}}\right)}{\left\|\pi^{i, \tilde{k}}\right\|}\right\rangle=\frac{1}{\gamma^{i}} \hat{\pi}_{J_{i}}^{\prime} \Lambda_{J^{i}}^{-1} \hat{\pi}_{J_{i}}>0
$$

from the positive-definiteness of $\Lambda_{J^{i}}^{-1}$ and the fact that $\hat{\pi}_{J_{i}}$ is not null. It follows that it is possible to find $\delta>0$ and a sufficiently large element $\bar{k}$ such that

$$
\left\langle\hat{\pi}, \frac{\hat{\omega}^{i}\left(P^{\hat{\epsilon}_{\tilde{k}}}\right)}{\left\|\pi^{i, \tilde{k}}\right\|}\right\rangle>\delta
$$

whenever $i \in I_{r \rightarrow \infty}$ and $\tilde{k}>\bar{k}$. Given that $A_{0}^{i}\left(P^{\hat{\epsilon} \tilde{k}}\right)$ is bounded from below for sufficiently high $\tilde{k}$ for all $i \in I_{r \rightarrow \infty}$, there exists $\delta_{1}>0$

$$
\left\langle\hat{\pi}, \sum_{i \in I_{r \rightarrow \infty}} n^{i} A_{0}^{i}\left(P^{\hat{\epsilon}_{\tilde{k}}}\right) \frac{\hat{\omega}^{i}\left(P^{\hat{\epsilon}_{\tilde{k}}}\right)}{\left\|\pi^{i, \tilde{k}}\right\|}\right\rangle>\delta_{1},
$$

\footnotetext{
${ }^{23}$ As prices are converging to zero, there are finitely many elements with $\sum_{j} \pi_{j}^{i, k}=0$. We can move to a subsequence that disregards these.
} 
for all $\tilde{k}>\bar{k}$. This directly implies that there exists one asset $j \in\{1, \ldots, m\}$ such that $\sum_{i \in I_{r \rightarrow \infty}} n^{i} A_{0}^{i}\left(P^{\hat{\epsilon}_{\tilde{k}}}\right) \hat{\omega}^{i}\left(P^{\hat{\epsilon}_{\tilde{k}}}\right)$ grows without bounds. It follows that excess demand for that asset is unbounded along the subsequence that is indexed by $\tilde{k}$. From C.2 this means that $P_{j}^{u p d}\left(P^{\hat{\epsilon}_{k}}, \hat{\epsilon}_{k}\right)=\alpha$ infinitely many times as $k \rightarrow \infty$, reaching a contradiction with $P_{j}^{*}=0$.

Suppose now, towards a different contradiction, that $r_{f} \rightarrow \infty$. Using arguments similar to the previous ones, it is possible to select a subsequence, indexed by $\tilde{k} \in \mathbb{N}$, in which the risk premium, $\pi_{j}^{i}\left(P^{\hat{\epsilon}_{\tilde{k}}}\right)$, perceived by each agent $i \in I$ for each asset $j \in J$ either converges to a finite constant, diverges to $+\infty$ or diverges to $-\infty$. Also, a premium can only diverge for all agents at the same time and in the same direction.

First, we deal with the case in which no premium diverges. In this situation, each asset price converges to zero. Adding equations C.1 over agents and assets, properly multiplied by prices and individual population shares, we get

$$
\sum_{i, j} P_{j}^{\hat{\epsilon}_{\tilde{k}}} n^{i} z_{j}^{i}\left(P^{\hat{\epsilon}_{\tilde{k}}}\right)=\sum_{i, j} n^{i}\left[\hat{\omega}_{j}^{i}\left(P^{\hat{\epsilon}_{\tilde{k}}}\right) A_{0}^{i}\left(P^{\hat{\epsilon}_{\tilde{k}}}\right)-P_{j}^{\hat{\epsilon}_{\tilde{k}}} x_{-1, j}^{i}\right]
$$

which after simplifications leads to

$$
\sum_{j} P_{j}^{\hat{\epsilon}_{\tilde{k}}} z_{j}\left(P^{\hat{\epsilon}_{\tilde{k}}}\right)=\sum_{i} n^{i} A_{0}^{i}\left(P^{\hat{\epsilon}_{\tilde{k}}}\right)-\sum_{i, j} P_{j}^{\hat{\epsilon}_{\tilde{k}}} n^{i} x_{-1, j}^{i}
$$

As $P^{\hat{\epsilon}_{\tilde{k}}} \rightarrow 0$, the right hand side converges to $\sum_{i} n^{i} Y_{0}^{i}>0$. As a consequence, the excess demand for at least one asset $j$ needs to approach $+\infty$ along a subsequence. Along this subsequence then $P_{j}^{u p d}\left(P, \hat{\epsilon}_{\tilde{k}}\right)=\alpha$ infinitely often, leading to a contradiction of the zero price limit.

For the case in which some premia diverge, we still obtain

$$
\lim _{\tilde{k} \rightarrow \infty} A_{0}^{i}\left(P^{\hat{\epsilon}_{\tilde{k}}}\right)-P_{j}^{\hat{\epsilon}_{\tilde{k}}} n^{i} x_{-1, j}^{i}=Y_{0}^{i}>0
$$

and

$$
\sum_{j} P_{j}^{\hat{\epsilon}_{\tilde{k}}} z_{j}\left(P^{\hat{\epsilon}_{\tilde{k}}}\right) \rightarrow \sum n^{i} Y_{0}^{i}>0
$$

If $P^{\hat{\epsilon}_{\tilde{k}}} \rightarrow 0$, we find the same contradiction as before. Therefore, for at least one asset $j \in J$, we need to have $P_{j}^{\hat{\epsilon}_{\tilde{k}}} \rightarrow P_{j}^{*} \neq 0$ which implies that $\pi_{j}^{i, \tilde{k}} \rightarrow-\infty$ for each $i \in I$. We can therefore follow all the previous steps leading to C.3, with the exception that $\hat{\pi}$ can now have negative entries. This means that we can find a subsequence and an asset $j^{\prime} \in J$, such that either $\pi_{j^{\prime}}^{i, \tilde{k}} \rightarrow-\infty$ and $z_{j^{\prime}}\left(P^{\hat{\epsilon}_{\tilde{k}}}\right) \rightarrow-\infty$ or $\pi_{j^{\prime}}^{i, \tilde{k}} \rightarrow+\infty$ and $z_{j^{\prime}}\left(P^{\hat{\epsilon}_{\tilde{k}}}\right) \rightarrow+\infty$. For the latter case, we would reach the 
same contradiction as before since $z_{j^{\prime}}\left(P^{\hat{\epsilon}_{\tilde{k}}}\right) \rightarrow+\infty$ implies that $P_{j}^{u p d}\left(P^{\hat{\epsilon}_{k}}, \hat{\epsilon}_{k}\right)=\alpha$ infinitely many times which contradicts positive infinity limits for both the riskless rate and the risk premium on $j^{\prime}$. Therefore, we need to rule out the former situation. Given that $P_{j}^{\hat{\epsilon}_{\tilde{k}}} \rightarrow P_{j}^{*}>0, \pi_{j}^{i, \tilde{k}} \rightarrow-\infty$ and $\hat{\pi}_{j^{\prime}} \neq 0$ together imply that $P_{j^{\prime}}^{*}>0$. But from $(\mathrm{C} .2), z_{j^{\prime}}\left(P^{\hat{\epsilon}_{\tilde{k}}}\right) \rightarrow-\infty$ implies $P_{j^{\prime}}^{\hat{\epsilon}_{\tilde{k}}}=\hat{\epsilon}_{\tilde{k}}$ infinitely many times with $\hat{\epsilon}_{\tilde{k}} \rightarrow 0$, reaching a contradiction with $P_{j^{\prime}}^{*}>0$.

We have, therefore, ruled out any possibility that $P_{j}^{*}=0$ for some asset $j \in J \cup\{f\}$. We still need to show that for sufficiently high $\alpha$, market clearing is ensured in all markets at prices $P^{*}$. Given that $P_{j}^{*} \gg 0$, it is possible to find a sufficiently high $\hat{k}$ and $\delta_{2}>0$, such that

$$
P_{j}^{\hat{\epsilon}_{k}}>\delta_{2}>\hat{\epsilon}_{k}
$$

for all $k>\hat{k}$. As a consequence, from $\sqrt{\text { C.2 } 2}$, for $k>\hat{k}, P_{j}^{\hat{\epsilon}_{k}} \geq 0$ and $z_{j}\left(P^{\hat{\epsilon}_{k}}\right) \geq 0$.

Additionally, for each $i \in I, C_{0}^{i}\left(P^{\hat{\epsilon}_{k}}\right) \in\left[0, Y_{0}^{i}+\alpha \sum_{j} x_{-1}^{i}, j\right]$ implying that

$$
-\alpha \sum_{i, j} n^{i} x_{-1, j}^{i} \leq \sum_{j} P_{j}^{\hat{\epsilon}_{\tilde{k}}} z_{j}\left(P^{\hat{\epsilon}_{\tilde{k}}}\right) \leq \sum_{i} n^{i} Y_{0}^{i}
$$

For $\alpha^{2}>\sum_{i} n^{i} Y_{0}^{i}$, it follows that $z\left(P^{\hat{\epsilon}_{\tilde{k}}}\right) \rightarrow z\left(P^{*}\right)=0$ ensuring market-clearing in the limit and existence of a Walrasian Equilibrium.

To establish the remaining proofs, we state a useful lemma that concerns the asset holding function defined in (11), which we replicate here

$$
a\left(r_{c e}\right)=\frac{\beta^{\varepsilon} \exp \left(r_{c e}(\varepsilon-1)\right)}{1+\beta^{\varepsilon} \exp \left(r_{c e}(\varepsilon-1)\right)} .
$$

Lemma 5. Whenever $\varepsilon>1$, the semi-elasticity $\frac{a^{\prime}\left(r_{c e}\right)}{a\left(r_{c e}\right)}$ is decreasing in $r_{c e}$.

Proof. From the Euler Equation in logarithmic form

$$
\log a\left(r_{c e}\right)-\log \left(1-a\left(r_{c e}\right)\right)=\varepsilon \log \beta+(\varepsilon-1) r_{c e}
$$

thus differentiating with respect to $r_{c e}$ and simplifying

$$
\frac{a^{\prime}\left(r_{c e}\right)}{a\left(r_{c e}\right)}=(\varepsilon-1)\left(1-a\left(r_{c e}\right)\right)
$$


so $\frac{a^{\prime}\left(r_{c e}\right)}{a\left(r_{c e}\right)}$ is decreasing in $a$ and therefore in $r_{c e}$, whenever $\varepsilon>1$.

Proof of Lemma 1. This proof is mostly included in Appendix A.2. There, we establish Eqs. (14) - 15). It remains to prove that this system of equations has a unique solution.

Toward that end let us first define the average level of savings out of wealth as $\bar{a}\left(r_{f}, \pi_{m}, n^{p}\right) \equiv$ $n^{p} a\left(r_{c e}^{p}\right)+\left(1-n^{p}\right) a\left(r_{f}\right)$, and the relative value of the asset endowment as $v\left(r_{f}+\pi_{m}\right) \equiv \frac{\eta_{m} P_{m}}{Y_{0}+\eta_{m} P_{m}}$. Combined they characterize

$$
\varphi_{1}\left(r_{f}, \pi_{m}, n^{p}\right) \equiv \bar{a}\left(r_{f}, \pi_{m}, n^{p}\right)-v\left(r_{f}+\pi_{m}\right) .
$$

Notice that $v^{\prime}\left(r_{f}+\pi_{m}\right) \propto-Y_{0} v\left(r_{f}+\pi_{m}\right)<0$. As a consequence, $\frac{\partial \varphi_{1}\left(r_{f}, \pi_{m}, n^{p}\right)}{\partial r_{f}}=\frac{\partial \bar{a}}{\partial r_{f}}-v^{\prime}>0$, and $\frac{\partial \varphi_{1}\left(r_{f}, \pi_{m}, n^{p}\right)}{\partial \pi_{m}}=\frac{\partial \bar{a}}{\partial \pi_{m}}-v^{\prime}>0$.

Additionally, we define

$$
\varphi_{2}\left(r_{f}, \pi_{m}, n^{p}\right) \equiv n^{p}\left(1-\omega_{m}^{p}\right) a\left(r_{c e}^{p}\right)+\left(1-n^{p}\right) a\left(r_{f}\right) .
$$

An equilibrium then is a solution to $\varphi_{1}\left(r_{f}, \pi_{m}, n^{p}\right)=\varphi_{2}\left(r_{f}, \pi_{m}, n^{p}\right)=0$.

Notice then that, $\frac{\partial \varphi_{2}}{\partial r_{f}}=n^{p}\left(1-\omega_{m}^{p}\right) a^{\prime}\left(r_{c e}^{p}\right)+\left(1-n^{p}\right) a^{\prime}\left(r_{f}\right)$. Additionally, $\varphi_{2}\left(r_{f}, \pi_{m}, n^{p}\right)=$ $0 \Longrightarrow\left(1-\omega_{m}^{p}\right)=-\frac{\left(1-n^{p}\right)}{n^{p}} \frac{a\left(r_{f}\right)}{a\left(r_{c e}^{p}\right)}$ and $\frac{\partial \varphi_{2}}{\partial r_{f}}=\left(1-n^{p}\right) a\left(r_{f}\right)\left[\frac{a^{\prime}\left(r_{f}\right)}{a\left(r_{f}\right)}-\frac{a^{\prime}\left(r_{c e}^{p}\right)}{a\left(r_{c e}^{p}\right)}\right]$ which is positive whenever $\varepsilon>1$, given Lemma 5. Last, $\frac{\partial \varphi_{2}}{\partial \pi_{m}}=-\frac{\partial \omega_{m}^{p}}{\partial \pi_{m}} n^{p} a\left(r_{c e}^{p}\right)+n^{p}\left(1-\omega_{m}^{p}\right) a^{\prime}\left(r_{c e}^{p}\right) \frac{\partial r_{c e}^{p}}{\partial \pi_{m}}<0$ since $\left(1-\omega_{m}^{p}\right)<0$ whenever $\varphi_{2}=0$.

As a consequence, locus $\varphi_{1}\left(r_{f}, \pi_{m}, n^{p}\right)=0$ is downward slopping in $\left(r_{f}, \pi_{m}\right)$-space while locus $\varphi_{2}\left(r_{f}, \pi_{m}, n^{p}\right)=0$ is upward slopping. Both loci are characterized by continuous functions. We can use $\varphi_{1}\left(r_{f}, \pi_{m}, n^{p}\right)=0$, with $\frac{\partial \varphi_{1}}{\partial \pi_{m}} \neq 0$, and the Implicit Function Theorem to define a decreasing function $\pi_{m}^{\varphi_{1}}(\cdot)$ of the interest rate $r_{f}$ over the first locus. We then look for a solution to $\varphi_{2}\left(r_{f}, \pi_{m}^{\varphi_{1}}\left(r_{f}\right), n^{p}\right)=0$, where the left-hand side is a strictly increasing function of $r_{f}$. The existence of a solution is guaranteed by Proposition 2 and uniqueness follows from strict monotonicity.

$$
\begin{gathered}
\text { Proof of Proposition }\left[\mathbf{3} \text { Let } J \equiv\left[\begin{array}{cc}
\frac{\partial \varphi_{1}}{\partial r_{f}} & \frac{\partial \varphi_{1}}{\partial \pi_{m}} \\
\frac{\partial \varphi_{2}}{\partial r_{f}} & \frac{\partial \varphi_{2}}{\partial \pi_{m}}
\end{array}\right] \text { and } \Delta_{J}<0\right. \text { denote its determinant. Then, } \\
\qquad\left[\begin{array}{c}
\frac{d r_{f}}{d n^{p}} \\
\frac{d \pi_{m}}{d n^{p}}
\end{array}\right]=-\frac{1}{\Delta_{J}}\left[\begin{array}{cc}
\frac{\partial \varphi_{2}}{\partial \pi_{m}} & -\frac{\partial \varphi_{1}}{\partial \pi_{m}} \\
-\frac{\partial \varphi_{2}}{\partial r_{f}} & \frac{\partial \varphi_{1}}{\partial r_{f}}
\end{array}\right]\left[\begin{array}{c}
a\left(r_{c e}^{p}\right)-a\left(r_{f}\right) \\
-\frac{a\left(r_{f}\right)}{n^{p}}
\end{array}\right] .
\end{gathered}
$$


Therefore, $\frac{d \pi_{m}}{d n^{p}}<0$. Also,

$$
\begin{aligned}
\frac{d\left[r_{f}+\pi_{m}\right]}{d n^{p}} & \propto\left(a\left(r_{c e}^{p}\right)-a\left(r_{f}\right)\right)\left(\frac{\partial \varphi_{2}}{\partial \pi_{m}}-\frac{\partial \varphi_{2}}{\partial r_{f}}\right)+\left(\frac{\partial \varphi_{1}}{\partial \pi_{m}}-\frac{\partial \varphi_{1}}{\partial r_{f}}\right) \frac{a\left(r_{f}\right)}{n^{p}} \\
& =\left(a\left(r_{c e}^{p}\right)-a\left(r_{f}\right)\right)\left(\frac{\partial \varphi_{2}}{\partial \pi_{m}}-\frac{\partial \varphi_{2}}{\partial r_{f}}\right)+\left(\frac{a^{\prime}\left(r_{c e}^{p}\right)}{a\left(r_{c e}^{p}\right)}-\frac{a^{\prime}\left(r_{f}\right)}{a\left(r_{f}\right)}\right) \frac{\left(1-n^{p}\right)}{n^{p}}\left(a\left(r_{f}\right)\right)^{2}<0
\end{aligned}
$$

again using Lemma 5 .

Proof of Lemma 2. Included in Appendix A.2.

Proof of Proposition 4. To show this result, notice first that part (i) of Lemma 2 implies that $r_{c e}^{\left(i_{A}^{1}, \mathbf{i}_{B}\right)} \geq r_{c e}^{\left(i_{A}^{0}, \mathbf{i}_{B}\right)}$. Next, re-write 18 as

$$
\sum_{i \in I} n^{i_{A}} n^{\mathbf{i}_{B}} a\left(r_{c e}^{\left(i_{A}, \mathbf{i}_{B}\right)}\right)-\frac{\eta_{m} P_{m}}{Y_{0}+\eta_{m} P_{m}}=0
$$

and notice that the left-hand side is increasing in $r_{f}$, since $r_{c e}^{\left(i_{A}, \mathbf{i}_{B}\right)}$ is increasing in $r_{f}$ and $a($.$) is an$ increasing function, so the first term is increasing in $r_{f}$, and also $P_{m}$ is decreasing in $r_{f}$, so the second term is also increasing in $r_{f}$. Finally, since $r_{c e}^{\left(i_{A}^{1}, \mathbf{i}_{B}\right)} \geq r_{c e}^{\left(i_{A}^{0}, \mathbf{i}_{B}\right)}$, it follows that $\sum_{i \in I} n^{i_{A}} n^{\mathbf{i}_{B}} a\left(r_{c e}^{\left(i_{A}, \mathbf{i}_{B}\right)}\right)$ is increasing in $\Delta n$, and so, the left-hand side of $C .5$ is increasing in $\Delta n$. Hence, $r_{f}$ is decreasing in $\Delta n$.

Showing that $\left\{\pi_{j}\right\}_{j \in \mathbf{J}}$ remain unchanged follows directly from Lemma 2 , part (ii). Finally, showing that the average expected return on risky assets decreases follows from the behavior of $r_{f}$ and $\left\{\pi_{j}\right\}_{j \in \mathbf{J}}$.

\section{C.2 Proofs of results in Online Appendix B}

Proof of Proposition 5. Let $R_{f}=1 / P_{f}$ denote the risk-free return. First consider the case after financial innovation. Since the market is complete, the background risks are effectively tradable . Thus, Assumption 1 holds and the analysis is similar to the proof of Proposition 1 . In view of Assumption $1^{\mathrm{P}}$, the value of the investors' background risks is given by, $E[M(\mathbf{z}) L(\mathbf{z})]=E[L(\mathbf{z})] / R_{f}$. Using this observation, and following similar steps as before, we obtain (assuming an interior solution),

$$
A_{0}^{i, n e w}+\frac{E[L(\mathbf{z})]}{R_{f}}=\frac{\beta}{1+\beta}\left(W_{0}+\frac{E[L(\mathbf{z})]}{R_{f}}\right) .
$$


In view of the assumption, $\varepsilon=1$, the desired total asset holdings is a constant fraction of the investor's total lifetime wealth. The calculation of the desired total assets as well as the total lifetime wealth also include the implicit background income.

Next consider the case before financial innovation. The investor's problem can be written as,

$$
\begin{array}{ll}
\max _{A_{0}} & \log \left(W_{0}-A_{0}\right)+\beta \log V_{1} \\
\text { s.t. } & V_{1}=\left(E\left[\left(A_{0} R_{f}+L(\mathbf{z})\right)^{1-\gamma}\right]\right)^{1 /(1-\gamma)} .
\end{array}
$$

Assuming an interior condition, the optimality condition implies,

$$
\begin{aligned}
\frac{1}{W_{0}-A_{0}^{i, \text { old }}} & =\beta R_{f} \frac{1}{V_{1}} V_{1}^{\gamma} E\left[\frac{1}{\left(A_{0}^{i, \text { old }}+L(\mathbf{z})\right)^{\gamma}}\right] \\
& =\beta R_{f} \frac{1}{E\left[\left(A_{0}^{i, \text { old }} R_{f}+L(\mathbf{z})\right)^{1-\gamma}\right]} E\left[\frac{1}{\left(A_{0}^{i, \text { old }}+L(\mathbf{z})\right)^{\gamma}}\right] \\
& =\beta R_{f} \frac{1}{E\left[C_{1}(\mathbf{z})^{1-\gamma}\right]} E\left[\frac{1}{C_{1}(\mathbf{z})^{\gamma}}\right] .
\end{aligned}
$$

Here, the last line substitutes, $C_{1}(\mathbf{z})=A_{0}^{i, o l d} R_{f}+L(\mathbf{z})$. Next note that $C_{1}(\mathbf{z})$ and $C_{1}(\mathbf{z})^{-\gamma}$ are negatively correlated, and strictly so if $C_{1}(\mathbf{z})$ is not constant. In particular, we have,

$$
\operatorname{cov}\left(C_{1}(\mathbf{z}), C_{1}(\mathbf{z})^{-\gamma}\right)=E\left[C_{1}(\mathbf{z})^{1-\gamma}\right]-E\left[C_{1}(\mathbf{z})\right] E\left[C_{1}(\mathbf{z})^{-\gamma}\right] \leq 0
$$

with strict inequality whenever $C_{1}(\mathbf{z})$ is not constant. Combining this observation with Eq. C.7), we obtain,

$$
\frac{1}{W_{0}-A_{0}^{i, \text { old }}} \geq \beta R_{f} \frac{1}{E\left[C_{1}(\mathbf{z})\right]}=\beta R_{f} \frac{1}{E\left[A_{0}^{i, \text { old }} R_{f}+L(\mathbf{z})\right]} .
$$

After rearranging terms, this implies,

$$
A_{0}^{i, o l d}+\frac{E[L(\mathbf{z})]}{R_{f}} \geq \frac{\beta}{1+\beta}\left(W_{0}+\frac{E[L(\mathbf{z})]}{R_{f}}\right) .
$$

Comparing Eqs. C.6 and C.8 implies $A_{0}^{i, \text { old }} \geq A_{0}^{i, \text { new }}$, with strict inequality if $C_{1}^{i, o l d}(\mathbf{z})$ is not constant. 
Proof of Lemma 3. First, we show that given prices characterized by Eqs. (B.2), (18), and $(B .3)$, the average portfolio shares for investors with market access $i_{A}$, are independent of the heterogeneity in beliefs or market access and satisfy Eq. A.2. An investor's perceived risk premium for a risky asset $j$ is

$$
\pi_{j}^{\left(i_{A}, \mathbf{i}_{\mathbf{B}}\right)}=\mathbf{F}_{j}^{\prime} \boldsymbol{\mu}_{z}^{i}+\left(\left(\Lambda_{j}\right) / 2\right)-\log P_{j}-r_{f}=\pi_{j}+\mathbf{F}_{j}^{\prime} \mathbf{i}_{\mathbf{B}}
$$

The first-order conditions for the investor can be written as

$$
\boldsymbol{\pi}_{J^{i} A}^{\left(i_{A}, \mathbf{i}_{\mathbf{B}}\right)}-\gamma \Lambda_{J^{i} A} \boldsymbol{\omega}_{J^{i} A}^{\left(i_{A}, \mathbf{i}_{\mathbf{B}}\right)}+\boldsymbol{\kappa}_{J^{i} A}^{\left(i_{A}, \mathbf{i}_{\mathbf{B}}\right)}=0
$$

where $\boldsymbol{\kappa}_{J^{i} A}^{\left(i_{A}, \mathbf{i}_{\mathbf{B}}\right)}$ consists of a $\left|\tilde{J}^{i_{A}}\right|$-by-1 vector $\boldsymbol{\kappa}_{\tilde{J}^{i} A}^{\left(i_{A}, \mathbf{i}_{\mathbf{B}}\right)}$ of Lagrange multipliers for the respective shortselling constraints and a $\left|J^{i_{A}} \backslash \tilde{\mathbf{J}}\right|$-by-1 vector of zeros for the assets that do not have short-selling constraints. Substituting for $\pi_{j}^{\left(i_{A}, \mathbf{i}_{\mathbf{B}}\right)}$ from C.9., we have,

$$
\boldsymbol{\pi}_{J^{i_{A}}}+\mathbf{F}_{J^{i} A}^{\prime} \mathbf{i}_{\mathbf{B}}-\gamma \Lambda_{J^{i} A} \boldsymbol{\omega}_{J^{i} A}^{\left(i_{A}, \mathbf{i}_{\mathbf{B}}\right)}+\boldsymbol{\kappa}_{J^{i} A}^{\left(i_{A}, \mathbf{i}_{\mathbf{B}}\right)}=0
$$

Next, we show that $\boldsymbol{\omega}_{J^{i} A}^{\left(i_{A}, \mathbf{i}_{\mathbf{B}}\right)}=\left[\mathbf{0}_{\left|\tilde{J}^{i} A\right|},\left(\boldsymbol{\omega}_{J^{i} A \backslash \tilde{\mathbf{J}}}^{\left(i_{A}, \mathbf{i}_{\mathbf{B}}\right)}\right)^{\prime}\right]^{\prime}$ satisfies the FOCs in C.11, where

$$
\boldsymbol{\omega}_{J^{i} A / \tilde{\mathbf{J}}}^{\left(i_{A}, \mathbf{i}_{\mathbf{B}}\right)}=\left(\frac{1}{\gamma} \Lambda_{J^{i} A \backslash \tilde{\mathbf{J}}}^{-1}\left(\boldsymbol{\pi}_{J^{i} A \backslash \tilde{\mathbf{J}}}+\left(\mathbf{F}_{J^{i} A \backslash \tilde{\mathbf{J}}}\right)^{\prime} \mathbf{i}_{\mathbf{B}}\right)\right)
$$

To show this, first note that for assets in $J^{i_{A}} \backslash \tilde{\mathbf{J}}$ we have

$$
\boldsymbol{\pi}_{J^{i} A \backslash \tilde{\mathbf{J}}}+\left(\mathbf{F}_{J^{i} \backslash \backslash \tilde{\mathbf{J}}}\right)^{\prime} \mathbf{i}_{\mathbf{B}}-\gamma \Lambda_{J^{i} A \backslash \tilde{\mathbf{J}}} \boldsymbol{\omega}_{J^{i} A \backslash \tilde{\mathbf{J}}}^{\left(i_{A}, \mathbf{i}_{\mathbf{B}}\right)}=0
$$

which is satisfied given the definition of $\boldsymbol{\omega}_{J^{i} \backslash \tilde{\mathbf{J}}}^{\left(i_{A}, \mathbf{i}_{B}\right)}$. Also, notice that the individual weights in $\boldsymbol{\omega}_{J^{i} A \backslash \tilde{\mathbf{J}}}^{\left(i_{A}, \mathbf{i}_{\mathrm{B}}\right)}$ are equivalent to the optimal individual portfolio weights in an equilibrium in which only $\mathbf{J} \backslash \tilde{\mathbf{J}}$ assets are available, with risk premia given in $(B .2)$, and the individual investor $i_{A}$ has access to $J^{i_{A}} \backslash \tilde{\mathbf{J}}$ of those. Therefore, the results from Lemma 2 apply for the average portfolio weights, $\boldsymbol{\omega}_{J^{i} A / \tilde{\mathbf{J}}}^{i_{A}}$, across investor with different beliefs, and so, a version of Eq. A.2 holds for these average weights. This in turn implies that we can simplify $\mathrm{C.12}$ to

$$
\boldsymbol{\omega}_{J^{i} A / \tilde{\mathbf{J}}}^{\left(i_{A}, \mathbf{i}_{\mathbf{B}}\right)}=\boldsymbol{\omega}_{J^{i} A / \tilde{\mathbf{J}}}^{i_{A}}+\frac{1}{\gamma} \Lambda_{J^{i} \backslash \backslash \tilde{\mathbf{J}}}^{-1}\left(\mathbf{F}_{J^{i} A, \tilde{\mathbf{J}}}\right)^{\prime} \mathbf{i}_{\mathbf{B}}
$$


For assets $j \in \tilde{J}^{i_{A}}$, these weights imply that

$$
\begin{aligned}
\boldsymbol{\kappa}_{j}^{\left(i_{A}, \mathbf{i}_{\mathbf{B}}\right)} & =-\pi_{j}-\left[\mathbf{F}_{j}^{\prime} \mathbf{i}_{\mathbf{B}}-\left(\gamma \tilde{\Lambda}_{\tilde{J}^{i_{A}}} \boldsymbol{\omega}_{J^{i} A \backslash \tilde{\mathbf{J}}}^{\left(i_{A}, \mathbf{i}_{\mathbf{B}}\right)}\right)_{j}\right] \\
& =-\pi_{j}-\left[\mathbf{F}_{j}^{\prime} \mathbf{i}_{\mathbf{B}}-\left(\gamma \tilde{\Lambda}_{\tilde{J}^{i} A} \boldsymbol{\omega}_{J^{i} A / \tilde{\mathbf{J}}}^{i_{A}}+\tilde{\Lambda}_{\tilde{J}^{i} A} \Lambda_{J^{i} \backslash\langle\tilde{\mathbf{J}}}^{-1}\left(\mathbf{F}_{J^{i} A \backslash \tilde{\mathbf{J}}}\right)^{\prime} \mathbf{i}_{\mathbf{B}}\right)_{j}\right] \\
& =-\pi_{j}+\frac{\Lambda_{j m}}{\Lambda_{m}} \pi_{m}-\left[\mathbf{F}_{j^{\prime}}^{\prime} \mathbf{i}_{\mathbf{B}}-\tilde{\Lambda}_{j, \tilde{J}^{i} A} \Lambda_{J^{i} \backslash \backslash \tilde{\mathbf{J}}}^{-1}\left(\mathbf{F}_{J^{i} A \backslash \tilde{\mathbf{J}}}\right)^{\prime} \mathbf{i}_{\mathbf{B}}\right] \geq 0,
\end{aligned}
$$

where the last inequality follows given the equilibrium values of $\pi_{j}$ in $B .2$.

To show the rest of the lemma, we use the observation that the individual portfolio weights on assets without short-selling constraints are equivalent to those in an equilibrium in which only $\mathbf{J} \backslash \tilde{\mathbf{J}}$ assets are available, with risk premia given in $(B .2)$, and the individual investor $i_{A}$ has access to $J^{i_{A}} \backslash \tilde{\mathbf{J}}$ of those. Therefore, an application of Lemma 2 implies that the investors' certaintyequivalent returns are given by equation $B .3$. Finally, Lemma 2 implies that Eqs. $B .2$, $(18)$, and (B.3) uniquely characterize the equilibrium prices on all assets and also all market clearing conditions are satisfied at these prices.

Proof of Proposition 6 . The result on assets $\mathbf{J} \backslash \tilde{\mathbf{J}}$ follows by observing that investors' portfolio weights and certainty-equivalent returns are equivalent to those in an equilibrium in which only $\mathbf{J} \backslash \tilde{\mathbf{J}}$ assets are available, and an individual investor with market access $i_{A}$ has access to $J^{i_{A}} \backslash \tilde{\mathbf{J}}$ of those, and applying Proposition 4 to the environment with $\mathbf{J} \backslash \tilde{\mathbf{J}}$ available assets. The result on the remaining assets $\tilde{\mathbf{J}}$ follow by applying Lemma 3 before and after customization, and observing that $\max _{\left(i_{A}, \mathbf{i}_{\mathbf{B}}\right)} \Delta_{j}^{\left(\mathbf{i}_{A}, \mathbf{i}_{\mathbf{B}}\right)}$ is the same in both cases.

Proof of Lemma 4. We proceed along the lines of the proof of Lemma 2. Specifically, we show that there exists an equilibrium in which the risk premia, risk-free rate, and the supply of the market portfolio are uniquely determined by the equations stated in the proposition. First, observe that the endogenous supply of the market portfolio does not affect any investor's portfolio problem directly, but only indirectly through the equilibrium prices. Therefore, given equilibrium prices, average portfolio shares for investors with market access $i_{A} \in I_{A}, \omega_{J^{i} A}^{i_{A}}$, defined in (A.1) still satisfy A.2 and investors' certainty-equivalent returns are given by (16).

Next, note that the equations stated in the proposition still uniquely characterize the equilibrium returns of all assets and the supply of the market portfolio. To see this, notice that after substituting $\pi_{m}=\gamma \Lambda_{m}$, Eq. B.4 describes a downward sloping relation between $r_{f}$ and $\eta_{m}$ in $\left(r_{f}, \eta_{m}\right)$-space. In addition, condition (B.6) describes an upward sloping relation, since the left-hand side of $(\mathrm{B} .6)$ is 
increasing in $\eta_{m}$ given that $Y_{0} \geq \eta_{m}$ in equilibrium, and the right-hand side of (B.6) is increasing in $r_{f}$ since $a($.$) is assumed to be an increasing function. Also, there exists a solution to these equations$ since by (B.6) and an Inada condition for the production function, $\lim _{\eta_{m} \rightarrow 0} r_{f}\left(\eta_{m}\right)=-\infty$ and also $\lim _{\eta_{m} \rightarrow Y_{0}} r_{f}\left(\eta_{m}\right)=\infty$.

Finally, we check that these returns and the supply of the market portfolio satisfy the market clearing conditions (B.5). The market clearing conditions for $j \neq m$ are clearly satisfied since $\omega_{j}^{i_{A}}=0$, for each $i_{A}$ and $j \neq m$. The market clearing condition for the risk-free asset is also satisfied since $\omega_{m}=1$ and $\omega_{f}=1-\omega_{m}$, so each investor has a zero weight on the risk-free asset. Finally, the market clearing condition for asset $m$ is equivalent to (B.6), so it also holds.

Proof of Proposition 7. First, as in Proposition 4. we have $r_{c e}^{\left(i_{A}^{1}, \mathbf{i}_{\mathbf{B}}\right)} \geq r_{c e}^{\left(i_{A}^{0}, \mathbf{i}_{\mathbf{B}}\right)}$. Next, we re-write B.6) as

$$
\sum_{i \in I} n^{i_{A}} n^{\mathbf{i}_{\mathbf{B}}} a\left(r_{c e}^{\left(i_{A}, \mathbf{i}_{\mathbf{B}}\right)}\right)-\frac{\eta_{m}+\frac{G_{L}\left(\eta_{m}, 1\right)}{G_{K}\left(\eta_{m}, 1\right)}}{Y_{0}+\frac{G_{L}\left(\eta_{m}, 1\right)}{G_{K}\left(\eta_{m}, 1\right)}}=0 .
$$

Implicitly differentiating this equation (while keeping $r_{f}$ constant), we obtain,

$$
\frac{\partial \eta_{m}}{\partial \Delta n} \propto \frac{\sum_{\mathbf{i}_{\mathbf{B}}} n^{\mathbf{i}_{\mathbf{B}}}\left[a\left(r_{c e}^{\left(i_{A}^{1}, \mathbf{i}_{\mathbf{B}}\right)}\right)-a\left(r_{c e}^{\left(i_{A}^{0}, \mathbf{i}_{\mathbf{B}}\right)}\right)\right]}{Y_{0}+\frac{G_{L}\left(\eta_{m}, 1\right)}{G_{K}\left(\eta_{m}, 1\right)}+\frac{\partial}{\partial \eta_{m}}\left(\frac{G_{L}\left(\eta_{m}, 1\right)}{G_{K}\left(\eta_{m}, 1\right)}\right)\left(Y_{0}-\eta_{m}\right)} \geq 0
$$

Here, we use the fact that $\frac{\partial}{\partial \eta_{m}}\left(\frac{G_{L}\left(\eta_{m}, 1\right)}{G_{K}\left(\eta_{m}, 1\right)}\right) \geq 0$ and $\eta_{m} \leq Y_{0}$ in equilibrium. The proof of Lemma 4 shows that $r_{f}$ and $\eta_{m}$ are jointly determined by Eqs. B.4 and (B.6), which are respectively downward and upward sloping in $\left(r_{f}, \eta_{m}\right)$-space. Eq. C.13 implies that an increase in $\Delta n$ leads to an upward shift in relation (B.6). This in turn implies that the equilibrium value of $r_{f}$ declines and the value of $\eta_{m}$ increases. By part (i) of Lemma 4 , the decline in $r_{f}$ translates into a decline in the expected return on all assets.

\section{Online Appendix D: Data details and additional analysis}

The PSID makes a distinction between family units and household units. Throughout the paper we will use the term households to refer to family units. 


\section{Active saving definition}

We construct active saving by following the definition used in the PSID to construct active saving between 1984 and 1989. The general idea behind the active savings that the PSID constructs is to sum all net active asset purchases. For example, to obtain net active purchases of stocks, the PSID takes the amount of stocks purchased since 1984 and subtracts the amount of stocks sold since 1984. Similarly, to obtain net purchases of other real estate, they take the value of other real estate purchased since 1984 and subtract the value of other real estate sold since 1984. For the assets for which measures of net active purchases are not available, the PSID takes the change in wealth between the different survey periods and subtracts from it the change in values of assets for which there is available information (such as home value, stocks, farm and business, etc.). Finally, the PSID removes changes of assets and debt due to changes in the household, as well as inheritances, since those are arguably not active savings. We use the same method to construct active savings between subsequent survey waves.

Formally, active saving during that period is generated by summing total wealth in 1989, the 1984 home value (unless the household has moved), the 1989 value of private annuities, equity in other real estate in 1984, equity in a farm or business in 1984, the value of stocks held in 1984, the value of other real estate purchased since 1984, the cost of additions and repairs to real estate since 1984, the amount invested in own business or farm since 1984, the amount of stocks purchased since 1984, assets removed by movers out of the household since 1984, and debts added by movers into the household since 1984. Out of this one subtracts total wealth in 1984, the 1989 home value, equity in other real estate in 1989, equity in a farm or business in 1989, the value of stocks held in 1989, the value of annuities and pensions cashed in since 1984, the value of other real estate sold since 1984, the value of farm or business sold since 1984, the value of stocks sold since 1984, debts removed by movers out of the household since 1984, assets added by movers into the household since 1984, and the inheritances received since 1984 24

\section{Sample selection}

We make the following sample restrictions. We look at households whose head is between 25 and 65 years old and who have positive net worth. In addition, we remove households with extremely low incomes by first removing zero-income heads and then removing heads with income below the 20th percentile. We remove such low income households because their active savings tend

\footnotetext{
${ }^{24}$ In case the household has moved between 1984 and 1989 the PSID constructs separate capital gains for each home owned. For simplicity, we drop households that have moved in between survey waves.
} 
Table D.1: Summary Statistics

\begin{tabular}{cccccc}
\hline \hline Variable & Observations & Mean & Std. Dev. & Min & Max \\
\hline active saving rate & 17,118 & .037 & .341 & -1.193 & 1.142 \\
stock mkt. participation & 17,118 & .288 & .453 & 0 & 1 \\
share of assets in stocks & 15,393 & .113 & .237 & 0 & 1 \\
income (log) & 17,118 & 10.734 & .608 & 9.10 & 13.869 \\
wealth $(\log )$ & 17,118 & 11.061 & 1.666 & 0 & 17.737 \\
age & 17,118 & 43.083 & 9.871 & 25 & 64 \\
\hline \hline
\end{tabular}

to be extremely volatile. Furthermore, we remove outliers by excluding the top and bottom 10 percent of the saving rate distribution in a given survey year. We opt for a relatively aggressive trimming procedure to alleviate measurement error problems since wealth and saving components are self-reported in the PSID. All of our results about the saving behavior of participants versus non-participants are present with a more conservative trimming choice. Finally, we also drop household-year observations that are not in subsequent survey waves and households that do not reside in the 50 US states plus the District of Columbia.

We are left with an unbalanced panel of household saving and stock market participation variables containing 6,410 unique households between 1984 and 2011 with a total of 17,118 householdyear observations. Table D.1 contains summary statistics for our main variables of interest.

In addition for our analysis of return dispersion we remove outliers in the implicit log return by excluding the top and bottom 10 percent of log returns in a given survey year. We also remove households that have owned a farm or business in any survey year. A more conservative trimming procedure leads to an increase in the level of return dispersion without affecting the positive time trend, which is the focus of our analysis.

\section{Additional data analysis}

Trends in savings Column 1 documents that the widening gap in savings between market participants and nonparticipants is robust to the inclusion of demographics, wealth controls and state fixed effects. While statistical significance is lost in the presence of household fixed effects, due to an increase in standard errors, the magnitude of the coefficient on the evolution of the gap is largely unchanged.

In columns 3 and 4 , we study how savings comove with respect to an alternative, continuous 
measure of participation: the share of the household's assets that is invested in stocks (excluding their primary residence). To focus on the intensive margin, we also restrict the analysis to stock market participants. There is a widening gap in saving rates based on this measure, even after controlling for household wealth, household head income and demographics, and household fixed effects. The share of wealth in stocks can be seen as a proxy of the household's risk tolerance. Through the lens of the choice channel, the saving of more risk tolerant investors increases relative to less risk tolerant investors as financial innovation accumulates 25

Trends in return dispersion One potential issue that could be causing a spurious positive trend in return dispersion (Figure 3 ) is the change in the frequency of data availability. For the early years of our data, annualized wealth growth is obtained by averaging across five years, while from 1999 onward, it is obtained by averaging across two years. Away from perfect autocorrelation in annual returns, this mechanically lowers the measured cross-sectional dispersion in the first half of the period relative to the second half.

A conservative adjustment for this problem is to assume independence of household returns across years and multiply the dispersion measures by the square root of five for the first period, and by the square root of two for the second. In this way, we obtain measures of annual return dispersion from the original dispersion of annual averages ${ }^{26}$ Figure D.1 replicates Figure 3 after this adjustment. Similarly, Figure D.2 replicates Figure 7 after this adjustment. The conclusions are unchanged.

\footnotetext{
${ }^{25}$ For the same beliefs, certainty equivalent returns are always higher for more risk tolerant agents. A formalization of this result was present in a previous working paper version and is available upon request.

${ }^{26}$ This adjustment is conservative because any alternative (constant) yearly return autocorrelation would require multiplication by smaller proportional factors and generate steeper positive trends.
} 


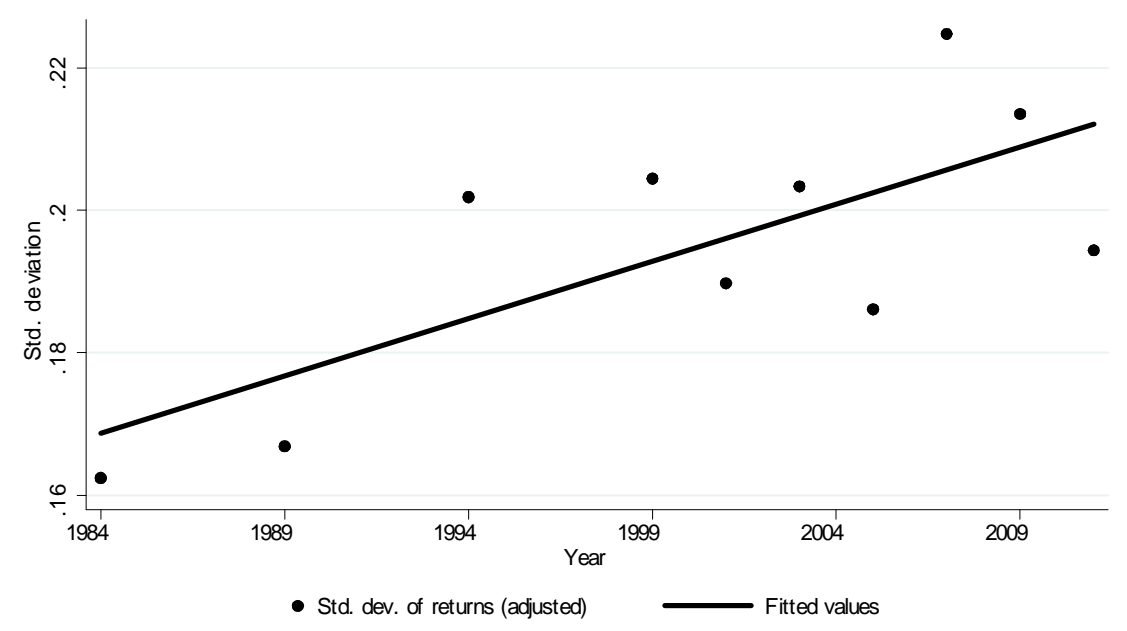

Figure D.1: Trends in dispersion of (implicit) returns on wealth among stock holders (excluding business owners). Adjusted averages.

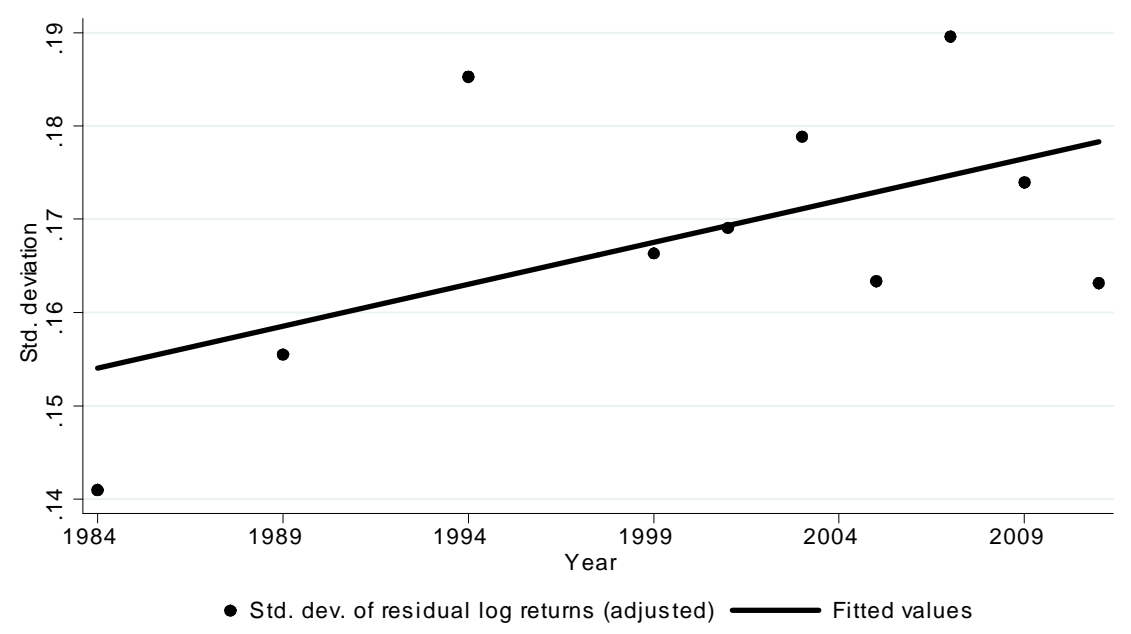

Figure D.2: Trends in conditional standard deviation of (implicit) returns on wealth among stock holders (excluding business owners). Adjusted averages. 
Table D.2: Trends in saving and stock market participation.

\begin{tabular}{ccccc}
\hline \hline & $(1)$ & $(2)$ & $(3)$ & $(4)$ \\
\hline stock mkt. participation & $0.0308^{* *}$ & 0.0168 & & \\
& $(0.0098)$ & $(0.0248)$ & & \\
year & $-0.0027^{* *}$ & -0.0027 & $-0.0029^{* *}$ & -0.0018 \\
& $(0.0005)$ & $(0.0055)$ & $(0.0005)$ & $(0.0057)$ \\
& & & & \\
stock market & $0.0019^{*}$ & 0.0015 & & \\
participation $\times$ year & $(0.0008)$ & $(0.0016)$ & & \\
share of assets & & & & $0.0430^{*}$ \\
in stocks & & & $(0.0189)$ & 0.0399 \\
& & & & \\
share of assets & & & $0.0392)$ \\
in stocks $\times$ year & & & $(0.0015)$ & $(0.0026)$ \\
& & & & \\
\hline Additional controls & Yes & Yes & Yes & Yes \\
Household FE & No & Yes & No & Yes \\
$R^{2}$ & 0.018 & 0.274 & 0.021 & 0.286 \\
Observations & 16,610 & 14,696 & 14,934 & 13,069 \\
\hline \hline
\end{tabular}

Notes. Standard errors in parenthesis. The standard errors are clustered at the state level. The active saving rate is defined as the annualized amount of active savings between two survey years, divided by the average of the household head's income in the two survey years. Active savings are constructed by extending the definition of active savings in the PSID for the period 1984-1989 to later survey waves. Year denotes the year of the survey relative to 1984 (the first year in the sample). Stock market participation is an indicator variable for whether the household holds shares of publicly traded companies or mutual funds (outside of IRAs post 1999). Share of assets in stocks is defined as the value of stocks (held outside of IRAs post 1999) relative to the value of all household assets, excluding the value of the household's primary residence. Additional controls include log of the household head's income and total household wealth, an educational category for the household head, gender of the household head, log of age for the household head and state of residence. For specifications (2) and (4) the additional control include log of the household head's income and total household wealth, and log age of the household head. All regressions are weighted using the PSID sampling weights. ${ }^{* *}$ denotes significance at $1 \%$, and ${ }^{*}$ denotes significance at $5 \%$. 